\title{
Clinical Equipment Standardisation and Its Impact on Patient Safety
}

\author{
by \\ Kimberley Greenwood, B.A.Sc. \\ A thesis submitted to the Faculty of Graduate and Postdoctoral Affairs in partial \\ fulfillment of the degree of:
}

\section{Master of Applied Science in Biomedical Engineering}

\author{
Ottawa Carleton Institute for Biomedical Engineering \\ Carleton University Ottawa, Ontario, Canada, K1S 5B6
}

C Kimberley Greenwood, 2010 
Library and Archives

Canada

Published Heritage Branch

395 Wellington Street Ottawa ON K1A 0N4

Canada
Bibliothèque et

Archives Canada

Direction du

Patrimoine de l'édition

395 , rue Wellington

Ottawa ON K1A ON4

Canada
Your file Votre référence

ISBN: 978-0-494-81713-1

Our file Notre référence

ISBN: 978-0-494-81713-1
NOTICE:

The author has granted a nonexclusive license allowing Library and Archives Canada to reproduce, publish, archive, preserve, conserve, communicate to the public by telecommunication or on the Internet, loan, distribute and sell theses worldwide, for commercial or noncommercial purposes, in microform, paper, electronic and/or any other formats.

The author retains copyright ownership and moral rights in this thesis. Neither the thesis nor substantial extracts from it may be printed or otherwise reproduced without the author's permission.

\section{AVIS:}

L'auteur a accordé une licence non exclusive permettant à la Bibliothèque et Archives Canada de reproduire, publier, archiver, sauvegarder, conserver, transmettre au public par télécommunication ou par l'Internet, prêter, distribuer et vendre des thèses partout dans le monde, à des fins commerciales ou autres, sur support microforme, papier, électronique et/ou autres formats.

L'auteur conserve la propriété du droit d'auteur et des droits moraux qui protège cette thèse. $\mathrm{Ni}$ la thèse ni des extraits substantiels de celle-ci ne doivent être imprimés ou autrement reproduits sans son autorisation.
In compliance with the Canadian Privacy Act some supporting forms may have been removed from this thesis.

While these forms may be included in the document page count, their removal does not represent any loss of content from the thesis.
Conformément à la loi canadienne sur la protection de la vie privée, quelques formulaires secondaires ont été enlevés de cette thèse.

Bien que ces formulaires aient inclus dans la pagination, il n'y aura aucun contenu manquant. 
The undersigned recommend to the Faculty of Graduate Studies and Postdoctoral Affairs acceptance of the thesis

\title{
Clinical Equipment Standardisation and Its Impact on Patient Safety
}

\author{
submitted by
}

Kimberley Greenwood, B.A.Sc.

in partial fulfillment of the requirements for

the degree of Master of Applied Science in Biomedical Engineering

Chair, Howard Schwartz, Department of Systems and Computer Engineering

Thesis Supervisor, Monique Frize

Carleton University

December 2010 


\begin{abstract}
The research conducted for this thesis has evaluated and proven how specific measurement tools can gauge clinical equipment standardisation, allowing for comparative benchmarking; and that by improving these benchmarks; a reduction in clinical errors will result. Evidence has already been provided by Charles Vincent[1] and many others that conclusively illustrate the link between improved health system results and a reduction in clinician errors.

This study has researched the level of equipment standardisation, the number of clinical user errors and adverse patient events for two common medical devices: syringe pumps and physiological monitors at the Children's Hospital of Eastern Ontario (CHEO), in Ottawa, Ontario, Canada.

Under certain conditions this link was found to be valid but can be impacted by other factors. There was not sufficient data found from this observational study to show that patient adverse events that involved the selected equipment decreased by improved standardisation of these devices.
\end{abstract}




\section{Acknowledgement}

I would like to thank Dr. Monique Frize for her encouragement, support and guidance throughout my research as my thesis advisor. I must also thank Dr. Donald Russell who first encouraged me to enrol in Graduate Studies at Carleton University and Dr. Andy Adler for his mentoring as my academic advisor. I must also recognise all of the staff at the Children's Hospital of Eastern Ontario who helped and advised my research.

I certainly must not forget my family's role in this endeavour, my dear wife Emilia along with my two sons and fellow students Jonathan and William, all of them provided me with support and encouragement throughout this challenge.

Lastly, to my brother Stephen, who has shown me what true resolve and courage is and how strong the human spirit really is in the presence of overwhelming odds during his personal fight with cancer. 


\section{Table of Contents}

ABSTRACT

ACKNOWLEDGEMENT …............................................................................................................ IV

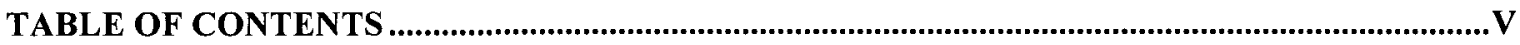

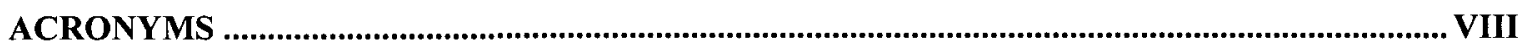

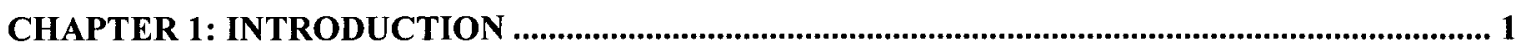

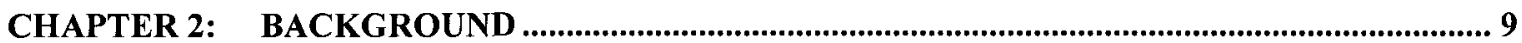

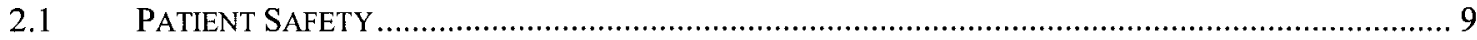

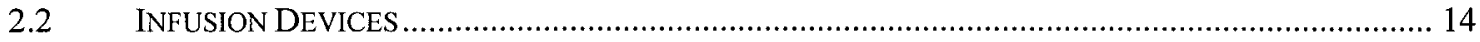

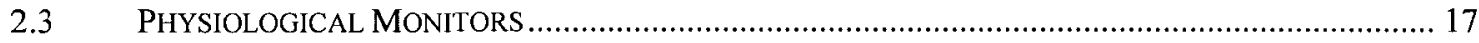

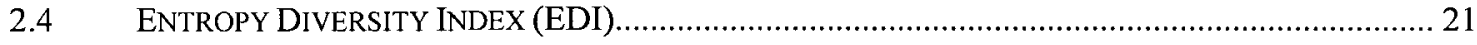

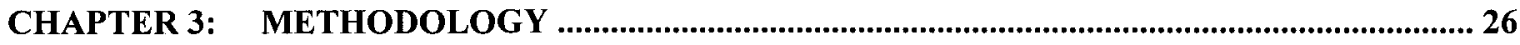

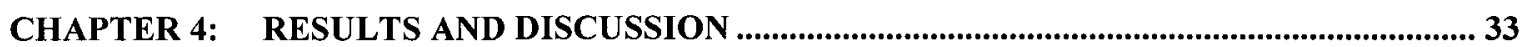

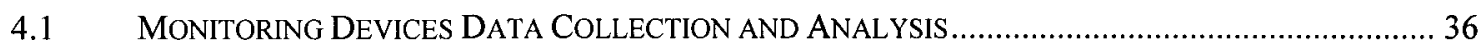

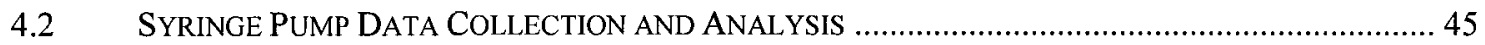

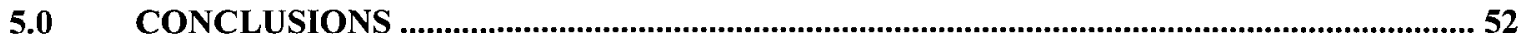

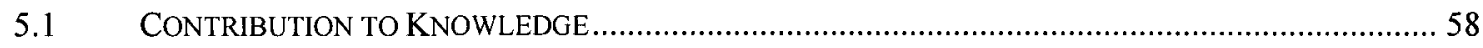

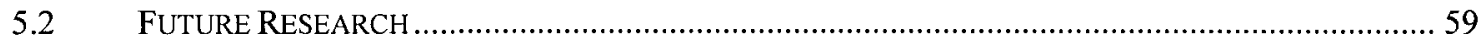

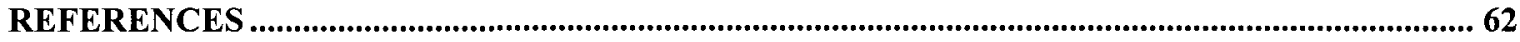

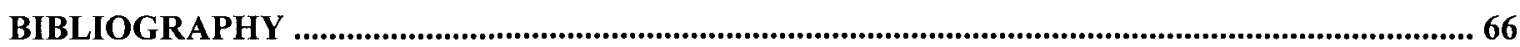

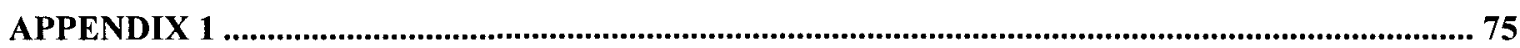

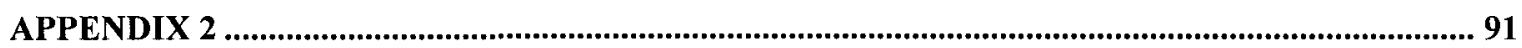

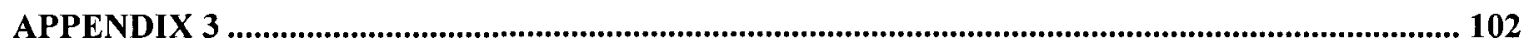

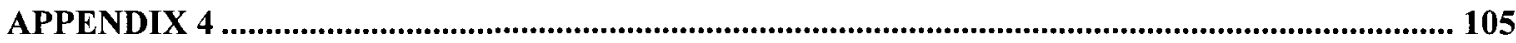




\section{List of Tables}

Table 2.1 The Major Entropy and Diversity Measurement Tools

Table 4.1 Inventory Spreadsheet Structure 36

Table 4.2 Physiological Monitor Inventory Summary by Year 38

Table 4.3 Summary of Monitor User Problems by Fiscal Year 39

Table 4.4 Impact of Standalone Monitors on Clinical User Problems 44

Table 4.5 Summary of Syringe Pumps Calculations 46

Table 4.6 Overall CHEO AE Statistics

Table 4.7 Suspected and Actual AE Reports for Monitors and Syringe Pumps $\quad 50$

Table 5.1 Documented Clinical User Errors

Table A3.1 Expanded Physiological Monitor Data Table 103

Table A3.2 Summary of Syringe Pump Data 104 


\section{List of Figures}

Figure 3.1 Relationship between EDI Value, Inventory State and Distribution Type 31

Figure 4.1 Physiological Monitor EDI by Quarter 41

Figure 4.2 EDI Value for Physiological Monitors against Time 42

Figure 4.3 Ratio of User Problems /Monitor Inventory vs. Time for Monitors 42

Figure 4.4 Multiparameter Monitor EDI values Against Time 45

Figure 4.5 Ratio of Clinical User Problems / Time for Multiparameter \& All Monitors $\quad 45$

Figure 4.6 Expanded Graph of EDI against Time for Syringe Pumps 47

Figure 4.7 Ratio of User Problems / Total Number for Syringe Pumps 48 


\section{Acronyms}

FDA - Food and Drug Administration

EDI - Entropy Diversity Index

CHEO - The Children's Hospital of Eastern Ontario

MPS - Harvard Medical Practice Study

NPSF - National Patient Safety Foundation

IOM - Institute of Medicine

FMEA - Failure Mode and Effects Analysis

IV - Intravenous Therapy

ECG - Electrocardiograph

CO2 - Carbon Dioxide

EEG - Electroencephalograph

CRT - Cathode Ray Tube

LCD - Liquid Crystal Display

USB - Universal Serial Bus

$\mathrm{AE}$ - Adverse Event

Q1 - $1^{\text {st }}$ quarter fiscal year

Q2 $-2^{\text {nd }}$ quarter fiscal year

Q3 $-3^{\text {rd }}$ quarter fiscal year

Q4 $-4^{\text {th }}$ quarter fiscal year

HIS -Hospital Information System 


\section{Chapter 1: Introduction}

Development of medical devices in the last half century underpinned advances in healthcare and enabled lower mortality rates and lengthened life spans. The sophistication and the integration of these medical devices, however, placed new stresses on clinicians, especially for those who were not receptive to new technology. Creators of medical devices failed to realize that their user-interfaces, while seemingly simple and straightforward, were actually problematic and complex. Some of this confusion is derived from mixing different makes and models of devices within an environment that has slight differences in operational characteristics. A by-product of the confusion can be an increase in medical errors.

Since publishing the book "To Err is Human: Building a Safer Health System" [2] in 2000 , the patient safety movement has grown at a rapid rate. This fact is hardly surprising after reviewing the stark statistics. Approximately one in six Canadians experience preventable adverse medical events annually with about 2.8 percent or 117,600 of these individuals incurring an injury per year [3]. The adverse event factor that attracts both public and professional interest is medication errors and as a result of this publicity, infusion pumps and their medication safety software have received the majority of the interest in the research community in the last few years over other key common clinical equipment such as ventilators and physiological monitors, which also account for a substantial number of fatalities. 
The FDA recently released data which states that an average of 11,200 adverse events and 100 deaths occur in the United States from infusion devices alone, based on annual data between 2004 and 2009[4]. One French study published in 2001 found that infusion pumps accounted for thirty percent and physiological monitors accounted for twelve percent of adverse event deaths per year in critical care and surgical patients.[5] Closer to home, the Canadian Adverse Events Study of 2004[6] stated that somewhere between 9,250 and 23,550 patient deaths occurred per year in Canada from preventable adverse events in surgical and critical care environments.

A medical adverse event has been defined as an unintended injury caused by medical management rather than the disease process. Medical management includes the failure to treat, diagnose or provision of an incorrect treatment or diagnosis [7]. The causation of an adverse event is measured on a six point scale, where a value of one on the scale denotes no evidence of an event, through to six which provides certain evidence of causation of an adverse event. Normally, only adverse events with a scoring of four or more are documented in adverse event reports [8]. The outcome of the adverse event may or may not inflict injury on the patient and is ranked on a categorical scale from negligible to severe in impact.

The rate of adverse events identified in recent studies ranges in the neighbourhood of eight to twelve percent per patient stay in hospital in the industrialised nations [9]. About seventy percent of all cases of adverse events can be classified as minor in nature, producing either no injury or negative long term impact to the patient [10]. When presented with these two facts, one would then conclude this situation to be clear cut and we need to only address the smaller percentage of adverse events incidents that actually 
cause harm. Not to discount the importance of the harmful adverse events, for they certainly need to be addressed, the other minor adverse events also have a substantial impact the healthcare system as well. Knowing that the most recently reported cost of healthcare in Canada was in the year 2008 and totalled 172 billion dollars [11], it can be estimated that these minor adverse events cost the Canadian healthcare system about five billion dollars in extended hospital stays and associated other costs, whereas the major adverse events which came close to the two billion dollar mark [12].

To respond to this challenge, clinical engineers have already identified issues which they can strive to resolve and consequentially make their contribution in reducing adverse events. Wilson et al. [13] illustrated that half of their evaluated incidents in the Australian Health Care Study found to have caused the adverse events were a result of information processing errors or commonly referred to today as cognitive errors. Clinical Engineering Departments must now re-evaluate their priorities from traditional issues, such as electrical safety, and focus more attention more broadly on patient safety. [14] Key topics such as equipment standardisation and human factors engineering need more attention in today's healthcare setting.

A number of recent publications have focused on human factors engineering in healthcare and they all identify the need for equipment standardisation, especially when it relates to the commonly used devices such as infusion pumps or physiological monitors, to reduce the likelihood of an increase in patient adverse events. $[15,16,17]$. Using different brands or models, amongst the already plentiful volume of clinical equipment within a healthcare facility, has shown to increase the likelihood of medical error. James Reason has theorised that humans try to reduce their mental workload by remaining in 
rule-based behaviour as much as possible and this is the primary reason for the occurrence of patient adverse events [18]. If a vital sign alarm is sounded, what would be the first reaction of the clinician: To reset the alarm or check the patient's condition? A lot depends upon the individuals, their training and the working environment at that specific point in time.

Rule-based behaviour is the intermediate of the three levels of human behaviour: skill, rule, and knowledge; each requires gradually more cognitive resources. [19] Skillbased behaviour requires minimal mental effort and is typically of long-duration and for routine type tasks. Rule-based behaviour uses skills acquired through training or readily available instruction to perform scheduled tasks which involve moderate cognitive skills. Individuals are tested to their limits only when unforeseen events occur, regardless of mental capacity and training. At this time, knowledge-based skills require critical thinking to solve complex or uncommon problems.

When equipment tends to be too diverse within a specific clinical setting, the individual clinician must use higher levels of cognitive or knowledge-based resources. The fallout of this situation is an above average level of cognitive fatigue for the clinicians working in this specific setting. This fact does not conclusively prove to cause more adverse events, but when this factor is coupled with more than a full patient load and inexperienced staff, the result could indeed end in more adverse events and or patient injuries. Since control over the patient census and retaining a high number of clinical staff are both daunting tasks for the clinical manager, there are only two options available that could reduce the likelihood of adverse events: Development of an effective and 
proactive medical equipment standardisation; and implementation of effective decisionsupport systems that can direct the equipment user out of a rule-based skill loop.

Clinical decision-support systems (CDSS) are currently in an early stage of development. CDSS are knowledge based systems that base treatment or diagnosis recommendations through inconsistencies in the available patient data. It will be at least another decade before the impact of decision-support systems will be felt by industrialised countries' healthcare systems. To make an immediate impact on minimising patient adverse events, medical equipment standardisation and routine staff training on common medical devices needs to be studied as an immediate method for reducing adverse events.

If equipment standardisation is to be priorized for action, there will be a need to measure the success of the endeavour. A small department with minimal equipment needs only a basic inventory to complete this exercise. This approach fails when a healthcare facility has an extensive array of clinical equipment, numbering in the thousands. Recently, this problem confronted a number of English facilities; for instance, by 2005, the Oxford Radcliffe Hospital System used as many as thirty four different models of infusion pumps. [20] This example was likely the result of purchases made gradually over a number of years in a health system that assigned acquisitions to the lowest bidder. In this scenario, equipment standardisation was never a priority. The likelihood of clinical staff becoming comfortable and competent with this large and diverse group of infusion devices is low.

The Oxford Radcliffe hospital system, however, attempted to rectify this problem. Two members of Oxford Radcliff Medical Physics and Clinical Engineering group, G.W. 
Brindle and C.W. Gibson, experimented with the use of the diversity indices to quantify the vast assortment of infusion pumps. They found that the use of the Shannon Entropy Diversity Index (EDI) produced numerical values, which measured the status of standardisation over time. Their studies validated efforts within the Oxford Radcliffe hospital system to improve infusion pump standardisation by finding a reliable benchmarking indicator to measure standardisation improvement. [21] Unfortunately, since this study's publication in 2007, no others have contributed further research in this area. No researcher has attempted to link these indices to other patient indicators such as patient adverse event reports or equipment maintenance history data.

The Standards of Practice for Clinical Engineering in Canada [22], last updated in 2007 , fails to refer specifically to management of these large fleets of common medical devices, and the importance of standardisation, although mention is clearly made about the need for involvement of Clinical Engineering in the management of the acquisition of clinical equipment. In the United States, the accrediting body for healthcare organisations, the Joint Commission on Accreditation of Healthcare Organisations (JCAHO), requires all hospitals to have a Medical Equipment Management Plan as part of their Environment of Care Standard of 2009. This standard states that all healthcare centres must have this plan in place "that promotes the safe use and effective use of medical equipment" and "should cover processes for the selection and acquisition of medical equipment”. [23] This standard, however, fails to specifically tackle the issue of equipment standardisation, but it encourages the use of effective management techniques to enable the availability of the appropriate medical devices when required for patient care. 
This study has validated a potential standardisation measurement tool's ability to measure the level of standardisation within two groups of like clinical devices through an observational study conducted over a five year period at The Children's Hospital of Eastern Ontario in Ottawa, Ontario, Canada. Once this tool was identified and validated, it was used to measure the level of standardisation of two distinctly different clinical devices, the physiological monitors and the syringe pumps. The resulting device standardisation measurements over time were then compared against clinical user error statistics and the adverse event reports over a five year period to identify if a relationship exists between equipment standardisation and either clinical user errors or adverse events.

Chapter 2 provides an account of the patient safety movement and illustrates the link between patient safety and both human factors engineering and clinical equipment standardisation. Next, a promising method to evaluate the degree of standardisation or diversity of clinical equipment within a defined sample size is discussed. This index, commonly known the Shannon Entropy Diversity Index (EDI), [24] has been successfully implemented in communication theory, ecological studies, and genetics to measure commonality for a specific entity within a defined sample. Finally, the second chapter concludes with a review of the history of infusion devices and physiological monitors, and introduces the reader to the devices' technological development, and to current trends.

Chapter 3 details data collection methodology of this study from the CHEO clinical equipment management and patient incident tracking systems. The time periods for which data analysis was conducted is identified along with criteria for the inclusion and exclusion of data into this study. 
Chapter 4 presents and explains the results and identifies reproducible trends in the EDI versus the equipment user problems and the patient adverse event data collected.

Chapter 5 provides a conclusion drawn from the summarised results. It also discusses whether the problem statement, which asks if there is a possible link between patient adverse event indicators and the concept that standardisation improves patient safety by reducing human factors issues in specific medical devices, was validated or disproved. Lastly the contributions to knowledge developed from this study are detailed. This chapter ends with potential future research work that could result as an outcome from the observations and conclusions drawn from this study.

This thesis reports on the impact of standardisation of more commonly used medical devices in today's healthcare setting and will answer the question "Will clinician operator error be reduced, and will patient adverse events be minimised by limiting the diversity of commonly used clinical equipment in a healthcare setting?"

This tool will allow the clinical engineer to monitor progress in equipment standardisation on key clinical devices in a healthcare facility. This work reduces the potential of patient risk by decreasing the chance of user errors occurring by minimising the number of like devices in active service in a facility at any given time. This approach reduces the chance of cognitive errors from occurring by the clinical user. By reducing the number of different devices in service at any given time, one also reduces ongoing operational and maintenance costs in a facility by reducing inventory and training costs. This tool will also provide a method for justifying further capital funding for clinical equipment if equipment replacement plans are not their meeting planned objectives. 


\section{Chapter 2: $\quad$ Background}

The patient safety movement has impacted all involved in healthcare in the last decade. One of this movement's mandates is to examine medical product design and use as well as how these products affect patients. A detailed look at the history of the patient movement and its achievements is outlined.

Next, the two devices that are investigated in this study, the infusion pump and the physiological monitor, are reviewed with a history of the technical developments of the two devices that bring them to their present state. Finally, background on the EDI is reviewed along with a discussion of its application to device standardisation.

\subsection{Patient Safety}

Every worker in the medical field has been made aware of the importance of patient safety but few really understand their role in keeping patients free from accidental injury. Many problems are systematic problems lying dormant, waiting to happen at some

time in the future. The early work of Schimmel with "The hazards of hospitalization"[25] in 1964 estimated that serious adverse accidents occurred in about of the $5 \%$ of the patient admissions, but these findings were kept within the medical community and did not reach the scrutiny of public opinion. It was not until the Harvard Medical Practice Study (MPS) in 1991 [26] that the public at large became aware of the number of preventable adverse events in healthcare. The MPS study used data from New York State 
in 1984 and concluded $3.7 \%$ of hospital patients suffered an adverse event and 14 $\%$ of these events resulted in fatalities.

From this point in time and throughout that decade, concern continued to escalate around safety in healthcare. Further study found that these adverse events resulted from errors. Healthcare quickly found parallels in the aviation and nuclear power industries and found applicability with the lessons learned from these two groups. [27] Research focused on cognitive psychology and human factors engineering to evaluate and redesign systems to reduce human errors. This research led to the founding of the National Patient Safety Foundation (NPSF) in 1996. This organisation's mandate was to lead safety research through a non-punitive reporting system in the United States. In spite of this ongoing attention, many American hospitals still did not give patient safety attention.

This situation changed with the release of the U.S. National Academy of Sciences' Institute of Medicine (IOM) report, "To Err is Human" [28] in late 1999. This study took the data from the earlier Harvard MPS work and other more recent studies and concluded from this data that somewhere between 44,000 and 98,000 unnecessary deaths occurred annually in the United States from error, and that the majority of the fatalities were preventable. The media caught on to this story and it remained in the public eye for some time, forcing action by politicians and the healthcare leadership. As a result of all of this attention, federal funding was provided specifically for patient safety research and all stakeholders throughout the United States realised action was needed to change practices to improve healthcare safety. The National Quality Forum, a public-private partnership, was established to design and implement standards for quality care and the mandatory reporting of errors. The accrediting body for U.S. hospitals, the JCAHO, then required all 
hospitals to implement their evidence-based safe practices known as the National Patient Safety Goals.

Every U.S. hospital now has a patient safety program in place and the results have been clear: in the two year period from July 2004 to June 2006, 3,100 hospitals joined the “100,000" Lives program [29] which resulted in a drop in patient mortality of 122,000 patients, mostly due to newly developed patient safety practices. Great Britain followed a parallel course with the release of "Supporting Doctors, Protecting Patients" by the Department of Health in 1999 [30] and the founding of the National Patient Safety Agency in 2001.

Many countries now follow the U.S. and Britons to develop patient safety programs for their health systems. Canada was delayed in reacting on patient safety; the first clear action was the establishment of a committee on Patient Safety by the Royal College of Physicians and Surgeons in 2001, but the government of Canada did not take any action on this issue until the Patient Safety Institute was established by Health Canada in 2003. Since that time, considerable progress has been made in Canada with the collaboration of the federal and provincial health authorities and the arms-length accreditation body for Canadian health facilities, Accreditation Canada. It took sometime for hospital boards to get past the hurdle of full disclosure by Canadian hospitals. An initiative such as the Ontario Ministry of Health and Long Term Care Patient Safety Indicator program was launched in 2008 and has now expanded to nine indicators in 2010. These patient safety indicators are presently focused on various infection rates, hand hygiene and patient mortality rates. Participation in the indicator program is mandatory for all Ontario hospitals and they must regularly report their results on these 
benchmarks publicly. This move has forced all healthcare facilities in this province to priorize patient safety initiatives. Recently, it has been estimated that about $10 \%$ of hospitalised patients are presently involved in a treatment induced injury globally [31]; this is an improvement over prior performance, but leaves more room for improvement.

Equipment standardisation has been identified [32] as an important step in improving safety, but why is this so? The human thought process tends to be error prone and imperfect. This is why all patient safety literature suggests that a systems approach must be taken to minimise the likelihood of patient harm by reducing the reliance on short term memory. All equipment should have specific procedures developed to clearly outline operation and use. If equipment is standardised, the operating procedures may be straightforward, thereby reducing the likelihood of error.

James Reason's "Swiss cheese model" [33] is a good approach to visualising system errors. It simply states that many holes in a single slice do not necessarily cause an adverse system outcome. Only when the slices are put together and a hole exists through the entire block does an error trajectory exist.

Reason [34] also coined the terms 'active error' and 'latent error' to describe the two types of human error. Active errors are acts that occur at the human-device interface; they are normally short lived and typically relate to lapses or mistakes by an individual. Latent errors are system errors that can also cause harm to the patient. Latent errors are errors that lie dormant within a system waiting to happen. There is tendency to blame the individual for these errors, but in fact they are system-design errors which were not identified by the device or process design team. Donald Norman identifies latent errors well in the statement: "If an error is possible someone will make it!" [35] 
Highly effective organisations proactively look for these potential trouble spots and work to correct them before they cause harm. These potential problems could be a single step in a complex procedure or a stand-alone device with an unintentionally designed flaw. A good example of a potential latent error would be the kilograms or pounds selector switch on a digital weight scale. The clinician may take a weight reading using this scale and use the weight measurement to calculate the correct dosage for a specific drug. If the clinician confuses the measurement standard, it would mean the drug dosage calculation would be too high or too low by a factor of 2.2. This is not such a hard situation to imagine when one keeps in mind that anyone under forty in Canada may not appreciate the significance of the error since they were trained only in the metric system. The systems approach would mitigate this type of potential problem from occurring. The systems approach focuses on the environment people work in and builds defences to eliminate or reduce the adverse effects of the fault. To correct and prevent this type of problem from occurring again, one must, in the future, only purchase new metric weight measuring scales. Existing weight scales that had the ability to switch from pounds to kilograms should either be modified to eliminate the pounds function or be replaced as soon as possible.

The scale scenario illustrates why all new equipment to be purchased by a healthcare facility should receive a human factors review prior to approval being given to purchase a specific device. Price should not be the key determinant in any clinical device selection process. Immediate savings sometimes create larger problems down the road. Failure Mode Error Analysis (FMEA) should be conducted on all newly adopted clinical 
procedures before they are put into general use; similarly, this should be done for any newly identified sources of error within a healthcare facility.

Lack of equipment standardisation can be clearly categorised as a latent error. Having several different devices performing the same function complicates operator procedures and increases the chance of human error. This is why equipment standardisation was implemented successfully in the airline industry. Unfortunately, the measurement of device commonality or diversity is not necessarily clear, especially when confronted with a large inventory in several different locations, in a large metropolitan teaching hospital system.

\subsection{Infusion Devices}

Intravenous therapy started with gravity delivery of hydration fluids, medication, and nutritional and blood products from a reservoir, initially made from glass and, later made from plastic. Rubber, then plastic tubing carried the contents of the reservoir into the circulation system by means of a catheter. In 1956, the Harvard Corporation developed the syringe pump to administer drugs in a controlled manner by driving the fluid from the syringe. The syringe pump was initially limited to critical care for adult and paediatric patients.

In 1969, the IVAC Corporation developed the first infusion controller that counted the drops accumulated in the intravenous (IV) drip chamber and regulated the preset drop rate by pinching the tubing. [36] This method worked better with low viscosity fluids, than with those with a thick consistency such as glucose solutions or blood products. A year later, IVAC redesigned the IV controller and added a peristaltic 
pump that massaged the IV tubing which, in turn, pushed the fluid in the tubing into the patient's circulatory system. Further refinements came with the development of the volumetric infusion pump in 1974 by IMED which improved the accuracy of the fluid delivery to approximately $2 \%$; it also was the first pump that controlled occlusion pressure; limiting occlusion pressure was a serious safety concern with infusion pump technology. Early peristaltic infusion pumps were capable of generating high pressure in IV lines that would either injure the patient or burst the IV line. Another safety concern involving the infusion pump at that time was IV flow runaway. This phenomenon occurred when IV lines are inadvertently left wide open. A free flowing IV line causes the patient to receive either a drug overdose or a fluid overload. Infusion delivery calculation errors result from mathematical calculation errors between the set drop rate of the device and the drops per millilitre size of the IV set used for the therapy administration. Finally, the last major error related to the insertion of the IV tubing in the wrong direction in the infusion drive mechanism. This action would draw blood out instead of pushing fluid into the patient. Infusion pump manufacturers introduced safety mechanisms in the 1970s and 1980s to counter these aforementioned problems.

Throughout the1980s and 1990s, infusion device technology improved with the addition of several safeguards to reduce patient injury. With the introduction of these technologies, amongst others, healthcare professionals saw an increase in the survival of acutely ill patients and longer life spans in general. One resultant from this positive outcome was an older patient population requiring increasingly complex care. By 2000, critical care patients commonly had five to ten infusion pumps attached. Rare cases required more pumps. Central IV lines connected the multiple number of IV pumps to the 
patients. Many safety problems arose from the proliferation of this technology. Examples include: the chemical reaction that results from the mixing of multiple drugs in the central line; human errors involving the IV line and infusion flow rates or the enteral feeding line and the central line; and non-invasive blood pressure hose connection to central lines.

Infusion pump manufacturers realised that these new concerns had to be addressed. Some chose to modify existing designs, while others embraced the human factors and patient safety movements. The latter launched massive redesign projects to develop the "smart pump". Smart pumps have an intuitively designed human interface with modifiable drug libraries incorporated within their design. The drug library or Drug Error Reduction System (DERS) includes comprehensive menus with safety limit parameters that do not allow the user to easily override these settings. All transactions, system warnings, and alarms recorded within the memory of the pump can be extracted at a later time for review and analysis using drug library software. Improvements to this technology recently introduced include wireless technology and an HL7 interface to the user's electronic health records (EHR) where they exist.

These improvements provide further flexibility allowing immediate and simultaneous library and software updates to be applied, transmission of selected datasets directly to the patient's file in the EHR, and device tracking. While these improvements made the infusion pump safer to use, Hankins states "Making the technology available will not be sufficient to ensure its successful use" [37]. A potential for human error lingers through the potential to override safety features by clinical staff and from library programming errors by pharmacy staff. To reduce the frequency of these problems, a 
well-designed review and quality assurance process is necessary. Implementing DERS is one step in developing an optimally safe drug, fluid, blood products, and an enteral feeding delivery system. Recent research $[38,39]$ reveals that DERS systems only provide marginal improvements in safety: approximately a $4 \%$ reduction in drug delivery errors. Theorists predict that only when infusion devices are fully interfaced with electronic health records and with computerised order entry systems, the pharmacy information system, and barcoded medication administration, will IV safety be optimised. [40] Unfortunately, the majority of health facilities in the industrialised world are not close to implementing this level of technology at this point in time, let alone in the rest of the world. It will still take a few years before North America implements these options and lead to the benefits of an IV safety system described above.

\subsection{Physiological Monitors}

Physiological monitors measure various parameters either by direct measurement of an electrical signal or by an electrical or electro-mechanical transducer. Today's monitors can measure a number of parameters that include ECG, pulse rate, respiration, both invasive and non-invasive blood pressure, temperature, noninvasive measurement of the blood oxygen saturation, oxygen gas concentration, transcutaneous blood CO2 concentration, expiratory gas $\mathrm{CO} 2$ concentration, cardiac output, and EEG. There are several sparsely used parameters such as bispectral index and co-oximetry which are available, but their use varies from one organisation to another. 
The origin of the bedside physiological monitor dates back to the 1950s, around the same time that intensive care units were created in hospitals to better manage the care of patients with complex disorders.[41] Early monitors were developed by companies such as Sanborn, Cambridge Instrument, Electrodyne, Dallons, and Levinthal. These monitors were built around oscilloscopes called cardioscopes. These early devices did not have heart rate measurement or alarm capabilities, and with the relatively limited persistence on the cathode ray tube screen, the waveform would fade before it had travelled across its three to five inch screen. If ECG waveform interpretation had to be done, either a thermal printer was attached to the monitor or the patient was linked to an electrocardiograph. There were few cardiac monitors in 1950-era intensive care; they were often placed on a resuscitation cart with a cardiac pacing unit and a defibrillator. Measuring the heart rate from this device involved a calculation of the beat-to-beat distance divided by the chart recorder's speed until the development of the cardiotachometers in the 1960s. During the late 1950s and the 1960s, the number of physiological parameters expanded to include invasive blood pressure, temperature, cardiac output along with oxygen and carbon dioxide concentration in the blood. As the 1960s progressed, the size of the cathode ray tube (CRT) display doubled in size and the feature of waveform persistence was incorporated on to the display creating the effect of memory for the physiological signal through the entire sweep cycle of the display. [42] The introduction of central stations allowed the monitoring of all patients in a clinical unit at the bedside and at the nursing station. New monitors at that time incorporated physiological alarm systems. 
The 1970s saw monitoring equipment become more commonplace in most hospitals, with the rapid growth of digital electronics in most hospitals. Parameters monitored by this equipment expanded to include non-invasive blood pressure, noninvasive blood oxygen saturation, and transcutaneous measurement of the partial arterial pressure of carbon dioxide and oxygen in the blood. Datascope and Tektronix manufactured the first portable transport monitors. This decade saw further development of the monitors as a result of microprocessors reaching maturity; it was also due to emergence of commercially marketed electronic health records such as the COSTAR system [43]

By the 1980s, physiological monitors had colour displays capable of displaying two to six waveforms. Bedside monitors were now able to analyse cardiac arrhythmias. Remote viewing of patient data from other bedsides was also possible. The introduction of membrane switches provided less chance of infection and thereby allowed data entry away from the central station. Later in the same decade, Hewlett Packard introduced the Merlin series of monitors which was the first "hot swappable" modular system available on the market. This distinct feature allowed parameter modules to be moved as required between bedsides. Many of these modules can still be found in service today, nearly twenty years later, as each successive generation of this monitor family has retained compatibility with previous models. [44]

The major monitoring manufacturers developed a new design strategy in the 1990s. The LCD display replaced the bulky CRT; the LCD reduced the overall weight of and power consumption for the device. As a result, specific bedside, critical care, and transport monitors were no longer necessary since the monitor could be configured as 
necessary. Manufacturers had begun to develop internal battery packs that were lightweight, compact and much more efficient. Therefore, the monitor could remain with patients throughout their entire stay. Interfacing other medical devices to the monitors was now possible; they could also display data. [45]

By the $21^{\text {st }}$ century, physiological monitors revolved around the personal computer and were connected to the internet. This online capability allowed the clinician to remotely view in real time the waveforms and the trends. Ten years later, monitors became wireless, and as this technology developed, it could be used to monitor vital signs remotely. Monitor displays now have the resolution to display ultrasound and radiographic images at the bedside. Additional parameters and functions can be added to the monitor through a USB connector. Additional parameters will be added in the future by this method and will likely follow the current trend of adding non-invasive sensing technologies. [46]

The once minimal three or four parameter bedside physiological monitor has now developed into a viewing system that allows the clinician to see laboratory and diagnostic test results along with patient documentation. The device continues to simultaneously monitor, document several physiological parameters, and record the function of several external devices such as ventilators or infusion pumps. Real-time data acquisition and analysis of physiological trends is now a commonplace function. A simple stand-alone medical device has transformed into a single component within a complex web of functions to support care of the patient. One concern this complex system creates is the increased probability of error in patient care since all of these functions have become interwoven and are complex. 


\subsection{Entropy Diversity Index (EDI)}

The standardisation of commonly used clinical equipment throughout a healthcare organisation simplifies clinician and nurse training, eases servicing of the devices by maintenance staff, and reduces overhead costs by minimising consumable inventory size. To date there is limited data available to illustrate that standardisation of clinical equipment improves patient safety by reducing medical errors, using conclusive numerical data. In many cases, analysis is conducted in a subjective manner and it is difficult to cross-correlate this information in a manner that will give any consistent findings.

Claude Shannon investigated the statistical repetitiveness of characters within a text and developed a method of determining a numerical measure of the uncertainty of the repetitiveness of a random variable or entropy in his research work around information communication theory. This concept was successfully applied to measure species diversity within a defined area by E.H. Simpson in 1949. [47] A method originally used to measure biodiversity in ecological environments, EDI [48] can also be applied to measure equipment diversity within an entity. This was successfully tested by Brindle and Gibson in 2007 [49] to evaluate infusion device diversity or standardisation within a multi-site hospital system known as the Oxford Radcliffe Hospitals in the United Kingdom. Steady efforts from the year 2000 to standardise their inventory of infusion pumps within the Oxford hospital system has seen a drop in EDI from 2.6 to 1.9 by the year 2005. This approach of measuring equipment standardisation provides a convenient tool that can work consistently with either a small or large diverse inventories providing valid benchmarks. Entropy, stated simply, can be defined as the measurement of the 
diversity or disorder of a given sample. The EDI is a statistic used to compare several different samplings of the same product in different locations. The EDI can be calculated by:

$$
\begin{aligned}
& \mathrm{E}=-\sum \text { pi } \ln (\mathrm{pi}) \\
& \text { and } \quad \mathrm{pi}=\mathrm{ni} /\left(\sum \text { ni }\right)
\end{aligned}
$$

Where pi is the fraction of the individuals belonging to the $\mathrm{i}$-th species and ni are the individuals within the $\mathrm{i}$-th sample. In the case of equipment and its diversity at a facility or group of facilities, the formula would translate to:

$$
\begin{aligned}
& \text { pi }=\text { ni } /(\Sigma \mathrm{ni})=\frac{\text { Number of units of a specific model }}{\text { Total number of specific devices }} \\
& \mathrm{Ei}=\text { pi } \ln (\mathrm{pi}) \\
& \mathrm{E}=\Sigma(\mathrm{E} 1+\mathrm{E} 2+\mathrm{E} 3+\ldots . . \mathrm{Ei})
\end{aligned}
$$

There are several other types of entropy and diversity measurement tools such as the Simpson, Berger-Parker, the Gini and the Renyi indices but to date the Shannon EDI has been the method of choice in the fields of communication theory, ecology and genetics research. Table 2.1 illustrates the various major indices and their key value. 


\begin{tabular}{|c|c|}
\hline Index & Purpose \\
\hline Simpson [50] & Measure evenness of diversity. \\
\hline Shannon [51] & $\begin{array}{l}\text { Measures richness or abundance of } \\
\text { diversity. }\end{array}$ \\
\hline Berger - Parker [52] & $\begin{array}{l}\text { Assesses the dominance of one type within } \\
\text { a community. }\end{array}$ \\
\hline Gini [53] & $\begin{array}{l}\text { Measures equality within a sample. } \\
\qquad \begin{array}{l}0=\text { Perfect Equality } \\
1=\text { Perfect Inequality }\end{array}\end{array}$ \\
\hline Renyi Entropy [54] & $\begin{array}{l}\text { Quantifies only entropy not diversity. It can } \\
\text { measure only the number of different types } \\
\text { of make and model of device amongst a } \\
\text { sample. }\end{array}$ \\
\hline
\end{tabular}

Table 2.1 The Major Entropy and Diversity Measurement Tools

A key goal of this work is to validate a tool that will index the measurement of the entropy and the diversity of a known sample of like medical devices or in other words index the number of different makes and models and the inventory dominance of each make and model the within a defined population.

The Shannon method indexes the level of diversity and the size of each make and model type amongst a defined sample population. The Simpson method indexes the spread or range of diversity within a population. Therefore, the Simpson method could only evaluate the spread of make and model types within a defined group. The Berger Parker method indexes the dominance of one group within a population so this measurement tool could identify which make and model type dominates a specific population. The Gini method indexes the equality of the groups within a population hence it could only identify when a specific make and model of device is not or is the only 
make and model present within a specific sample. The Renyi method measures the variation in the number of different types of makes and models amongst a defined population. The Renyi Index does not factor the dominance of the different types within a specified sample. Since this study is attempting to index both the diversity and the concentration of makes and models of medical devices within a defined inventory, all but the Shannon method must be ruled out as an effective means of measuring the level of disorder or entropy and the diversity of makes and models of devices amongst a defined inventory.

The ability to quantify the diversity of a specific device numerically allows comparison of this factor against other indicators such as documented user problems and patient incident reports. This key indicator can then be used to prove or disprove a link between equipment standardisation and patient safety.

The extracted inventory census information, by year, and by defined area will be used to calculate the EDI as illustrated by Brindle and Gibson [55]. Calculating the EDI for a defined sample is a straightforward exercise. First the total number of like devices within the sample is calculated. An example of a device with the same function is the syringe pumps. The sample could be a single department, an entire facility or several facilities on different sites. Next, the sum of each specific manufacturer and model of each like device is determined. Once these numbers are available, they are divided by the total number of like devices to find the ratio of each different make and model of device to the grand total of devices within the study. The number of ratios will correspond to the number of different manufacturers and models of the like devices within the sample. 
Finally, to calculate the Entropy Diversity Index, the negative sum of all ratios, multiplied by the natural logarithm of the same ratio, is done.

If the first column of Figure A3.1 is used as an example, then we will have six different types of devices and a total of 134 devices, then:

$$
\begin{aligned}
& \mathrm{P} 1=6 / 134=0.0448 \\
& P 2=29 / 134=0.2164 \\
& \mathrm{P} 3=7 / 134=0.0522 \\
& \mathrm{P} 4=35 / 134=0.2612 \\
& \text { P5 }=10 / 134=0.0746 \\
& \text { P6 }=47 / 134=0.3507
\end{aligned}
$$

Then:

$E=-[[0.0448 \ln (0.0448)]+[0.2164 \ln (0.2164)]+[0.0522 \ln (0.0522)]+[0.2612$ $\ln (0.2612)]+[0.0746 \ln (0.0746)]+[0.3507 \ln (0.3507)]=1.53$ 


\section{Chapter 3: Methodology}

Before extensive data collection could be made on this study, an Ethics Committee approval of the use of patient medical record information from the CHEO adverse event reporting system was obtained from both CHEO and Carleton University. A patient adverse event report is the documentation completed in a standardised report format to document a suspected or actual patient incident where harm has or nearly has been caused to a patient. The specifics of the particular incident are documented along with actions to correct the negative outcomes of the incident and action plans to permanently prevent a reoccurrence of the incident are all usually documented within a incident report.

While all CHEO patient adverse event reports were reviewed in detail within the prescribed five year time span; no specific patient identifiers such as name, patient number, or date of birth were recorded. This study's interest is in the precise details of the equipment involved, the outcome, and the determined root causes of each event, if available.

Information pertaining to the medical equipment inventory and maintenance history of both the syringe pumps and physiological monitors used at CHEO over the determined period of data collection are confidential corporate records. Permission for the use and publication of this data within the boundary of this study has been obtained from the Executive Vice President and Chief Financial Officer of the Children's Hospital of Eastern Ontario, Mr. Gerard Bisson. 
After initial review, the collected data from both information systems come from a sixty-five month period between April 1, 2005 and August 31, 2010. Collecting at least five years of data establishes reliability and can identify any reproducible trends from the datasets. Normally, information is documented in the Canadian healthcare system by fiscal year, from April $1^{\text {st }}$ to March $31^{\text {st }}$ of the next calendar year; and it was decided it would be best to collect the research information, by fiscal year over five years since all departments at CHEO compile their statistics based on hospital fiscal year. This approach worked well in the case of physiological monitors but taking this direction with the syringe pumps could result in inconclusive results because the syringe pump fleet was replaced in the fiscal year of 2009/10. Therefore, an additional period of five months of data was collected in the hope that this extra data would give more definitive results in the case of the syringe pumps.

A five step course of action was conducted in the data collection process. It is important to note that all these components were undertaken in concert to enable the most efficient use of time. The above mentioned steps included:

I. The CHEO physiological monitor and syringe pump inventory was reviewed to collect data categorised by year, make, model, serial number, and patient unit over a five year period from April 1, 2005 to August 31, 2010 from the CHEO Biomedical Engineering ServicePlus enterprise management system. Equipment that was either added or removed from the operational equipment inventory had its change in operational status documented on a quarterly incremental basis. The dates where each device was placed into active service and if applicable, the date of decommissioning of each device, were 
documented. These dates will allow the determination of the size of each different population of make and model of the specific device type within a specific time period. These numbers are used to calculate the EDI for each specified time period.

II. As the inventory list was being completed, a detailed review of the equipment service histories was conducted, identifying and documenting each instance of a user problem and each equipment failure by device make, model, and year, for the period from April 1, 2005 to August 30, 2010 from the CHEO Biomedical Engineering ServicePlus system. Data identified as potential instances for the inclusion of suspected user problems was screened by reviewing the user reported problem description and the comments made by the technologist who performed the operational assessment; it was determined if the equipment exhibited the reported user-problem or not. Usually, when the technical evaluation of the device is being performed, if the problem is not reproducible or it is obvious by comments made in the user description that the problem is connected to operator error, the technologist comments accordingly in the work completed section of the work order. A detailed review of all work orders in the entire history for each of the devices accepted into this study had to be carried out, as task code identifiers were not implemented when the ServicePlus system was set-up in 1999. Task codes provide an alphanumerical code that represents a specific task and are usually documented in a specific field within a work order. Adding task codes provides a quick and effective evaluation of work service histories on 
equipment. This feature was not implemented at that time because it would have added too much time to the entry of each work order, thereby pushing documentation overheads to an unacceptable level.

If the technologist comments documented on each work order are not clearly identifiable as a user problem, the specific event was not accepted as a valid user problem. The occurrence of user problems is documented by increasing the number in the year column in which the event occurred by one each time a problem is encountered in the specific device summary spreadsheet. This spreadsheet is illustrated in Appendix 1. The sixth year of data is actually the partial year of data from April 1 to August 31, 2010. The first operational date of service and the date of device decommissioning are also recorded for each device. This information is recorded to allow for the EDI calculations by fiscal year once the inventory data is compiled.

Once the data collection was completed in this phase, the inventory statistics were summarized by device model; department and user problems could then be summarized by department and year in a separate spreadsheet. Once this spreadsheet was completed, it was expanded to add the EDI calculations by department and year. Aggregated total EDI calculations were added to the spreadsheet at this time. Taking this approach provides an excellent decision-support tool that aided in the decision making process on how to best determine which way to proceed with this EDI data, either focusing on individual departments and years, or on the total inventory EDI calculations by year. 
III. In the next phase, a review of the incident report database was done manually and electronically, as the CHEO Risk Management electronic adverse events database was phased-in one department at a time during fiscal year 2007. All records prior to this date were kept in hardcopy format only and each report predating the electronic system required a manual review and the reports had to be vetted for inclusion into this study. This manual review was conducted for the years 2005/6, 2006/7 and partially for fiscal year 2007/8, as some of the data is retained in the manual record system and the remainder of the records for this year were available on the electronic adverse events system along with the years 2008/9, 2009/10 and 2010/11.

The review of the electronic record system was conducted for the period of from April 1, 2008 to August 30, 2010. Any incident record with the word monitor or pump was reviewed for inclusion as a documented user issue with a physiological monitor. Once the detailed reports for all events involving pumps or monitors were available, these reports were reviewed to screen out any incidents that did not directly involve syringe pumps or physiological monitoring equipment. Once a final summary of these events for these specific devices was available, the incidents were analyzed to determine if these adverse events were likely caused by user error or equipment failure. Once this work was finished, the data was summarized in tabular format for later comparison with the EDI data. Figure 3.1 illustrates the relationship of EDI value against the state of the inventory and the distribution type. 


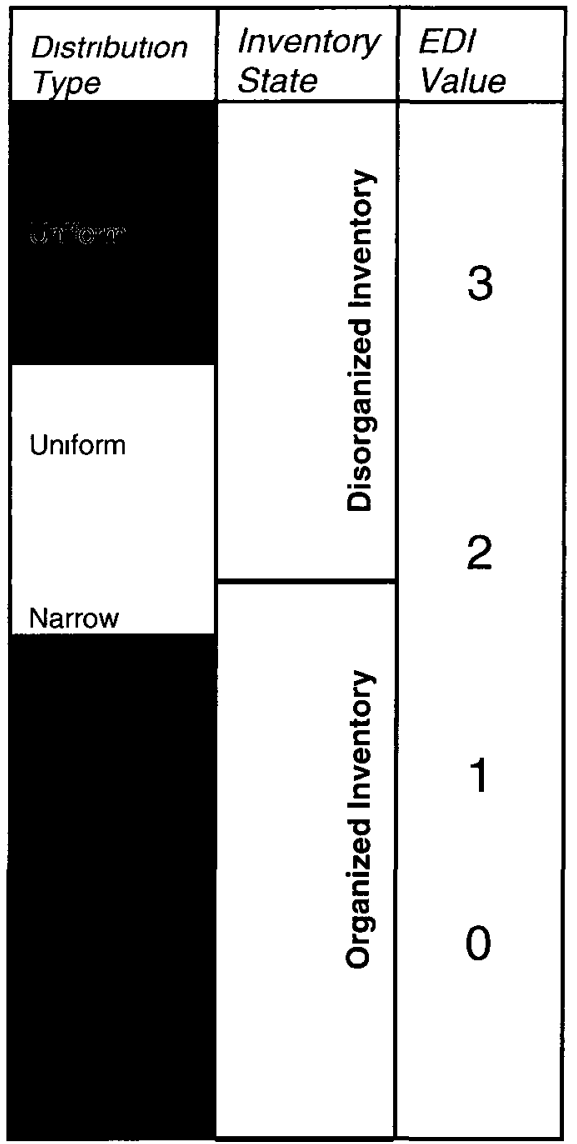

Figure 3.1 - Relationship between EDI Value, Inventory State and Distribution Type

The EDI data will be reviewed and the status of the inventory can be determined against time by comparing calculated EDI values and the chart in Figure 3.1. The EDI will approach zero as an inventory of equipment becomes less diverse; and as the inventory becomes less standardised, the EDI number will grow, but in most cases in this application, the EDI is expected to remain under a value of three, with this value representing a diverse but evenly distributed inventory. 
IV. Review and comparison of the EDI values against the user problems and adverse events, compiled annually as a whole, and by department, by fiscal year, was conducted. Both the EDI values for the total inventory for each of the devices by year and the EDI by department annually were calculated, documented and compared against the annual number of user problems and adverse events. The total inventory approach was selected as the method of choice for presentation of the data against the user problems and the adverse events by fiscal year. There simply was not enough data provided by this study to enable clear results to be drawn at the smaller department level on the effects of equipment standardisation. The data was collected and presented both by department and as the total inventory, from the onset of this study, to give a better choice of the selection of time, and to prevent having to backup and take a second look at the same data again if the results are unclear.

V. Finally, research was carried out to determine the best way to present this data in order to have clear results for testing the hypothesis. 


\section{Chapter 4: Results and Discussion}

The first step in the data collection process was the documentation of the equipment inventory for both devices under study on a spreadsheet of identical structure and format for both of these devices. The service status of each device studied within the project was documented in the spreadsheet by noting the start of service date and the date of decommissioning of the device. The attributed clinical user problems for each device was documented within each of the time intervals during the period of study. One must remain cognisant of the fact that the clinical user problems documented within the Biomedical Engineering work order system were only included within this study if they had been documented as a confirmed user problem on a work order and no corrective repair action had been necessary to resolve any functional or safety issues with the device. The documented data will allow for the calculation of the EDI values for each time period within the study period for both the physiological monitors and the syringe pumps. The clinical user problems documented on the same inventory spreadsheets will allow linking these problems to specific devices at defined time periods. Compiling both of these spreadsheets allows the EDI calculations to be determined for each of the device populations and the comparison of this data to the clinical user problems tied to these specific devices. From these data sets, a determination can be made whether there is a link to the EDI values and clinical user problems.

It is important to clarify that the documented clinical user problems and the Adverse Event (AE) reports are two different data sets. An AE report is a document completed by clinical staff detailing an incident that either did or nearly caused harm to a patient. This report is the corporate record document detailing the event and related 
outcomes. AE reports will be reviewed and analysed over the study period to identify whether they involved physiological monitors or syringe pumps. Although there may be an adverse event report and a user error documenting the same incident, the similarities stop at this point. In many cases, the identity of the equipment involved in an adverse event is not documented on an adverse event report by the clinical staff completing the document. Therefore, these events cannot be documented on the spreadsheets that the equipment inventory and user error data are stored. The adverse event data must be tabulated separately and then compared to the other datasets against time. The documented events, from both systems are compared against the applicable EDI values in order to identify trends in the data that would establish links between the different data sets.

For reference, the clinical equipment inventories were extracted from the ServicePlus information system in Microsoft Excel format through a Crystal Reports utility. Separate spreadsheets were then built to collect the physiological monitor and syringe pump data. These data tables were designed identical in structure and in a manner to allow for straightforward data manipulation during the analysis phase of this study.

Both spreadsheets contain the following nineteen data fields for each device record as outlined in Table 4-1. The first six columns detail the equipment with control number, assigned department, manufacturer name, model and serial numbers and device description fields. The next two columns provide the dates on which the device was placed into service and or was removed from active service, if applicable.

Following the equipment information, the next five columns detail whether the device was in active service or not during each of the specific time slots of the five years 
of the study. If a device was actively in service in a specific year, the cell will hold a value of " 1 " but if the device was not in service, the cell will hold a value of " 0 ". These columns were created for analysis purposes to simplify the summing the total inventory numbers of the specific model of device under evaluation. Finally, the last six columns document the number of user problems documented each fiscal year on Biomedical Engineering work orders in each specific device. Each of the blue columns are summed at the bottom of the spreadsheet to total number of user problems documented on work orders by fiscal year for the specific device type.

\begin{tabular}{|l|l|l|}
\hline Column & Column Label & Content \\
\hline 1 & Asset ID & $\begin{array}{l}\text { CHEO Biomedical Engineering Control } \\
\text { Number }\end{array}$ \\
\hline 2 & Location & Assigned Department \\
\hline 3 & Make ID & Manufacturer Code \\
\hline 4 & Model ID & Device Model Number \\
\hline 5 & Serial Number & Device Serial Number \\
\hline 6 & Description & Device Description \\
\hline 7 & Date INS & The date of first use of the device. \\
\hline 8 & Date RET & The date of retirement of the device. \\
\hline 9 & $2005-6$ (orange header) & $\begin{array}{l}\text { This cell notes whether the device was in active } \\
\text { service during fiscal 2005-6. The cell contains } \\
\text { either a "1" denoting active use or a "0" if the } \\
\text { device was no longer in service. }\end{array}$ \\
\hline 10 & $2006-7$ (orange header) & $\begin{array}{l}\text { This cell notes whether the device was in active } \\
\text { service during fiscal 2006-7. The cell contains } \\
\text { either a "1" denoting active use or a "0" if the } \\
\text { device was no longer in service. }\end{array}$ \\
\hline 11 & 2007-8 (orange header) & $\begin{array}{l}\text { This cell notes whether the device was in active } \\
\text { service during fiscal 2007-8. The cell contains } \\
\text { either a "1" denoting active use or a "0" if the } \\
\text { device was no longer in service. }\end{array}$ \\
\hline 12 & $2008-9$ (orange header) & $\begin{array}{l}\text { This cell notes whether the device was in active } \\
\text { service during fiscal 2008-9. The cell contains } \\
\text { either a "1" denoting active use or a "0" if the }\end{array}$ \\
\hline
\end{tabular}




\begin{tabular}{|l|l|l|}
\hline & & device was no longer in service. \\
\hline 13 & $2009-10$ (orange header) & $\begin{array}{l}\text { This cell notes whether the device was in active } \\
\text { service during fiscal 2009-10. The cell contains } \\
\text { either a "1" denoting active use or a "0" if the } \\
\text { device was no longer in service. }\end{array}$ \\
\hline 14 & $2005-6$ (blue header) & $\begin{array}{l}\text { The number of identified user device problems } \\
\text { found in the ServicePlus System during the } \\
\text { identified fiscal year. }\end{array}$ \\
\hline 15 & $2006-7$ (blue header) & $\begin{array}{l}\text { The number of identified user device problems } \\
\text { found in the ServicePlus System during the } \\
\text { identified fiscal year. }\end{array}$ \\
\hline 16 & $2007-8$ (blue header) & $\begin{array}{l}\text { The number of identified user device problems } \\
\text { found in the ServicePlus System during the } \\
\text { identified fiscal year. }\end{array}$ \\
\hline 18 & $2008-9$ (blue header) & $\begin{array}{l}\text { The number of identified user device problems } \\
\text { found in the ServicePlus System during the } \\
\text { identified fiscal year. }\end{array}$ \\
\hline 19 & $2009-10$ (blue header) & $\begin{array}{l}\text { The number of identified user device problems } \\
\text { found in the ServicePlus System during the } \\
\text { identified fiscal year. }\end{array}$ \\
\hline & $\begin{array}{l}\text { The number of identified user device problems } \\
\text { found in the ServicePlus System during the } \\
\text { identified fiscal year. Data for this fiscal year } \\
\text { will be only collected for the period of April 1 } \\
\text { to August 31, 2010. This factor must be } \\
\text { considered when conducting the analysis of the } \\
\text { data. }\end{array}$ \\
\hline
\end{tabular}

Table 4.1 - Inventory Spreadsheet Structure

\subsection{Monitoring Devices Data Collection and Analysis}

Complete versions of both the syringe pump and physiological inventory

spreadsheets are located in Appendices of this report for reference purposes. The

physiological monitor spreadsheet contains the summarized data from the service

histories of 400 monitoring devices. Each time there was a report of an equipment

problem identified, it was documented on a CHEO Biomedical Engineering work order

and if the problem could be definitely attributed to user- error, the event was documented

on the spreadsheet within the cell labelled for the specific fiscal year. Within the 
spreadsheet, physiological parameter module histories were assessed and documented to accurately reflect all user problems documented by clinical staff and communicated to Biomedical Engineering. Physiological parameter modules are an accessory that connects to a port on the bedside physiological monitor and adds multiple parameters such as invasive or non-invasive blood pressure, transcutaneous or end tidal $\mathrm{CO} 2$ or temperature measurement to a specific bedside monitor.

When an annual count of each specific type and make of physiological monitor as conducted during the development of Entropy Diversity Index (EDI) estimations, the physiological modules were not included the census counts to allow for a concise reflection of the population groups of specific monitors and thus not inaccurately skew EDI calculations. For the initial inventory exercise only, the temperature and the trend strip chart recorder were excluded from the inventory, they are not heavily used modules and do not provide any value to this study. Essentially the two specific modules do not impact the routine monitoring capabilities and operational number of the monitors available.

Once each of the inventory spreadsheets was complete, the data was sorted and summarised by fiscal year with the user problems added. User problem totals may be derived by department, make and model type, if these approaches seem beneficial when the data is evaluated. To remain consistent in the data collection methodology, if a device was removed from active service during a fiscal year, the user problems were not logged for that specific fiscal year as inclusion of these events would impact the accuracy of the results. 
The physiological monitoring inventory is summarized in Table 4.2. The data shows an increase in the amount of monitors from 134 in fiscal year 2005-6 to 232 in fiscal year 2010-11. The monitoring equipment standardisation has improved at CHEO with a drop from seven different varieties in fiscal year 2006-7 to four different varieties in fiscal 2010-11.

\begin{tabular}{|c|c|c|c|c|c|c|}
\hline 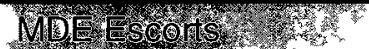 & 6 & 3 & 3 & 3 & 0 & 0 \\
\hline 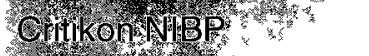 & 29 & 24 & 26 & 20 & 20 & 20 \\
\hline MP/788340suries & 7 & 1 & 1 & 0 & 0 & 0 \\
\hline HIM & 35 & 35 & 37 & 37 & 0 & 0 \\
\hline GE $10.0 \mathrm{sen}$ & 10 & 10 & 10 & 10 & 9 & 9 \\
\hline Neycorsaty & 47 & 44 & 78 & 75 & 75 & 75 \\
\hline Monitors & 0 & 53 & 53 & 65 & 121 & 128 \\
\hline Total Active & 134 & 170 & 208 & 210 & 225 & 232 \\
\hline Different Types & 6 & 7 & 7 & 6 & 4 & 4 \\
\hline
\end{tabular}

Table 4.2 - Physiological Monitor Inventory Summary by Year

The identified user problems are summarised on the physiological monitor spreadsheet and the data, which were extracted from the Service Plus system are documented in Table 4.3. The number of documented user problems related to bedside monitors illustrates a steady increase of 32.7 percent per year in the number of user problems identified over initial the five year period of the study. Even though the number of user problems were on the rise in the five year period of study it does not mean that users were finding one device more difficult to use over another since the total inventory of monitors has increased substantially from 134 at the beginning of the start of the study to 232 at the end of the study, as illustrated in Table 4.2. The ratio of the total number of user problems to total numbers of devices in active use per specific time period would take into account the variability in the inventory of monitors or syringe pumps to more 
accurately gauge whether user issues with equipment are really becoming more problematic or not.

Data collected for fiscal year 2010-11 only encompasses the first five months of the fiscal year. The operator problem data values were extrapolated to twelve divided by five, and rounded to the nearest whole number, to obtain meaningful results for both the syringe pump and monitors.

\begin{tabular}{|c|c|}
\hline Fiscal Year & $\begin{array}{c}\text { Number of Documented } \\
\text { User Problems }\end{array}$ \\
\hline $2005-6$ & 22 \\
\hline $2006-7$ & 24 \\
\hline $2007-8$ & 40 \\
\hline $2008-9$ & 50 \\
\hline $2009-10$ & 58 \\
\hline $2010-11$ & 36 \\
\hline
\end{tabular}

Table 4.3 - Summary of the Identified Monitor User Problems by Fiscal Year.

With the inventory data now available along with the user problems documented on work orders, the EDI calculations by year and the ratio of user problems to total number of devices were calculated and these findings are available in Table A3.1 in Appendix 3 on page 100 . The ratio of user problems to total inventory were added to the table to provide an indication of the user problems in proportion to the changing size of the inventory, as this factor can skew the results when large variations in overall sample size occur.

The calculated EDI values for monitors show a drop over time from 1.58 at the beginning of the study to 1.03 as of fiscal year 2010-11, which correlates with the decrease in the number of different physiological monitors in use at CHEO. The EDI value is not impacted by fluctuations in the inventory but by the number of different 
manufacturers and models present within the specified inventory group and the relative size of each subgroup against the total inventory. Referring back to Figure 2.1, it shows that CHEO, with a current EDI value for its inventory of monitors of 1.03 , is approaching a peak level of standardisation, while the ratio of user problems, compared to the total inventory, rose every fiscal year until 2009-10 and then dropped off during the last year of the study based on the adjusted data available for the first five months of the year.

In an effort to better interpret the user problem data and the adverse event data, the data sampling was increased to four quarterly points, from one point per fiscal year. There are twenty-one points of data for each of the three measured parameters. Table A3.1 on page 101 illustrates the data set for the physiological monitors. In Table A3.1, the seven rows noted as $\mathrm{P} 1$ to $\mathrm{P} 7$ give the calculated fractional value for each different type of monitor against to total number of monitors in use during the specific period of time. Since there were seven different types of physiological monitor used at CHEO within the period of study, there were seven fractional values for each time period. These fractional values are then employed to calculate diversity index for each of the devices as shown in formula 2.1 on page 23 of Chapter 2. Finally, the negative sum values of these individual index numbers were derived to calculate the EDI value for the specific time period as shown in Table A3.1 
The graphs in Figures 4.1 show the EDI values against time for the monitors while Figures 4.2 and 4.3 illustrate the plots of the user problems and the ratio of user problems over the total number of devices in service, both against time. The graph of the EDI value against time in Figure 4.1 illustrates a drop in EDI against time for the physiological monitors. Both the number of user problems and the ratio of user problems graphs in Figures 4.2 and 4.3 respectively document an increase in user problems against time until nearly the end of the study. User problems rose during fiscal year 2007-8 and began to drop in fiscal year 2009-10 and continued this trend in fiscal year 2010-11 based on the available data.

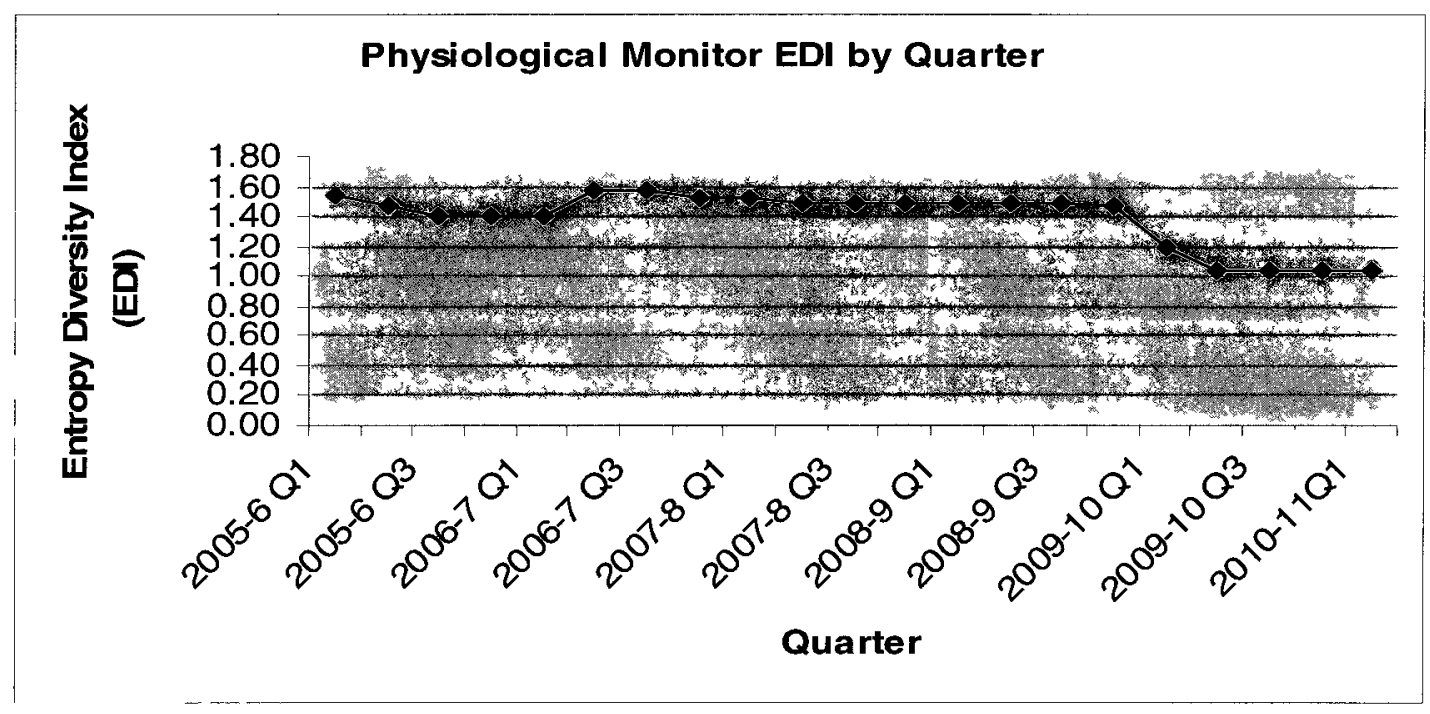

Figure 4.1 - Physiological Monitor EDI by Quarter 


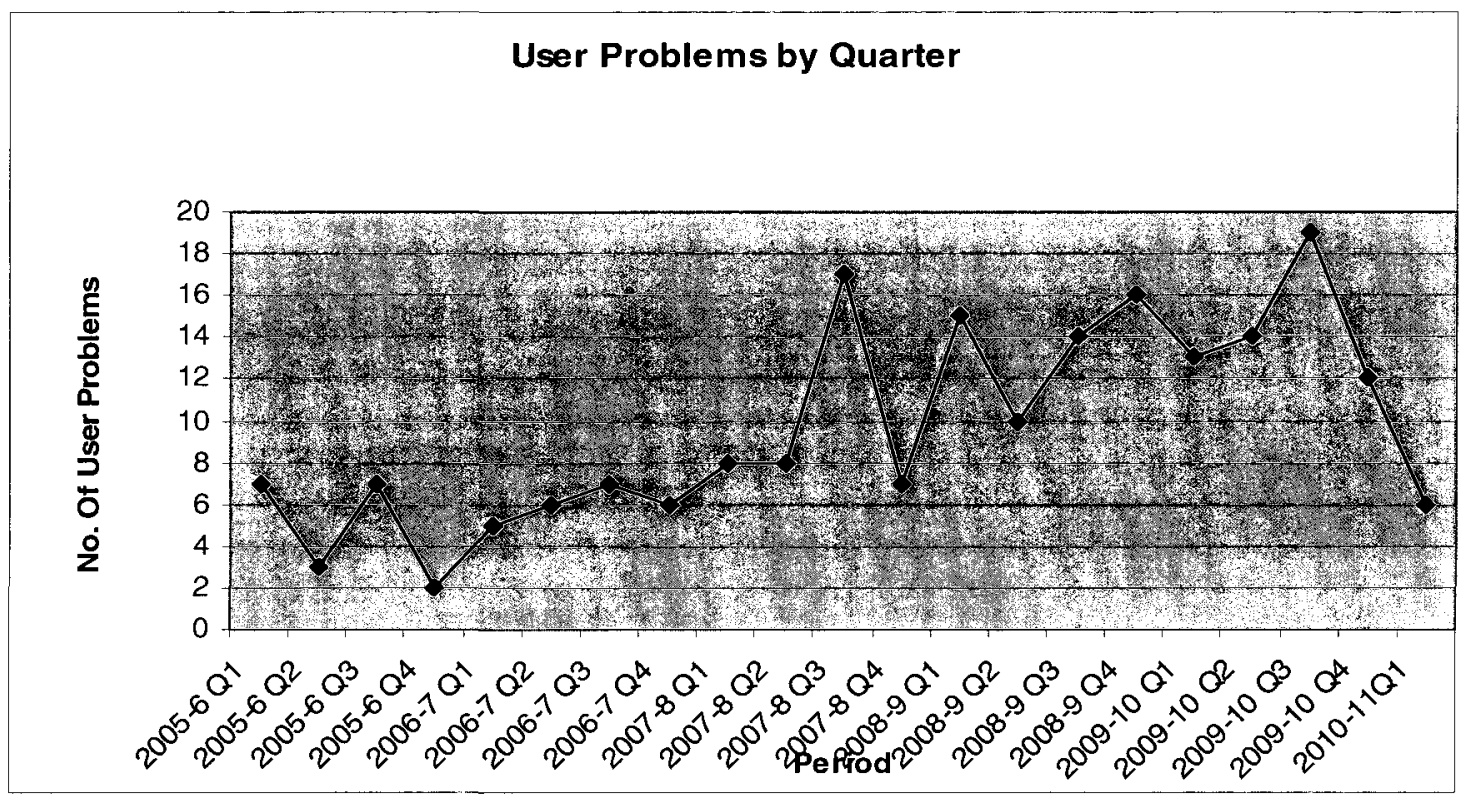

Figure 4.2- EDI Value for Physiological Monitors against Time.

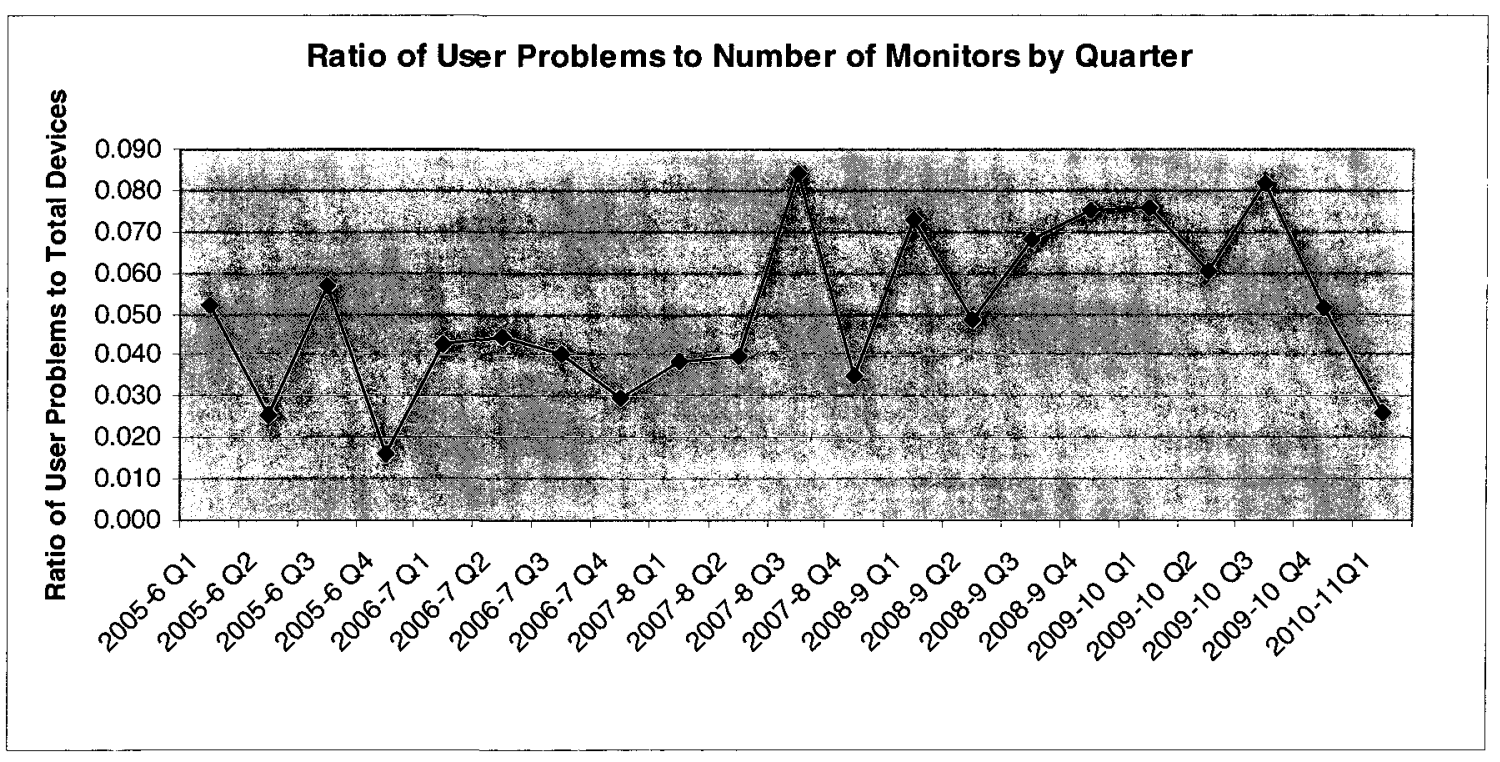

Figure 4.3 - Ratio of User Problems over Total Monitor Inventory versus Time for Physiological Monitors

The graph in Figure 4.1 portrays the EDI value starting with a value of 1.6 , which shows an inventory that with a moderate level of disorganisation when compared to its entire population. By the end of the period of study, the inventory exhibits a more 
organised distribution trend with an EDI value of 1.03. The EDI values shown in Figure 4.1 can be confirmed by the number of different makes of physiological monitors exhibited in Table A3.1 on page 101. The actual different makes of physiological monitors dropped from the peak of seven in fiscal year 2006-7 to the present four different types.

When one looks at the Adverse Event data provided at the bottom of Table A3.1, one can see that there was very little Adverse Event data to work with in this case, with only six adverse events occurring over the period of study. This translates of an average of approximately one adverse event per year for physiological monitors based on the current data. Therefore, a similar plot as in Figure 4.2 or 4.3 on pages 41 and 42 respectively, was not attempted as it would not provide useful results.

It is important to note at this juncture that, as the newer standardised Drager monitors were placed into service, an additional group of Nellcor standalone pulse oximeters were placed into service at the same time. These monitors were not planned purchases, but they were provided at no cost as part of the disposable sensor contract. If one looks at the number of annual user problems that were associated with the Nellcor and GE standalone units, as opposed to the standardised Hewlett Packard and Drager physiological monitors, one can see the impact of standalone monitors in creating clinical user problems. As shown in Table 4.4 on the next page, nearly half of the user problems documented during the fiscal years 2008-9 and 2009-10 involved the standalone Nellcor and GE Dinamap devices. 


\begin{tabular}{|c|c|c|c|}
\hline Year & $\begin{array}{c}\text { Standalone Monitor } \\
\text { User Problems } \\
\text { (Nellcor \& GE) }\end{array}$ & $\begin{array}{c}\text { Total Monitor User } \\
\text { Problems }\end{array}$ & $\begin{array}{c}\% \\
\text { Standalone/ } \\
\text { Total }\end{array}$ \\
\hline $2008-9$ & 21 & 50 & 42 \\
\hline $2009-10$ & 25 & 58 & 43 \\
\hline
\end{tabular}

Table 4.4 - Impact of Standalone Monitors on Clinical User Problems

If the multiparameter physiological monitors are only considered for study, results change dramatically. Figure 4.4 shows this changing trend. The EDI curve although similar to the ones presented before for monitoring equipment, seems to have its baseline shifted downward with the value remaining at close to 1.0 until the major replacement program started and the value dropped to an impressive value of around 0.2 . In the case of the revised plot of user problems over total devices versus time in Table 4.5 , one can notice an increase in user problem events during the time of transition from the Philips to Drager multiparameter monitoring equipment. This trend tapered off early in year 200910, as staff confidence improved. 


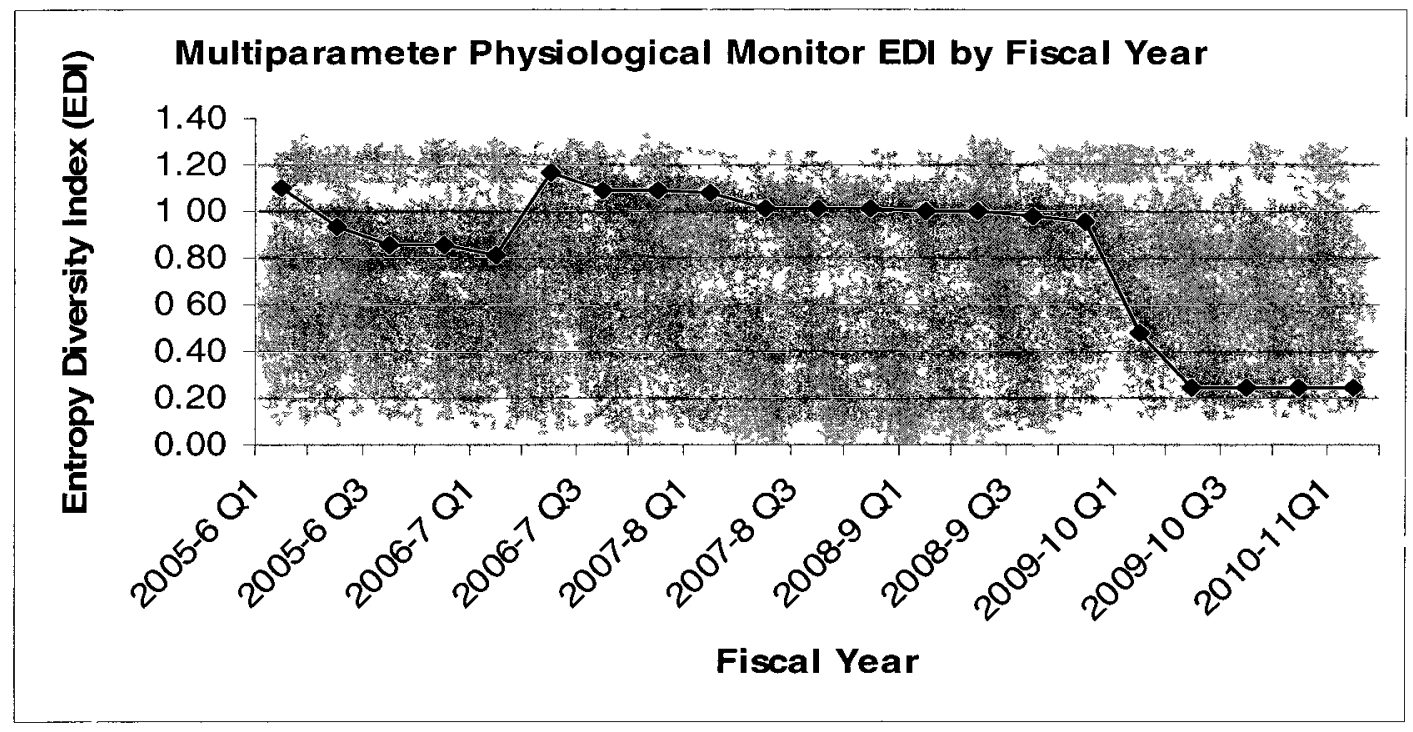

Figure 4.4 - Plot of EDI Values against time for the Multiparameter Physiological Monitor

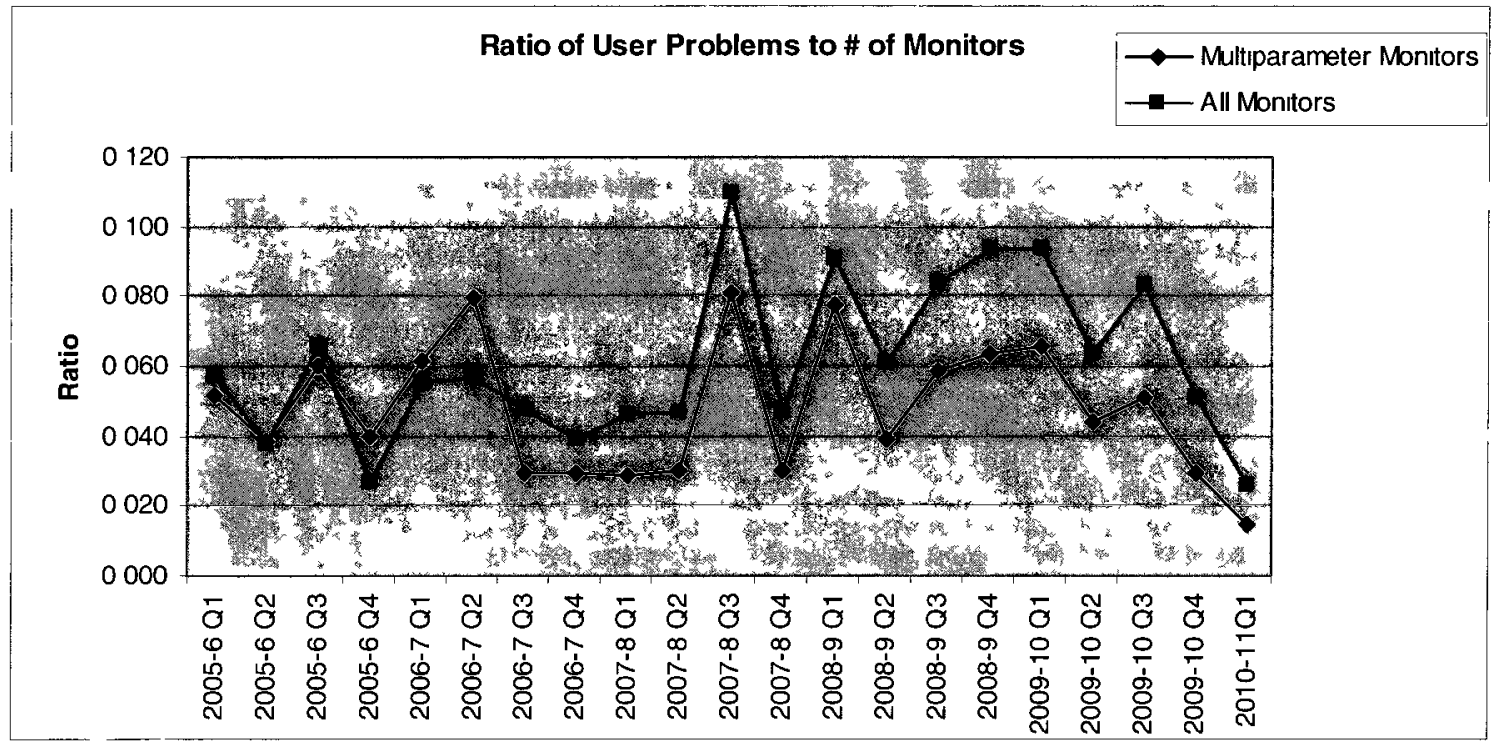

Figure 4.5 - Plot of the Ratio of Clinical User Problems against Time for Multiparameter Physiological Monitors and All Monitors

Figure 4.5 clearly shows the comparison of the multiparameter monitors separately and when included with the entire monitor population. Both plots trend each other closely but the data of the multiparameter monitor plot illustrates a consistently lower ratio of clinical user problems incidents in relationship to the inventory.

\subsection{Syringe Pump Data Collection and Analysis}


The inventory of syringe pumps increased from 97 in 2005-6 to 224 devices in 2010-11, an increase of $131 \%$ in the size of the syringe pump inventory at CHEO over the period of the six fiscal years. The hospital's inventory of syringe pumps remained constant at three different types over four years, peaking to four types in fiscal year 200910 , during the fleet replacement of syringe pumps, and was finally reduced to two different types during fiscal year 2010-11.

The EDI values for the syringe pumps as illustrated in Table 4.5 over the six fiscal years remained relatively flat between 0.49 and 0.45 except during the inventory transition year of 2009-10 when the EDI peaked at 0.81 . All of these EDI values sit in the acceptable range for an inventory of like devices of between 0 and about 2.0. The EDI value for 2009-2010, with its peak value of 0.81 , needs some further examination as it is probably not an accurate way to calculate an EDI value during an inventory changeover. Practically, the Asena and the Medfusion 3500 were not operational simultaneously as the main syringe pump at CHEO, except during the transition periods from one system to another during the fall of 2009 and winter of 2010.

\begin{tabular}{|c|c|c|c|c|c|c|}
\hline & 2005 & 20 & 20078 & 18 & Q0 & 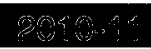 \\
\hline Antân & 84 & 84 & 84 & 96 & 87 & 37 \\
\hline Graesby 340 & 7 & 7 & 7 & 7 & 7 & 0 \\
\hline Alatis INA & 6 & 6 & 6 & 6 & 6 & 0 \\
\hline Mediesion S5oo & 0 & 0 & 0 & 0 & 187 & 187 \\
\hline Total Active & 97 & 97 & 97 & 109 & 287 & 224 \\
\hline Different Types & 3 & 3 & 3 & 3 & 4 & 2 \\
\hline & 8 & 8 & 2. & 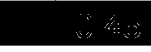 & sis & a. \\
\hline 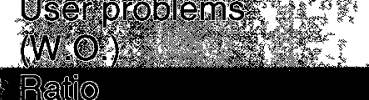 & 37 & 23 & 21 & 19 & 18 & 14 \\
\hline Prololendavention & (0.981: & (0.298. & (0.) 216 & 0.174 & (0), 0.63 & (0), 0.63 \\
\hline
\end{tabular}

Table 4.6 - Summary of Syringe Pump EDI Calculations and Problem/Inventory Ratios by Year 
The summarized work order user problems illustrate a gradual decrease in the number of documented user problems, from thirty-seven to fourteen, over the six year period This translates into a $62 \%$ drop over the six year period The ratıo of the user problems to total inventory also shows a gradual drop from 0381 to 0.063 in the study period

Undertakıng the same approach as with the physiological monitors, that 1s, and increasing the number of sample points to four from one per year, and utılising the first full quarter of data from the fiscal year 2010-11, lllustrates the point that the user problems have dropped over tıme, but in the case of the syringe pumps, there was only a marginal decrease in the EDI value. The graphs in Figures 4 6, 47 and Table A3 2 in Appendix A3 2 on page 102 display the expanded data set of twenty versus six data points over the period of study

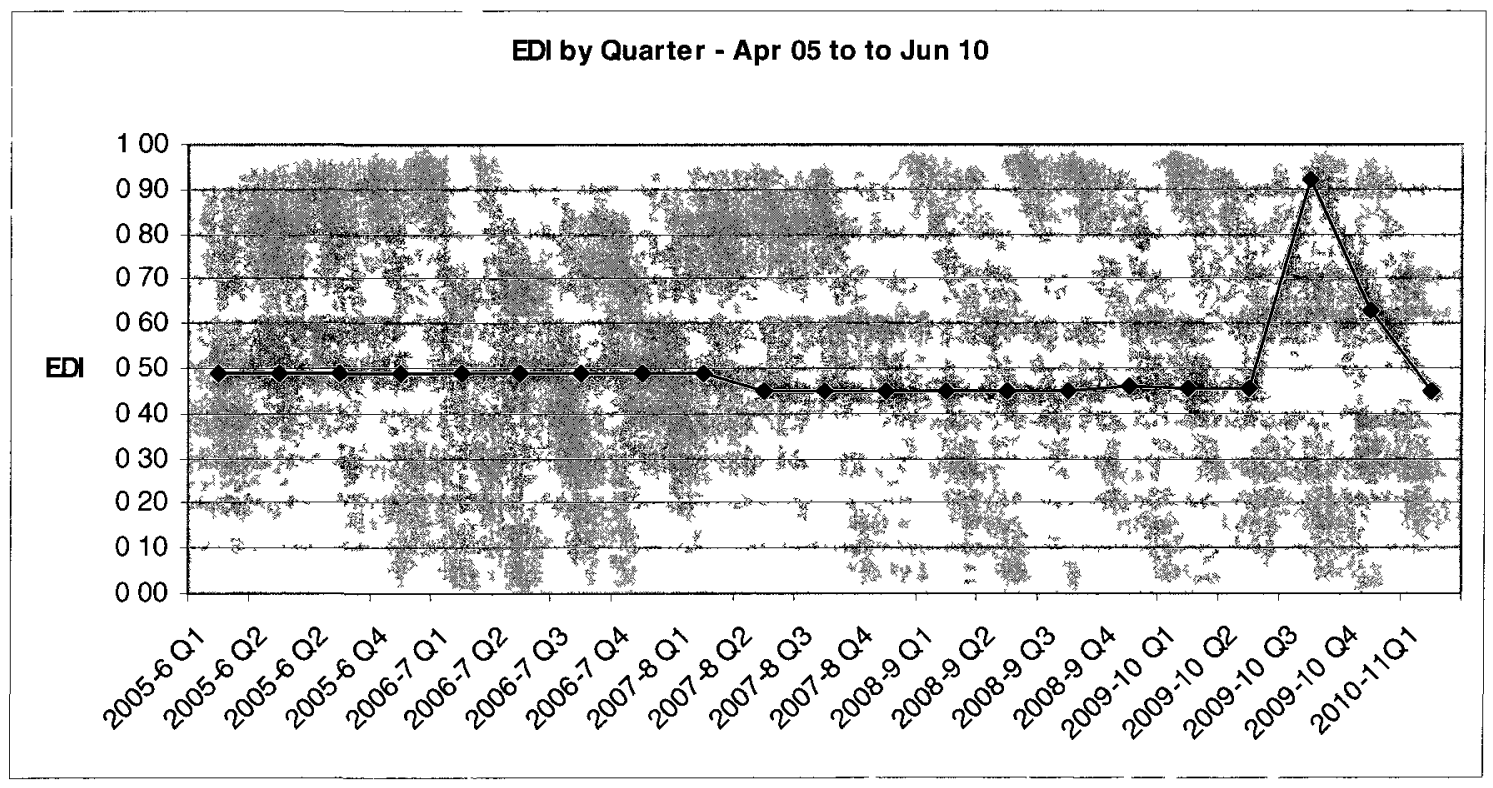

Figure 46 - Expanded Graph of EDI against Time 


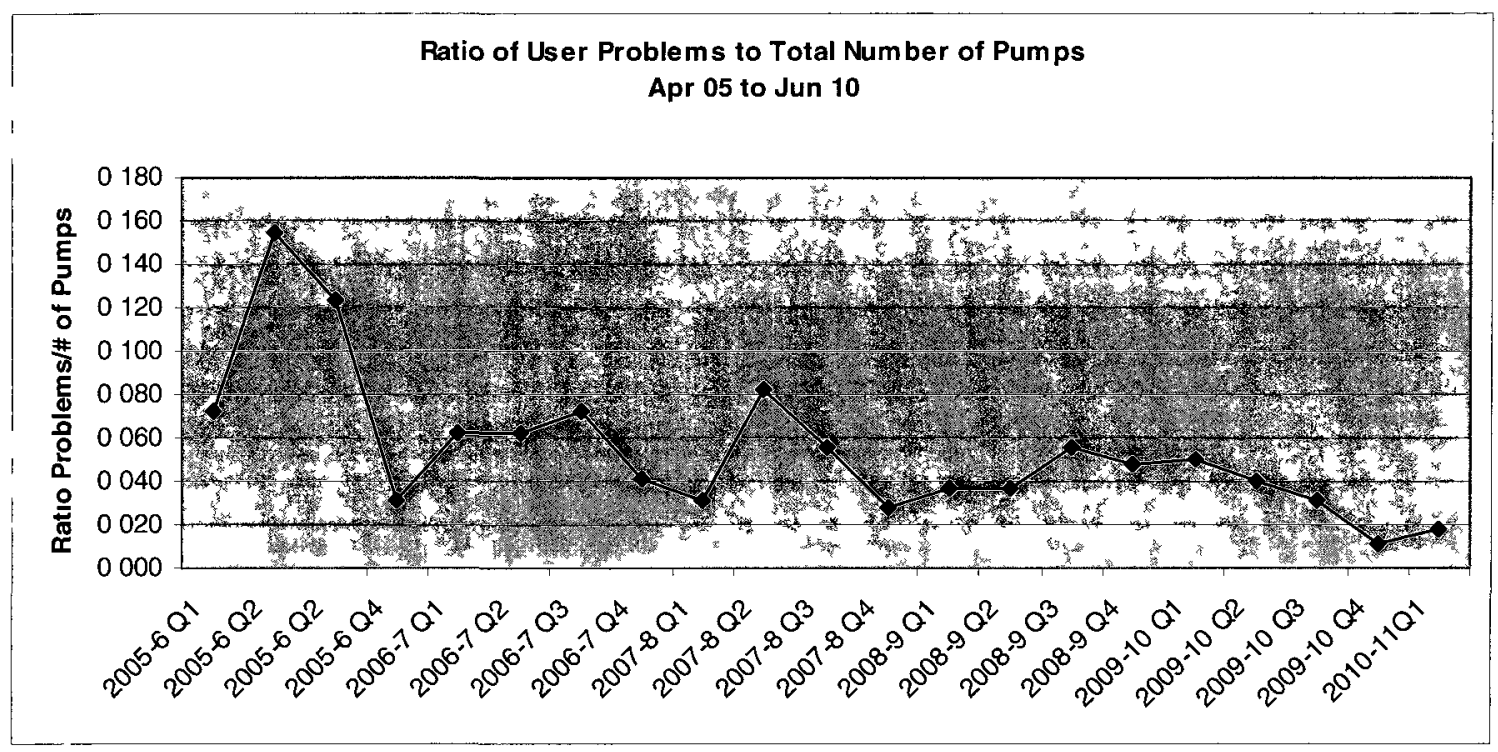

Figure 4.7 - Ratio of User Problems versus the Total Number of Syrınge Pumps

Taking a second look at the syringe pump data set, brings an important environmental factor to light that needs to be considered as $1 \mathrm{tmpacts}$ the results. During fiscal year 2009-10, when the syringe pumps were replaced with the Medfusion 3500, both inventories were not both operational simultaneously, even though the data in Table 4.6 suggests this fact. If the two outlying EDI points from 2009-10 Q3 and Q4 are recalculated taking into consideration that both type of pumps were not operational simultaneously, the revised EDI values for these points would be 0.45 , resulting in an essentially flat line response when EDI is plotted against time.

Returning to the data in Table A3.2 on page 102, the level of standardization of the syringe pumps at CHEO has increased slightly with a drop in the EDI by 8.2 percent withın this sample of syringe pumps against time. Also, the number of active syringe pumps jumped by 129 percent, to 222 devices. At the same time, the number of clinical user errors dropped.

Since there was very little Adverse Event (AE) data to work with, in this case as in the last case, a plot of the data was not carried out. A detalled review of the manual Adverse Event reports for fiscal years 2005/6, 2006/7 and 2007/8 was completed. Next, the electronic AE for fiscal years 2007/8, 2008/9, 2009/10 and 2010/11 was conducted with the total number of $\mathrm{AE}$ reports reviewed, the number of equipment related $\mathrm{AE}$ reports, and the percentage of the $\mathrm{AE}$ reports that involved equipment was documented in 
Table 4.6. Both the manual and the electronic systems were in use simultaneously in 2007, until the electronic system was fully implemented.

By the time of the implementation of the electronic system in 2007, the manual reporting system had become unworkable. During the years 2005 and 2006, there were 1,355 AE reports filed at the hospital. This deluge of paperwork pushed the AE review process nearly to a complete halt, as there were only four event reviews conducted on these 1,355 paper reports.

\begin{tabular}{|c|c|c|c|c|}
\hline & $\begin{array}{l}\text { Fiscal } \\
\text { Years }\end{array}$ & $\begin{array}{l}\text { Total } \\
\text { Reports }\end{array}$ & $\begin{array}{l}\text { Equipment } \\
\text { Related } \\
\text { Reports } \\
\end{array}$ & $\begin{array}{c}\% \text { of } \\
\text { Equip/Total } \\
\text { AEs }\end{array}$ \\
\hline 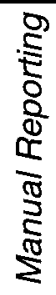 & $\begin{array}{l}2005 / 6 \\
2006 / 7 \\
2007 / 8\end{array}$ & 1946 & 187 & $9.6 \%$ \\
\hline 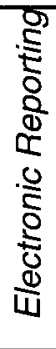 & $\begin{array}{l}2007 / 8 \\
2008 / 9 \\
2009 / 10 \\
2010 / 11\end{array}$ & 4441 & 49 & $1.1 \%$ \\
\hline
\end{tabular}

Table 4.6 - Overall CHEO AE Report Statistics

Table 4.6 has provided some interesting data trends on AE reports. First, the overall average reporting rate of adverse events increased considerably with the electronic AE reporting System. The number of equipment related $\mathrm{AE}$ reports decreased, when compared to the total number of average reports per year, from 9.6 to 1.1 percent. The potential reasons for these sudden changes in reporting rates needs further research to identify the root causes of these trends. Insight provided on this matter from the hospital Risk Management staff suggests that the changes in statistics noted in Table 4.6 
may be due to the increased reporting of $\mathrm{AE}$ incidents by clinical staff since the introduction of the electronic system. When a comparison was made of the two full paper AE reporting years of 2005/6 and 2006/7, against two full years of electronic AE reporting such as 2008/9 and 2009/10, the results show an increase in AE reporting from 1,797 to 3,152 AE reports, or 132.8 percent using the electronic reporting system. It is important to keep in mind that the data for fiscal year $2010 / 11$ provided in this report only covers the period of April $1^{\text {st }}$ to August $31^{\text {st }}$.

Table 4.7 summarizes the suspected and actual AE reports involving physiological monitors and syringe pumps over each fiscal year. The Suspected AE report numbers were tallied during the first high level data assessment while the Actual AE report numbers were the confirmed numbers collected after the detailed report reviews were conducted later in the study. Even with reporting increases as a result of the electronic reporting system, reported $\mathrm{AE}$ incidents have not increased proportionately. The most recent results show only about one percent of AE reports involves equipment, and of this amount, less than half of one percent involves infusion devices and physiological monitors.

\begin{tabular}{|c|c|c|c|c|c|}
\hline \multicolumn{3}{|c|}{ Suspected } & \multicolumn{3}{|c|}{} \\
\hline $\begin{array}{c}\text { Fiscal } \\
\text { Year }\end{array}$ & $\begin{array}{c}\text { Syringe } \\
\text { Pump }\end{array}$ & Monitor & $\begin{array}{c}\text { Fiscal } \\
\text { Year }\end{array}$ & $\begin{array}{c}\text { Syringe } \\
\text { Pump }\end{array}$ & Monitor \\
\hline $05 / 06$ & 6 & 1 & $05 / 06$ & 0 & 1 \\
\hline $06 / 07$ & 4 & 5 & $06 / 07$ & 0 & 4 \\
\hline $07 / 08$ & 6 & 1 & $07 / 08$ & 3 & 0 \\
\hline $08 / 09$ & 3 & 2 & $08 / 09$ & 4 & 1 \\
\hline $09 / 10$ & 4 & 4 & $09 / 10$ & 4 & 1 \\
\hline $10 / 11$ & 4 & 3 & $10 / 11$ & 1 & 1 \\
\hline
\end{tabular}

Table 4.7 - Suspected and Actual AE Reports for Syringe Pumps and Monitors 
It will be difficult to explain why the number of $\mathrm{AE}$ reports is actually so low when compared to the user problems identified in either Tables A3.1 or A3.2. The number of actual serious incidents per year for both syringe pumps and monitors never exceeded five events annually per device during the entire period of study, while on average clinical user problems per year for physiological monitors and syringe pumps were approximately forty and twenty-four respectively, based on the data supplied by Tables A3.1 and A3.2 from the Service Plus system. 


\subsection{Conclusions}

The first objective of this thesis was to confirm that EDI is able to benchmark equipment standardisation over different clinical equipment types. This study has shown that the Entropy Diversity Index (EDI) can be used as a measuring tool for gauging the level of equipment standardisation amongst a grouping of like medical devices. The EDI can be used to benchmark the level of standardisation against other groups of medical devices within a facility or at other facilities. Therefore, it could be used to gauge the effectiveness of a facility's equipment replacement plan, or of their fleet equipment management program, in achieving optimum standardisation.

Within the confines of this work, the EDI trends illustrated different but discernable trends with both the physiological monitor and the syringe pump EDI calculations against time. If we return to Figure 2.1, then reflect on the resulting EDI data for both devices, the EDI values against time are predictable based on the changes that occurred to the equipment inventory over the period of study. Any standardisation statistic for infusion devices should have clearly produced results illustrating that infusion devices at CHEO are an example of peak organisation since the infusion devices at CHEO have been standardised since the late 1990s. This was in fact the case, as the EDI syringe pump calculations showed a consistent trend with a range of values from 0.45 to 0.49 , except for one year where the value jumped to 0.81 in $2009-10$. These values illustrate a population of like devices that exhibit a narrow distribution and a high degree of organisation or standardisation, except during the one period where it peaked. This 
peak of 0.81 is still within the range considered as organised within the range of EDI values when referenced against the diagram in Figure 2.1 on page 23. Upon further investigation of this elevated peak, it was identified as the point of transition from one type to another type of syringe pump. It is important to note that, except during the identified transition period, when the Alaris Asena was removed from service and Smiths Medical Medfusion 3500 syringe pump was commissioned, neither of the fleets of these devices where operational simultaneously. Therefore, it is suggested that these periodic peaks be identified as transition points and discounted when one is monitoring EDI values against time.

In the case of the EDI values against time for the physiological monitors, the EDI value clearly shows a trend towards improved standardisation against time with a flat line in EDI value of about 1.5 until the end of fiscal year 2008-9, when the EDI began to drop to its current value of 1.03 . This drop illustrates an inventory that starts with a narrow to uniform distribution that moves to improved physiological monitor standardisation during year fiscal 2009-10. This trend shows the gradual replacement of the older monitoring equipment in the inpatient clinical units and the whole replacement in the Critical Care department of physiological monitoring equipment to the fleet standard of Drager Infinity Delta XL monitor during fiscal year 2009-10. As the fleet management program continues at CHEO, with the physiological monitors, the older non-standard equipment is being retired, and thus the EDI will continue to drop over time below a fractional value of less than one.

The second objective of this study was to use the identified standardisation tool to investigate if a link can be found between clinical user problems and the level of 
standardisation in commonly used clinical devices such as, in this case, physiological monitors and syringe pumps. This objective was only partially successful in this study. In the case of the syringe pumps, even with wider sampling of data within the period of study, a reliable trend could not be established with the rate of user problems against the total inventory, unless the peak point in the EDI versus time graph for the syringe pumps occurring during fiscal year 2009-10 Q3 and Q4 are reconsidered. As the data stands, the existing results show a sudden EDI peak which does not truly reflect the actual situation. After taking a second look at the syringe pump dataset, then looking into the background causes of the resulting data, an important factor comes to light that needs to be considered. During fiscal year 2009-10, when the syringe pumps were replaced with the Medfusion 3500, both inventories were not both operational simultaneously, even though the data in Table 4.6 suggests this. If the two outlying EDI points from 2009-10 Q3 and Q4 are recalculated, taking this factor into consideration, then the revised EDI values for these points would be 0.45 , resulting in an essentially flat line response when EDI is plotted against time. This recalculation can be accomplished by moving the breakpoint for 2009-10 Q3 and Q4 to the transition point of the replacement fleet to Medfusion 3500 syringe pumps. The level of standardization of the syringe pumps at CHEO has increased slightly within this sample population against time, registering about an eight percent improvement and since the size of sample has more than doubled in size and the clinical user errors has dropped over time to about one third of the original total as shown in Figure 4.6. Therefore, it can be concluded the under controlled conditions, where no major fleet changes are being undertaken, the hypothesis stating that improved equipment standardisation improves patient safety can be considered valid. The syringe pumps saw a 
drop in the ratio of clinical user problems to the total inventory drop from an average in year $2005 / 6$ of 0.096 rising to a peak value in the third quarter of year $2005 / 6$ of 0.155 and reaching a minimum value of 0.018 in year $2010 / 11$ while the EDI value only exhibited a drop of 8.1 percent for the same five year period. The variance in the results of change of ratio of clinical user problems to the total inventory and the EDI value in the case of the syringe pumps can be explained by the influence of environmental factors such as increased nursing staff training on the Medfusion 3500 syringe pump and the more intuitive user interface on this same device.

The same dilemma was faced with the physiological monitor population and their related documented user problems. There were again in this case as well as with the syringe pumps, a number of extenuating circumstances that affected the results from this portion of the study. In fact the graph in Figure 4.7 illustrates a situation where the value of the EDI decreases, or conversely the equipment standardisation increases, and the clinical user problems decrease. There were a number of factors that impacted the results of this observational study. First, the hospital inpatient units leaped from very limited standalone monitoring capabilities, to an advanced system that is interfaced to a central station, the Hospital Information System (HIS), a nurse call system and wireless communication systems over the course of a few short years. It was and it continues to be an immense learning process for all staff involved. A similar parallel impact was felt as the entire hospital moved to electronic patient charting during the calendar year 2010 , finally forcing all clinical staff to embrace computer technology, whether they wanted to or not. 
drop in the ratio of clinical user problems to the total inventory drop from an average in year $2005 / 6$ of 0.096 rising to a peak value in the third quarter of year $2005 / 6$ of 0.155 and reaching a minimum value of 0.018 in year 2010/11 while the EDI value only exhibited a drop of 8.1 percent for the same five year period. The variance in the results of change of ratio of clinical user problems to the total inventory and the EDI value in the case of the syringe pumps can be explained by the influence of environmental factors such as increased nursing staff training on the Medfusion 3500 syringe pump and the more intuitive user interface on this same device.

The same dilemma was faced with the physiological monitor population and the related their documented user problems. There were again in this case as well as with the syringe pumps, a number of extenuating circumstances that affected the results from this portion of the study. In fact the graph in Figure 4.7 illustrates a situation where the value of the EDI decreases, or conversely the equipment standardisation increases, and the clinical user problems decrease. There were a number of factors that impacted the results of this observational study. First, the hospital inpatient units leaped from very limited standalone monitoring capabilities, to an advanced system that is interfaced to a central station, the Hospital Information System (HIS), a nurse call system and wireless communication systems over the course of a few short years. It was and it continues to be an immense learning process for all staff involved. A similar parallel impact was felt as the entire hospital moved to electronic patient charting during the calendar year 2010 , finally forcing all clinical staff to embrace computer technology, whether they wanted to or not. 
As the remaining older monitors are decommissioned and standardisation efforts are continued, further positive results may be demonstrated if the study was repeated.

As the newer standardised physiological monitors were placed into service, an additional group of Nellcor standalone pulse oximeters were placed into service at the same time. Seventy-five of these devices were given to CHEO at no cost as part of the single use sensor contract. These standalone oxygen saturation monitors, although reliable, are not as user-friendly as the Drager or Philips physiological monitors. The Nellcor monitors provide the user with an alpha numeric code, for a number of the user or device problems, such as a low battery. As a result the Nellcor monitors are removed from service on many occasions, and sent for servicing, for what ends up being a trivial problem that should have be corrected by clinical staff on the unit. If one looks at the number of annual user problems that were associated with the Nellcor and GE standalone units as illustrated in Table 4.13, it is clear why the clinical user problem data trend did not decrease as the EDI value for physiological monitors decreased. On average, the standalone oxygen saturation and non invasive blood pressure monitors contributed to 42.5 percent of the clinical user problems during the fiscal years 2008-9 and 2009-10. This error factor skewed the results for the EDI values versus the results of the ratio of clinical user problems to total number of devices illustrated in Figure 4.5. If the boundaries of this study were modified to include only the multiparameter monitoring equipment, and have the standalone single parameter physiological monitors either minimised, or totally removed from the study, the results would provide the desired trends and thus support research goals of this study, supporting the hypothesis that 
equipment standardisation supports patient safety when the study sample size is narrowed to include only multiparameter physiological monitors.

In the case of the physiological monitors, the overall ratio of clinical user problems to the total inventory over the five year period of study started at 0.0375 in year $2005 / 6$ went to a peak of 0.075 in the third quarter of year 2007/8 and then dropped to a low in year $2010 / 11$ of 0.0259 . When comparing the ratio values of clinical user problems to total inventory from the start and the end of the study showed a decline of 33.1 percent while the EDI for the same period showed a nearly proportional drop of 29.4 percent which supports the second objective of this study.

This study has made it clear that when considering the relationship of EDI to clinical user errors, the study sample should be carefully evaluated before data collection commences and the results must be watched closely to identify potential environmental factors, such as large scale device replacements during the course of the study, that may impact the results in a negative way. This study has also shown why a health care facility should have a comprehensive long range clinical capital plan that receives full endorsement of the facility's executive team and clinical staff. To be effective, such a long range plan must encourage fleet management concepts that encourage standardisation of common key clinical equipment.

The final objective of this thesis was to use an identified standardisation tool to investigate if a link can be found between adverse event reports and the level of standardisation in commonly used clinical devices such as physiological monitors and syringe pumps. This study was unable to find a link between equipment standardisation and the adverse event reports generated by the hospital specifically involving 
physiological monitors and syringe pumps due to the lack of reported events involving these types of equipment from the AE reporting system. Since there has been a conscious effort to standardise key fleets of commonly used clinical equipment at CHEO for a number of years, and the number of adverse events are very low, it is unlikely that further improvements in this area will be achieved in the future. But efforts to standardise clinical equipment should be continued to try to maintain a low number of equipmentrelated adverse events.

\subsection{Contribution to Knowledge}

This study has contributed to knowledge on the following points:

(a) The Entropy Diversity Index (EDI) was successfully applied as a method of benchmarking the level of equipment standardisation for other types of equipment than just infusion devices. This research confirms the earlier work conducted by Brindle and Gibson [56] that shows EDI to be a useful tool in summarizing the frequency distribution of devices. This work has gone one step further than Brindle and Gibson [57] to test this Index on more than one type of device and thereby further prove its value in measuring equipment standardisation. In using this Index, one must keep in mind that different frequency distributions may in fact have the same index value. Therefore, it is recommended that caution be used when drawing conclusions on the state of an inventory from a single parameter. This Index remains an accurate method of predicting when changes in population diversity occur as long as measurements are consistently made over a period of time. 
(b) The research established the point that: If you wish to conduct an observational study that attempts to relate issues such as equipment standardisation and patient safety, prior analysis of potential environmental factors, such as large scale replacement of equipment, should be considered before framing the scope of the research study.

(c) The study illustrates why it is important to develop and enforce a long range clinical equipment replacement plan that discourages sudden changes, as these changes could create more problems than they actually solve, such as in the case of the no cost pulse oximeters.

(d) This is the first time that the EDI is related to adverse events and to user-errors. The findings of this study, and of others that can follow on other types of equipment in the clinical environment, will lead to long term safety improvements.

\subsection{Future Research}

(a) It would be possible to use EDI to create a benchmark that measures the standardisation of a hospital's twelve to fifteen major fleet devices such as defibrillators, ventilators and stretchers for example that comprise the majority of the clinical equipment within in most hospitals. One might be able to use the EDI calculations for these devices to create a benchmark that will allow for the comparison of standardisation efforts of multiple hospitals within a region.

(b) The EDI for a specific device population could be factored with the median age of this specific population and the published anticipated life expectancy to create a potential comparative indicator. This benchmark could then be calculated for the 
major group of fleet devices mentioned above and the top fifteen to twenty nonfleet devices to derive an indicator that would allow for comparison of any hospital against another or a defined group of facilities to gauge both the useful life expectancy and level of standardisation of a hospital's clinical equipment inventory.

(c) Investigate nursing staff turnaround and its relationship to adverse events on specific common clinical devices.

(d) Study the human interface on common medical devices such as infusion devices and physiological monitors and link the difficulty of use of this interface to clinical user errors.

(e) Investigate the relationship between in-service training of clinical staff and its relationship to adverse events on specific common clinical devices.

(f) Consider incorporating a level of severity for AEs and user errors and their relationship to equipment standardisation. No attempt was made to assess the severity of AEs or the clinical user errors nor was a concerted effort undertaken to document the types of user errors during the present research study. Table 5.1 demonstrates some of the common clinical user errors occurring during this study on both studied devices. This information could be considered as a starting point for further research. 


\begin{tabular}{|l|l|}
\hline \multicolumn{1}{|c|}{ Physiological Monitor } & \multicolumn{1}{c|}{ Syringe Pump } \\
Meart Rate not accurate & Interstitial IV but no pump alarms \\
patient is fine & Low battery alarm when pump is plugged in. \\
Not working & Inaccurate drug delivery when compared to set \\
Sudden desaturation not detected & Constant occlusion pressure alarm when IV line \\
Saturation reading inaccurate & appears to be fine \\
Monitor shut down when in use & Pump shut down when in use \\
Monitor alarming leads off when & \\
leads attached &
\end{tabular}

Table 5.1 - Documented Clinical User Errors 


\section{References}

[1] C. Vincent, Patient Safety, $2^{\text {nd }}$ ed. (Chichester, UK: John Wiley and Sons, Chichester, UK, 2010), 49-74.

[2] L. T. Kohn et al, To Err are Human: Building a Safer Health System, (National Academies Press, Washington, D.C. 20418, 2000), 312.

[3] G. Ross Baker, "The Canadian Adverse Events Study”, Canadian Medical Association Journal, Volume 170, No.11, (2004), 1679-1686.

[4] FDA Press Release April 23, 2010.

[5] L. Beydon et al, "Analysis of the French health ministry's national register of incidents involving medical devices in anaesthesia and intensive care", British Journal of Anaesthesia, Volume 86, (2001), 382-7.

[6] Baker, “The Canadian Adverse Events Study”, 1679-1686.

[7] T.A. Brennan et al., "Incidence of adverse events and negligence in hospitalized patients", New England Journal of Medicine, Volume 324, Number 6, (1991), 370375.

[8] Vincent, Patient Safety, 53.

[9] E.N. de Vries, M.A. Ramrattan, S.M. Smorenburg, "The incidence and nature of inhospital adverse events: a systematic review", Quality and Safety in Health Care, Volume 11, No. 3, (2008), 216-223.

[10] Baker, “The Canadian Adverse Events Study”, 1679-1686.

[11] Canadian Institute for Health Information (CIHI), Healthcare in Canada, 2009: A Decade in Review, CIHI, 2009, (2009), 11.

[12] Baker, "The Canadian Adverse Events Study", 1679-1686.

[13] R.M. Wilson, B.T. Harrison, R.W. Gibberd, J.D. Hamilton. "An analysis of the cases of adverse events from the Quality in Australian Health Care Study", Medical Journal of Australia MJA 170(9): (1999), 411-415.

[14] M. Frize, S. Weyand, K. Greenwood, “Clinical Engineering and Patient Safety: a forty year cycle”, MEDICON 2010 - IFBME Proceedings, Volume 29, (2010), 9991002.

[15] T. Walsh, P.C.W Beatty, "Human factors errors and patient monitoring", Physiological Measurement, Volume 23, (2002), R111 - R132. 
[16] J. Dankelman, C.A. Grimbergen, "Systems approach to reduce errors in surgery", Surgical Endoscopy, Volume 19, (2005), 1017-1021.

[17] B. Bjorn, K. Garde, B.L. Pedersen, "Infusion pumps and patient safety", Ugeskr Laeger, Volume 169, No. 4, (January 2007), 315-8.

[18] J. Reason, Understanding Adverse Events: Human Factors, Quality in Health Care, BMJ Group, London, UK, Volume 4, (1995), 80-89.

[19] J. Rasmussen et al., "Human Error Mechanisms in Complex Work Environments", Reliability Engineering and System Safety, Volume 22, Number 1-4, (1988), 155-167.

[20] G.W. Brindle, C.W. Gibson, "Entropy as a measure of diversity in an inventory of medical devices", Medical Engineering and Physics, Volume 30, (2008), 399-401.

[21] T.A. Brennan et al., "Incidence of adverse events and negligence in hospitalized patients", pp.370-375.

[22] Canadian Medical and Biological Engineering Society (CMBES), Clinical Engineering Standards of Practice for Canada, (September 2007), 15.

[23] JCAHO, Environment of Care - Essentials for HealthCare, (JC Press, 2010), 175.

[24] Brindle, Gibson, "Entropy as a measure of diversity in an inventory of medical devices", 399-401.

[25] E. M. Schimmel, “The hazards of hospitalization”, Annuals of Internal Medicine, American College of Physicians, Volume 60, (1964), 100-110.

[26] T.A. Brennan et al., "Incidence of adverse events and negligence in hospitalized patients", 370-375.

[27] L. L. Leape, "Error in medicine", Journal of the American Medical Association, Volume 272, (1994), 1851-1857.

[28] L.T. Kohn, J. Corrigan, M.S. Donaldson, Editors, To Err is Human: Building a Safer Health System. (National Academies Press, Washington, D.C. 20418, ISBN 0309-06837-1, 2000), 312.

[29] Department of Health, Supporting Doctors, Protecting Patients, National Health Service, London. U.K., (1999), 85.

[30] C. J. Cannon et al, "Saving 100,000 lives in US Hospitals", British Journal of Medicine, Volume 332, (2006), 1328-1330. 
[31] L. Leape, "Scope and Problem of Patient Safety", Obstetrics and Gynecology Clinics of North America, Volume 35, (2008), 2.

[32] Brindle, Gibson, "Entropy as a measure of diversity in an inventory of medical devices", 399-401.

[33] J. Reason, "Human Error: models and management", British Journal of Medicine, Volume 320, (June 2000), 768-770.

[34] Brindle, Gibson, "Entropy as a measure of diversity in an inventory of medical devices", 399-401.

[35] D. Norman, The design of everyday things, Basic Books, London, UK, (1988), 272.

[36] J. Hankins ed., Infusion Therapy in Clinical Practice, W.B. Saunders Co., Philadelphia, Pa, (2001), 414.

[37] J. Hankins, ed., Infusion Therapy in Clinical Practice, 414.

[38] Ibid.

[39] B. Bjorn, K. Garde, B.L. Pedersen, "Infusion pumps and patient safety", Ugeskr Laeger, Vol. 169, no. 4, (January 2007): 315-8.

[40] B. Bjorn, K. Garde, B.L. Pedersen, "Infusion pumps and patient safety", 315-8.

[41] L.A. Geddes, "Perspectives in Physiological Monitoring", Medical Instrumentation, Vol. 10, No.2, (April 1976), 91-97.

[42] L.A. Geddes, L.A., "Perspectives in Physiological Monitoring", 91-97.

[43] J.J. Carr, J. M. Brown, Introduction to Biomedical Equipment Technology, (Wiley, New York, 1981), 238-255.

[44] ECRI Institute, "Evaluation - Physiological Monitors", Health Devices, Vol. 28, No.1, (January February 1999), 6-28.

[45] ECRI Institute, "Evaluation - Physiological Monitors", 6-28.

[46] ECRI Institute, "Evaluation - Physiological Monitors", Health Devices, Vol. 34, No.1, (January 2005), 4-11.

[47] E.H. Simpson, "Measurement of Diversity", Nature, Volume 63, (April 30, 1949), 688.

[48] Brindle, Gibson, "Entropy as a measure of diversity in an inventory of medical devices", 399-401. 
[49] Ibid.

[50] E. H. Simpson, "Measurement of Diversity", Volume 63, 688.

[51] C. Shannon, and W. Weaver, The Mathematical Theory of Communication, $5^{\text {th }}$ ed. (Champaign, IL: University of Illinois Press, 1964).

[52] W. H. Berger, F. L. "Parker, Diversity of Plantonic Variability and Motability in Deep-Sea Sediments”, Science, 168, (1970), 1345-1347.

[53] C. W. Gini, "Variability and Mutability, contribution to the study of statistical distributions and relations," Studi Economico-Giuricici della R. Universita de Cagliari (1912).

[54] A. Rényi, "On Measures of Entropy and Information." Proc. Fourth Berkeley Symp. Math. Stat. and Probability, Vol. 1. Berkeley, CA: University of California Press, (1961), 547-561.

[55] Brindle, Gibson, "Entropy as a measure of diversity in an inventory of medical devices", 399-401.

[56] Ibid.

[57] Ibid. 


\section{Bibliography}

1. Allen, J.D., "Components of diversity", Occologia, Vol. 18, (1975): 359-367.

2. Aspden Phillip, Janet M. Corrigan, Julie Wolcott, Shari M. Erickson, eds., Patient Safety: Achieving a New Standard of Care, National Academies Press, Washington D.C., 2004

3. Baker G.R. et al, "The Canadian Adverse Events Study; the incidence of adverse events among hospital patients in Canada", Canadian Medical Association Journal, Vol.170, no.11, (2004): 1679-1686.

4. Baker, G.R., P. Norton, Making Patients Safer! Reducing Error in Canadian Healthcare (Healthcare Papers), (Longwoods Publishing, Toronto, Ontario, Vol. 2, no. 1, 2001): 10-31.

5. Berger, Wolfgang H., Frances L. Parker, Diversity of Plantonic Variability and Motability in Deep-Sea Sediments, Science, 168, (1970): 1345-1347.

6. Berwick, D.M., L.L. Leape, "Reducing errors in medicine, It's time to take them more seriously", British Medical Journal, Vol. 319, (July 17, 1999): 316-317.

7. Beydon L., et al, "Analysis of the French health ministry's national register of incidents involving medical devices in anaesthesia and intensive care", British Journal of Anaesthesia, Vol. 86 (2001), 382-7.

8. Bjorn, B., K. Garde, B.L. Pedersen, "Infusion pumps and patient safety”, Ugeskr Laeger, Vol. 169, no. 4, (January 2007): 315-8.

9. Blike, G.T., "The challenges of human engineering research", Journal of Clinical Monitoring and Computing, Vol. 15, (1999): 413-415.

10. Bogner, Marilyn S., "Designing Medical Devices to Reduce the Likelihood of Error”, Biomedical Instrumentation Technology, Vol. 33, (1999): 108-113.

11. Botney, Richard, David M. Gaba, Human Factors in Monitoring, Monitoring in Anesthesia and Critical Care, $3^{\text {rd }}$ ed., (New York, NY: Livingstone, 1996): 23-54. 
12. Brennan T.A., et al., "Incidence of adverse events and negligence in hospitalized patients", New England Journal of Medicine, Vol. 324, no. 6, (1991): 370-375.

13. Brindle, G.W and C.J. Gibson, "Entropy as a measure of diversity in an inventory of medical devices", Medical Engineering and Physics, Vol. 30 (2008): 399-401.

14. Bruhn, J., L.E. Lehmann, H. Ropcke, T.W. Bouillon, A. Hoeft, "Shannon Entropy Applied to the Measurement of Electroencephalographic Effects of Desflurane, Anesthesiology", Vol. 95, no. 1, (July 2001): pp. 30-35.

15. Canadian Institute for Health Information (CIHI), Healthcare in Canada, 2009: A Decade in Review, (CIHI, Ottawa, ON, 2009): 118 pages.

16. Canadian Medical and Biological Engineering Society (CMBES), Clinical Engineering Standards of Practice for Canada, (CMBES, Toronto, ON, September 2007): 1-15.

17. Cannon C.J., et al, Saving 100,000 lives in US Hospitals, British Journal of Medicine, Vol. 332, (2006): 1328-1330.

18. Carayon, Pascale ed., Handbook of Human Factors and Ergonomics in Healthcare, Human Factors in Hospital Safety Design, (Routledge, New York, NY, 2007): 275-286.

19. Carr Joseph J., John M. Brown, Introduction to Biomedical Equipment Technology, (Wiley and Sons, New York, NY, 1981), 238-255.

20. Corrado W. Gini, "Variability and Mutability, contribution to the study of statistical distributions and relations," Studi Economico-Giuricici della $R$. Universita de Cagliari (1912).

21. Crist, T.O., J.A. Veech, J.C. Gering, K.S. Summerville, "Partitioning species diversity across landscapes and regions: a hierarchical analysis of $\alpha, \beta$ and $\gamma$ diversity, American Naturalist”, Vol. 162, (2003): 734-743.

22. Dankelman, J., C.A. Grimbergen, "Systems approach to reduce errors in surgery", Surgical Endoscopy, Vol. 19, (2005): 1017-1021.

23. David, F.N., "Measurement of Diversity", Proceedings of the $6^{\text {th }}$ Symposium on Mathematics, Statistics and Probability, Vol. 4, (1976), 109-136. 
24. De Vries, E.N., M.A. Ramrattan, S.M. Smorenburg, "The incidence and nature of in-hospital adverse events: a systematic review", Quality and Safety in Health Care, Vol. 11, no. 3, (2008): 216-223.

25. Dekker, Sidney, Ten Questions about Human Error. A New View of Human Factors and System Safety (Human Factors in Transportation), Erlbaum Associates Inc., Mahwah, New Jersey, (2005).

26. Department of Health, Supporting Doctors, Protecting Patients, National Health Service, London. U.K., (1999).

27. Drews, Frank A., Patient Monitors in Critical Care: Lessons for Improvement, (Agency for Health Care Research and Quality, Washington, DC, 2008). www.ahrq.gov/downloads/pub/advances $2 / . . . /$ advances-drews $16 . p d f$

28. ECRI Institute, "Evaluation - Physiological Monitors", Health Devices, ECRI Institute, Plymouth Meeting, PA, Vol. 28, No.1, (January February 1999), 6-28.

29. ECRI Institute, "Evaluation - Physiological Monitors", Health Devices, ECRI Institute, Plymouth Meeting, PA, Vol. 34, No.1, (January 2005), 4-11.

30. ECRI Institute, Product Comparison: Infusion Pumps General Purpose, ECRI Institute, Plymouth Meeting, PA, (December 2008).

31. Emslie, Stuart, Kristine Knox, Martin Pickstone, Improving Patient Safety (Insights from American, British and Australian Healthcare), ECRI, Plymouth Meeting, Pennsylvania, 2002): 71-139.

32. Encinosa, W.E., F.E. Hellinger, "What Happens After a Patient Event? Medical Expenditures and Outcomes in Medicare", Advances in Patient Safety, Vol. 1, (2004): 423-436.

33. Fisher, R.A., A.S. Corbet, C.B. Williams, "The Relation between the Number of Species and the Number of Individuals in a Random Sample of an Animal Population", The Journal of Animal Ecology, Vol. 12, no.1, (May 1943):42-53.

34. Frank, Jason R. and Susan Brien, eds., The Safety Competencies - Enhancing Patient Safety Across the Health Professions, $1^{\text {st }}$ ed., The Canadian Patient Safety Institute, Ottawa, Ontario, (2008).

35. Frize, M., "The clinical engineer: a full member of the health care team?" Medical and Biological Engineering and Computing, Vol. 26, (1988): 461-465. 
36. Frize, M., S. Weyand, K. Greenwood, "Clinical Engineering and Patient Safety: a forty year cycle”, MEDICON 2010 - IFBME Proceedings, Vol. 29, (2010): 9991002.

37. Geddes, Leslie A., Perspectives in Physiological Monitoring, Medical Instrumentation, Vol. 10, No.2, (March - April 1976), 91-97.

38. Glenister, H.M, Developing Solutions to Promote Safer Practice, Patient Safety and Quality Healthcare, Lionheart Publishing Inc., Marietta, GA, (September / October 2005).

39. Gray, Robert .M., Entropy and Information Theory, Springer-Verlag, New York, NY, 2009.

40. Greenwood, M., G.U. Yule, “An Inquiry into the Nature of Frequency

Distributions Representative of Multiple Happenings with Particular Reference to the Occurrence of Multiple Attacks of Disease or of Repeated Accidents", Journal of the Royal Statistical Society, Vol. 83, no.2, (March 1920): 255-279.

41. Hamilton, C., "Critical assessment of new devices", Perfusion, Vol. 22, no. 3, (May 2007): 167-71.

42. Hankins, Judy ed., Infusion Therapy in Clinical Practice, W.B. Saunders Co., Philadelphia, PA, 2001.

43. Health Canada, Health Products and Food Branch, Health Risks Associated With Use of INFUSION PUMPS, (Health Canada, Ottawa, Ontario, April 16, 2004): 14.

44. Helmreich, R., On error management: lessons learned from aviation, British Medical Journal, Vol. 320, (2000): 781-785.

45. Hill, M.O., "Diversity and Evenness: A Unifying Notation and Its Consequences", Ecology, Volume 54, No.2, (March 1973), 427-432.

46. Hoffman, C., P. Beard, J. Greenall, D. U, J. White, Canadian Root Cause Analysis Framework, (Canadian Patient Safety Institute, Edmonton, AL, ISBN: 09739270-11, March 2006): 58.

47. Hollnagel, E., "Cognitive ergonomics: it's all in the mind”, Ergonomics, Vol. 43, (1997): 1170-1182. 
48. Hostutler, Jennifer J., “A Better Way to Select Medical Equipment”, Nursing Management, Vol. 27, no.9, (September 1996): 32M-32 P.

49. Husch, M., C. Sullivan, D. Rooney, C. Barnard, M. Fotis, J. Clarke, G. Noskin, "Insights from the sharp end of intravenous medication errors: implications for infusion pump technology”, Quality Safety Healthcare, Vol. 14, (2005): 80-86.

50. Hyman, W.A., V. Wangler, Human Factors: Environment, (Clinical Engineering Handbook, Elsevier Academic Press, Burlington, Massachusetts, (2004): 353-355.

51. Iedema, Rick, "New approaches to researching patient safety", Social Science and Medicine, Vol. 69, no. 12, (Dec 2009):1701-1704.

52. Ilan R., et al., "Prolonged time to alarm in infusion devices operated at low flow rates", Critical Care Medicine, Vol.36, no. 10, (2008): 2763-2765.

53. Jost, L., T. Banos, "Entropy and diversity", OIKOS Journal of Ecology, Volume 113, No. 2, (2006): 363-375.

54. Keohane, C.A., J. Hayes, C. Saniuk, J.M. Rothschild, D.W. Bates, “Intravenous Medication Safety and Smart Infusion Systems", Journal of Patient Safety, Vol. 28, no. 5, (September / October 2005): 321-328.

55. Keylock, C.J., "Simpson diversity and the Shannon/Wiener index as special cases of generalized entropy", Oikos, Vol. 109, (2005): 203-207.

56. Kohn, Linda T., Janet M. Corrigan, Molla S. Donaldson, eds., To Err is Human: Building a Safer Health System, National Academies Press, Washington, D.C. 20418, 2000.

57. Lannon, C.M., B.J. Coven, F.L. France, "Principles of Patient Safety in Pediatrics", Pediatrics, Vol. 107, no. 6, (June 2001):1473-1475.

58. Leape L.L., et al, "The Nature of Adverse Events in Hospital Patients", New England Journal of Medicine, Vol. 324, (1991): 377-384.

59. Leape, L.L., "Error in medicine", Journal of the American Medical Association, Vol. 272, (1994): 1851-1857.

60. Leape, L.L., Berwick, D.M., Bates, D.W., "What Practices Will Most Improve Patient Safety? Evidence-Based Medicine Meets Patient Safety", Journal of the American Medical Association, Vol. 288, no.4, (2002): 501-507. 
61. Leape, L.L., "Scope and Problem of Patient Safety", Obstetrics and Gynecology Clinics of North America, Vol. 35, (2008): 1-10.

62. Lyons, M., S. Adams, M. Woloshynowych, C. Vincent, Human reliability analysis in healthcare: a review of techniques, International Journal of Risk and Safety in Medicine, Vol. 16, no. 4, (2004): 223-237.

63. Martin, H.F. "Improving Patient Safety with Technology”, International Journal of Medical Informatics, Vol. 73, (2004): 543-546.

64. Mendelsohn, D., M. Bernstein, "Patient Safety in Surgery", Israeli Journal of Emergency Medicine, Vol.9, no. 2, July 2009:15-21.

65. Meyers, C., "Analysis and Prevention of Medical Errors", North East Florida Medicine, Vol. 60, no.3, (2009): 29-31.

66. National Institutes of Health National Center for Research Resources, Electronic Health Record Overview, (Mitre Corporation, Bedford, MA, 2006): 30 pgs.

67. National Patient Safety Agency, Improving Infusion Device Safety, (NPSA Safer Practice Notice, London UK, May 2004): 4 pgs.

68. Norman, Donald, The design of everyday things, Basic Books, London, UK, 1988.

69. NQF Safe Practices Consensus Committee, Safe Practices for Better Healthcare, National Quality Forum, Washington, D.C., 2009.

70. Nuckols T.K., et al., "Programmable Infusion Pumps in ICUs: An Analysis of Corresponding Adverse Drug Events", Journal of General Internal Medicine, Vol. 23, sup. 1, (2007): 41-45.

71. Patail, Bryanne M., Patient Safety and the Clinical Engineer, Clinical Engineering Handbook, Dyro, Joseph F., ed., (Elsevier Academic Press, Burlington, Massachusetts, 2004): 227-234.

72. Rasmussen J., et al., "Human Error Mechanisms in Complex Work Environments", Reliability Engineering and System Safety, Vol. 22, Number 1-4, (1988): 155-167.

73. Rasmussen, J., The role of error in organising behaviour, Ergonomics, Vol. 33, (1990):1185-1199.

74. Reason, James, Managing the Risks of Organizational Accidents, Ashgate Publishing Co., Burlington, Vermont, 1997. 
75. Reason, J., "Human Error: models and management", British Journal of Medicine, Vol. 320, (June 2000): 768-770.

76. Reason, James, Human Error, University of Cambridge Press, Cambridge, U.K, 2000.

77. Reiling, J.G., Creating a Culture of Patient Safety through Innovative Hospital Design, Advances in Patient Safety: From Research to Implementation, Vol. 2, (Agency for Health Research and Quality (AHRQ), Rockville, MD, February 2005): 425-439.

78. Reiling, J., Safe design of healthcare facilities, Quality and Safety in Health Care, Vol. 15, supp. 1, (2006): 134-140.

79. Relf, J.D., Theoretical Models for Research and Program Development in Agriculture and Health Care - Avoiding Acts of Random Research, Farming for Health, Springer Ltd., Rotterdam, Netherlands, 2006.

80. Rényi, A., "On Measures of Entropy and Information." Proc. Fourth Berkeley Symposium. Math. Stat. and Probability, Vol. 1. Berkeley, CA: University of California Press, (1961): 547-561.

81. Routledge, R.D., “Diversity indices: which ones are admissible?” Journal of Theoretical Biology, Vol. 76, (1979): 503-515.

82. Sandroni, C., J. Nolan, F. Cavallaro, M. Antonelli, In-hospital cardiac arrest: incidences, prognosis and possible measures to improve survival. Intensive Care Medicine, Vol. 33, no. 2, (2007): 237-245.

83. Sawyer, Dick et al, Do It by Design: An Introduction to Human Factors in Medical Devices, U.S. Department of Health and Human Services, Public Health Service, Food and Drug Administration, Center for Devices and Radiological Health, December 2009. http://www.fda.gov/MedicalDevices/DeviceRegulationandGuidance/GuidanceDo cuments/ucm094957.htm

84. Schimmel, E.M., "The hazards of hospitalization”, Annuals of Internal Medicine, American College of Physicians, Vol. 60, (1964): 100-110.

85. Shannon, Claude, Warren Weaver, The Mathematical Theory of Communication. University of Illinois: Champaign, IL, 1964. 
86. Sherwin, W.B., F. Jabot, R. Rush, M. Rossetto, "Measurement of Biological Information with Applications from Genes to Landscapes", Molecular Ecology, Vol. 15, (2006): 2857-2869.

87. Simpson, Edgar H., "Measurement of Diversity", Nature, Vol. 63, (April 1949):688.

88. Spear, S., M. Schmidhofer, Ambiguity and workarounds as contributors to medical error, Annals of Internal Medicine, Vol. 142, no. 8, (2005): 627-630.

89. Stellfox, H.T., S. Palmisani, C. Scurlock, E.J. Orav, D.W. Bates, "The "To Err is Human" report and the patient safety literature", Quality Safety Health Care, Vol. 15, (2006):174-178.

90. Strauch, Barry, Investigating Human Error Incidents, Accidents and Complex Systems), (Ashgate Publishing Ltd., Aldershot, U.K., 2002.

91. Sugihara, G., "Diversity as a Concept and Its Measurement: Comment", Journal of the American Statistical Association, Vol. 77, no. 379, (September 1982): 564565.

92. Summers, Donna S.C., Quality, Pearson Prentice-Hall, Upper Saddle River, NJ, 2006.

93. The Institute for Safe Medication Practices Canada (ISMP Canada Safety Bulletin), Failure Mode and Effects Analysis (FMEA): Proactively Identifying Risk in Healthcare, Vol. 6, no. 8, (HIROC Canada, Toronto, ON, December 23, 2008): 1-2.

94. The Institute for Safe Medication Practices Canada (ISMP Canada Safety Bulletin), Infusion Pump Project: Survey Results and Time for Action, Vol. 4 no. 1, (HIROC Canada, Toronto, ON, January 2004): 1-2.

95. Thompson, J.P., R.P. Mahajan, "Monitoring the monitors- beyond risk management", British Journal of Anaesthesia, Vol. 97, no.1, (July 2006): 1-3.

96. Tothemeresz, B., T. Magura, "Diversity and scalable characterizations", European Carabidology, DIAS Report, no.114, (2005):353-368.

97. U.S. Food and Drug Administration, Infusion Pump Improvement Initiative, (U.S. 98. Ulrich, R., S. Eppinger, Product Design and Development, $4^{\text {th }}$ ed., McGraw-Hill Irwin, New York, NY, 2007. 
99. Ventola, C. Lee, "Challenges in Evaluating and Standardizing Medical Devices in Health Care Facilities", Pharmacy and Therapeutics, Vol. 33, no. 6, (June 2008):348 - 359 .

100. Vincent, Charles, Analysis of clinical incidents: a window on the system not a search for root causes, Quality and Safety in Health Care, Vol. 13, no. 4, (2004): pp.242-243, 2004.

101. Vincent, Charles, Patient Safety, $2^{\text {nd }}$ ed., John Wiley and Sons, Chichester, UK, 2010.

102. Volpp, K., K. Grande, Residents' suggestions for reducing errors in teaching hospitals, New England Journal of Medicine, Vol. 348, no. 9, (2003): 851-855.

103. Wachter, Robert M., Understanding Patient Safety, McGraw-Hill Publishing, New York, New York, 2000.

104. Walsh, T. and P.C.W. Beatty, "Human factors errors and patient monitoring”, Physiological Measurement, Vol. 23 (2002), R111 - R132.

105. Wetterneck T.B. et al., "Using failure mode and effects analysis to plan implementation of Smart i.v. pump technology", American Journal of HealthSystem Pharmacists, Bethesda, MD, Vol. 63, no. 16, (2006): 1528-1538.

106. Wilson, R.M., B.T. Harrison, R.W. Gibberd, J.D, Hamilton, “An analysis of the causes of adverse events from the Quality in Australian Health Care Study", Medical Journal of Australia (MJA), Vol. 170, no. 9, (1999): 411-415. 107. Wilson, S., C. Davey, M. Lipson, "Improving Infusion Pump Safety: An Analysis of Aggregated Evaluation Results", (CEPIA, Bath, UK, 2010): 108. Woods, D., R. Cook, Nine Steps in move forward from error, Cognition, Technology and Work, Vol. 4, (2002): 137-144.

109. Zahl, S., "Jackknifing An Index of Diversity, Ecology”, Vol. 58, (1977): 907-913. 


\section{Appendix 1}

\section{Physiological Monitor Data Spreadsheet}




\begin{tabular}{|c|c|c|c|c|c|}
\hline AssetlD & Location & MakelD & ModellD & - Serial Number & \pm Description \\
\hline 4E/046 & 4 East & Critikon - GE & 8100 & $8100-K 5092$ & Monitor, Vital Signs \\
\hline 4E/060 & 4 East & Nellcor-Mallincrodt & $N=20$ & 20042616 & Pulse Oximeter \\
\hline 4E/061 & 4 East & MDI & $E 100$ & "713177 & Monttor, Physiological \\
\hline 4E/063 & 4 East & Critikon - GE & 8100 & $8100-L 4649$ & Monitor, Vital SIgns \\
\hline $4 E / 064$ & 4 East & Nellcor-Mallincrodt & $\mathrm{N}-2 \mathrm{O}$ & 20633176 & Pulse Oximeter \\
\hline 4E/071 & 4 East & Nelicor-Mallincrodt & N200 & 20781454 & Pulse Oximeter \\
\hline 4E/077 & 4 East & Nellcor-Mallincrodt & $\mathrm{N}-20$ & 20875362 & Pulse Oximeter \\
\hline 4E/078 & 4 East & Hewlett Packard & $78834 \mathrm{~A}$ & $2637 G 01000$ & Monitor, Physiological \\
\hline 4E/089 & 4 East & Cntikon - GE & 9300 & $9300-K 5074$ & Monitor, Vital Signs \\
\hline 4E/098 & 4 East & Critikon - GE & 117222 & $990 \mathrm{HO015411}$ & Monitor, Physiological \\
\hline 4E/099 & 4 East & Critikon - GE & 117277 & 4E/099 & Power Supply, Mps Select \\
\hline $4 E / 100$ & 4 East & Critikon - GE & 117322 & $990 \mathrm{H} 0017253$ & Module, ECG/resp/temp \\
\hline |4E/101 & 4 East & Critikon - GE & 117300 & $990 \mathrm{H} 0016763$ & Module, N.I.B.P. \\
\hline $4 E / 102$ & 4 East & Critkon - GE & 117310 & $990 \mathrm{H} 0017285$ & Module, Sao2/pleth \\
\hline $4 E / 103$ & 4 East & Critikon - GE & 117335 & $990 \mathrm{H} 0017406$ & Module, Recorder \\
\hline $4 E / 118$ & 4 East & GE & 1000 & 030M2940006 & Monitor, Vital SIgns \\
\hline $4 E / 120$ & 4 East & Nellcor-Mallincrodt & $\mathrm{N}-595$ & G03844542 & Monitor, Pulse Oximeter \\
\hline $4 E / 163$ & 4 East & Nellcor-Malincrodt & NPB-40 & G05859686 & Pulse Oximeter \\
\hline $4 E / 164$ & 4 East & Nellicor-Mallincrodt & NPB-40 & G05859720 & Pulse Oximeter \\
\hline $4 E / 165$ & 4 East & Nellcor-Mallincrodt & NPB-40 & G05859634 & Pulse OxImeter \\
\hline $4 E / 166$ & 4 East & Nellcor-Mallincrodt & NPB-40 & G05859661 & Pulse Oximeter \\
\hline $4 E / 167$ & 4 East & Nellcor-Mallincrodt & NPB-40 & G05859593 & Pulse Oximeter \\
\hline $4 E / 168$ & 4 East & Nellcor-Mallincrodt & NPB-40 & G05859587 & Pulse Oximeter \\
\hline $4 E / 169$ & 4 East & Nellcor-Mallincrodt & NPB-40 & G05859611 & Pulse Oximeter \\
\hline $4 E / 170$ & 4 East & Nellcor-Mallincrodt & $\mathrm{NPB}-40$ & G05859767 & Pulse Oximeter \\
\hline $4 E / 188$ & 4 East & Drager & MS18597E539D & 5397755855 & Monitor, Physiological \\
\hline $4 E / 189$ & 4 East & Drager & MS18597E539D & 5397878945 & Monitor, Physiological \\
\hline $4 E / 190$ & 4 East & Drager & MS18597E539D & 5397869153 & Monitor, Physiological \\
\hline $4 E / 191$ & 4 East & Drager & MS18597E539D & 5397880158 & Monitor, Physiological \\
\hline
\end{tabular}

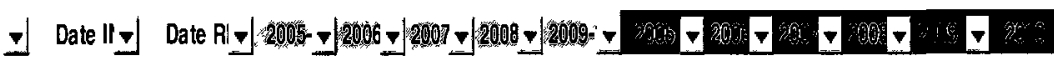

20-Jul-92

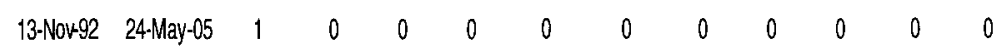

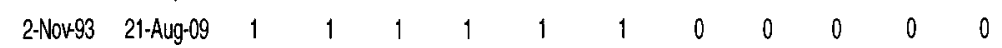

$\begin{array}{llllllllllll}\text { 8-Dec-94 } & 1 & 1 & 1 & 1 & 1 & 0 & 0 & 0 & 0 & 0 & 0\end{array}$

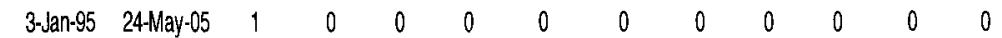

$\begin{array}{lllllllllllll}3-M a r-95 & 24-M a y-05 & 1 & 0 & 0 & 0 & 0 & 0 & 0 & 0 & 0 & 0 & 0\end{array}$

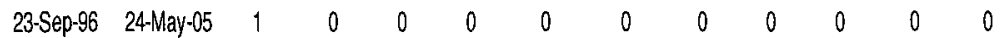

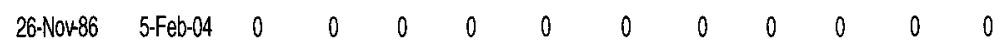

$\begin{array}{llllllllllll}\text { 10-Jun- }-97 & 1 & 1 & 1 & 1 & 1 & 0 & 1 & 1 & 1 & 2 & 1\end{array}$

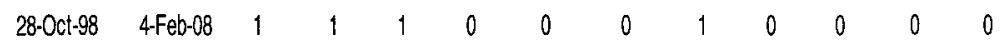

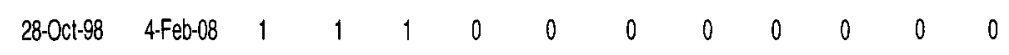

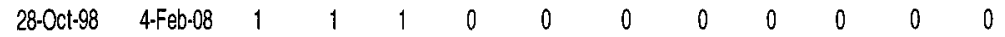

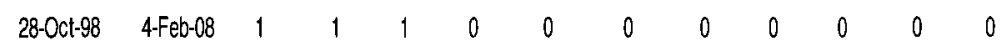

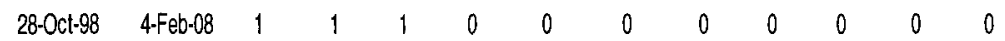

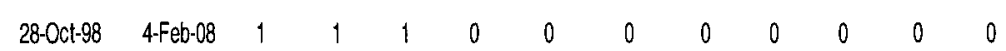

$\begin{array}{llllllllllll}\text { 1-Dec-03 } & 1 & 1 & 1 & 1 & 1 & 0 & 0 & 0 & 1 & 0 & 0\end{array}$

$\begin{array}{llllllllllll}11 . F e b-04 & 1 & 1 & 1 & 1 & 1 & 0 & 0 & 0 & 0 & 0 & 0\end{array}$

$\begin{array}{llllllllllll}27.0 c t-05 & 1 & 1 & 1 & 1 & 1 & 0 & 0 & 0 & 0 & 1 & 0\end{array}$

$\begin{array}{llllllllllll}27-0 c t-05 & 1 & 1 & 1 & 1 & 1 & 0 & 0 & 0 & 0 & 1 & 0\end{array}$

$\begin{array}{llllllllllll}27-0 c t-05 & 1 & 1 & 1 & 1 & 1 & 0 & 0 & 0 & 0 & 1 & 0\end{array}$

$\begin{array}{llllllllllll}27.0 \mathrm{ct}-05 & 1 & 1 & 1 & 1 & 1 & 0 & 0 & 0 & 0 & 0 & 0\end{array}$

$\begin{array}{llllllllllll}27.0 c t-05 & 1 & 1 & 1 & 1 & 1 & 0 & 0 & 0 & 0 & 1 & 0\end{array}$

$\begin{array}{llllllllllll}27-0 c t-05 & 1 & 1 & 1 & 1 & 1 & 0 & 0 & 0 & 0 & 0 & 0\end{array}$

$\begin{array}{cccccccccccc}27-0 c t-05 & 1 & 1 & 1 & 1 & 1 & 0 & 0 & 1 & 1 & 1 & 0\end{array}$

$\begin{array}{llllllllllll}27-0 \mathrm{ct}-05 & 1 & 1 & 1 & 1 & 1 & 0 & 0 & 0 & 1 & 1 & 0\end{array}$

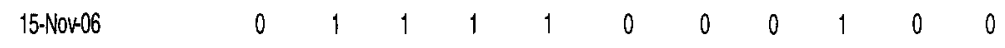

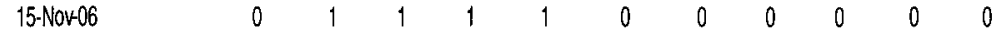

$\begin{array}{llllllllllll}\text { 15-Nov-06 } & 0 & 1 & 1 & 1 & 1 & 0 & 0 & 0 & 0 & 0 & 0\end{array}$ 


\begin{tabular}{|c|c|c|c|c|c|}
\hline AssettD & Location & MakelD & ModellD & - Serial Number & $\nabla$ Description \\
\hline $4 \mathrm{E} / 192$ & 4 East & Drager & MS18597E539D & 5397878847 & Monitor, Physiological \\
\hline $4 E / 193$ & 4 East & Drager & MS18597E539D & 5397859449 & Monitor, Physiological \\
\hline $4 E / 194$ & 4 East & Drager & MS18597E539D & 5397875057 & Monitor, Physiological \\
\hline $4 E / 195$ & 4 East & Drager & MS18597E539D & 5397880256 & Montor, Physiological \\
\hline $4 E / 196$ & 4 East & Drager & MS18597E539D & 5397877349 & Montor, Physiological \\
\hline $4 \mathrm{E} / 197$ & 4 East & Drager & MS18597E539D & 5397881852 & Monitor, Physiological \\
\hline $4 E / 198$ & 4 East & Drager & MS18597E539D & 5397863756 & Monitor, Physiological \\
\hline $4 \mathrm{E} / 199$ & 4 East & Drager & MS18597E539D & 5397882058 & Monitor, Physıological \\
\hline $4 \mathrm{E} / 200$ & 4 East & Drager & MS18597E539D & 397874450 & Monttor, Physiological \\
\hline $4 \mathrm{E} / 201$ & 4 East & Drager & MS18597E539D & 397881950 & Monitor, Physiological \\
\hline $4 \mathrm{E} / 202$ & 4 East & Drager & MS18597E539D & 8870855 & Monitor, Physiological \\
\hline $4 \mathrm{E} / 203$ & 4 East & Drager & MS18597E539D & 5397871061 & Monitor, Physiological \\
\hline $4 \mathrm{E} / 204$ & 4 East & Drager & MS18597E539D & 5397870659 & Monitor, Physiological \\
\hline $4 E / 205$ & 4 East & Drager & MS18597E539D & 5397876448 & Monitor, Physiological \\
\hline $4 \mathrm{E} / 285$ & 4 East & Nellcor-Mallincrodt & NPB-290 & G00807602 & Pulse Oximeter \\
\hline $4 E / 328$ & 4 East & Drager & MS18597 & 6000933869 & Monitor, Physiological \\
\hline $4 E / 329$ & 4 East & Drager & MS18597 & 6000923176 & Monitor, Physiological \\
\hline $4 \mathrm{E} / 330$ & 4 East & Drager & MS18597 & 00015274 & Monitor, Physiological \\
\hline $4 E / 331$ & 4 East & Drager & MS18597 & 600092865 & Monitor, Physiological \\
\hline $4 N / 073$ & 4 North & Cntikon - GE & 8100 & $8100-K 5516$ & Monitor, Vital Signs \\
\hline 4N/074 & 4 North & Critikon-GE & 8100 & $8100-K 5521$ & Monitor, Vital Signs \\
\hline $4 N / 091$ & 4 North & J\&J Critikon GE & СОМРACT T & $9800013218 Y 0$ & Monitor, Vital Signs \\
\hline $4 N / 105$ & 4 North & Nellcor-Mallincrodt & $N-20$ & CHECK & Pulse Oximeter \\
\hline $4 N / 114$ & 4 North & Cntikon - GE & 9300 & J6346 & Monitor, Vital Signs \\
\hline $4 N / 124$ & 4 North & Nellcor-Mallincrodt & $\mathrm{N}-20$ & 21678453 & Pulse Oximeter \\
\hline $4 \mathrm{~N} / 141$ & 4 North & Nellcor-Mallincrodt & NPB-290 & G99835611 & Pulse Oximeter \\
\hline $4 N / 142$ & 4 North & Hewlett Packard & $78834 A$ & $2815 G 02410$ & Monitor, Physiological \\
\hline $4 \mathbb{N} / 145$ & 4 North & Hewlett Packard & $78351 \mathrm{~A}$ & $2332 A 01045$ & Monitor, Physiological \\
\hline $4 N / 152$ & 4 North & GE & 1000 & $030 \mathrm{M} 070001$ & Monitor, Vital Signs \\
\hline $4 \mathbb{N} / 153$ & 4 Noth & GE & 1000 & O30M0490005 & Monitor, Vital Signs \\
\hline
\end{tabular}

\begin{tabular}{|c|c|c|c|c|c|c|c|c|c|c|c|c|}
\hline Date $\mathrm{II}=$ & $\mathrm{RI}=$ & 200 & 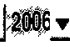 & 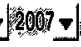 & $2008 \mathrm{\nabla}$ & 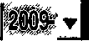 & 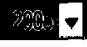 & 7 & 1 & & $\nabla$ & 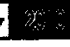 \\
\hline 15-Nov-06 & & 0 & 1 & 1 & 1 & 1 & 0 & 0 & 0 & 1 & 1 & 0 \\
\hline 15-Nov-06 & & 0 & 1 & 1 & 1 & 1 & 0 & 0 & 0 & 0 & 1 & 0 \\
\hline 15-Nov-06 & & 0 & 1 & 1 & 1 & 1 & 0 & 0 & 0 & 0 & 0 & 0 \\
\hline 15-Nov-06 & & 0 & 1 & 1 & 1 & 1 & 0 & 0 & 1 & 0 & 1 & 0 \\
\hline 15-Nov-06 & & 0 & 1 & 1 & 1 & 1 & 0 & 0 & 0 & 0 & 0 & 0 \\
\hline 15-Nov-06 & & 0 & 1 & 1 & 1 & 1 & 0 & 0 & 1 & 0 & 0 & 0 \\
\hline 15-Nov-06 & & 0 & 1 & 1 & 1 & 1 & 0 & 0 & 0 & 0 & 0 & 0 \\
\hline 15-Now-06 & & 0 & 1 & 1 & 1 & 1 & 0 & 0 & 0 & 0 & 1 & 0 \\
\hline 15-Nov06 & & 0 & 1 & 1 & 1 & 1 & 0 & 0 & 0 & 0 & 1 & 0 \\
\hline 15-Nov-06 & & 0 & 1 & 1 & 1 & 1 & 0 & 0 & 0 & 0 & 1 & 0 \\
\hline 15-Nov-06 & & 0 & 1 & 1 & 1 & 1 & 0 & 0 & 0 & 0 & 1 & 0 \\
\hline 15-Nov-06 & & 0 & 1 & 1 & 1 & 1 & 0 & 0 & 0 & 0 & 1 & 0 \\
\hline 15-Nor-06 & & 0 & 1 & 1 & 1 & 1 & 0 & 0 & 0 & 0 & 2 & 0 \\
\hline 15-Nov-06 & & 0 & 1 & 1 & 1 & 1 & 0 & 0 & 0 & 0 & 0 & 0 \\
\hline 5.Jan- 00 & & 1 & 1 & 1 & 1 & 1 & 0 & 0 & 0 & 0 & 0 & 0 \\
\hline 1.Jun-09 & & 0 & 0 & 0 & 0 & 1 & 0 & 0 & 0 & 0 & 0 & 0 \\
\hline 1-Jun-09 & & 0 & 0 & 0 & 0 & 1 & 0 & 0 & 0 & 0 & 0 & 0 \\
\hline 1-Jun-09 & & 0 & 0 & 0 & 0 & 1 & 0 & 0 & 0 & 0 & 0 & 0 \\
\hline 1-Jun-09 & & 0 & 0 & 0 & 0 & 1 & 0 & 0 & 0 & 0 & 0 & 0 \\
\hline 2-Jun-92 & & 1 & 1 & 1 & 1 & 1 & 0 & 0 & 0 & 1 & 0 & 0 \\
\hline 20-Jul-92 & & 1 & 1 & 1 & 1 & 1 & 1 & 0 & 0 & 0 & 0 & 1 \\
\hline 23-Apr-98 & 20-Juil-09 & 1 & 1 & 1 & 1 & 0 & 0 & 0 & 0 & 0 & 0 & 0 \\
\hline 23-Apr-98 & 21-May-05 & 1 & 0 & 0 & 0 & 0 & 1 & 0 & 0 & 0 & 0 & 0 \\
\hline 20-Nov-96 & & 1 & 1 & 1 & 1 & 1 & 1 & 0 & 1 & 1 & 0 & 0 \\
\hline 4-Dec-01 & 21-May-05 & 1 & 0 & 0 & 0 & 0 & 0 & 0 & 0 & 0 & 0 & 0 \\
\hline 5-Jan- 00 & & 1 & 1 & 1 & 1 & 1 & 0 & 0 & 0 & 0 & 1 & 0 \\
\hline 9-Dec-88 & 21-May-05 & 1 & 0 & 0 & 0 & 0 & 1 & 0 & 0 & 0 & 0 & 0 \\
\hline 27-0ct-83 & 21-May-05 & 1 & 0 & 0 & 0 & 0 & 1 & 0 & 0 & 0 & 0 & 0 \\
\hline 23-Aug-05 & & 1 & 1 & 1 & 1 & 1 & 0 & 1 & 1 & 0 & 0 & 0 \\
\hline 23-Aug-05 & 25-Sep-08 & 1 & 1 & 1 & 1 & 0 & 0 & 0 & 1 & 0 & 0 & 0 \\
\hline
\end{tabular}




\begin{tabular}{|c|c|c|c|c|c|}
\hline Assetlo & Location & MakelD & ModellD & - Serial Number & $\checkmark$ Description \\
\hline $4 N / 154$ & 4 North & GE & 1000 & $030 M 0480018$ & Monitor, Vital Signs \\
\hline $4 N / 155$ & 4 North & Nellcor-Mallincrodt & $N-20 E$ & G03802519 & Pulse Oximeter \\
\hline $4 \mathrm{~N} / 156$ & 4 North & Nellcor-Mallincrodt & $\mathrm{N}-20 \mathrm{E}$ & G03802523 & Pulse Oximeter \\
\hline $4 N / 159$ & 4 North & Nellcor-Mallincrodt & $\mathrm{N}-65$ & G06803289 & Pulse Oximeter \\
\hline $4 \mathbb{N} / 165$ & 4 North & GE & 400 & AAW06160039SA & Monitor, Vital Signs \\
\hline $4 N / 172$ & 4 North & Drager & MS18597E539D & 5397844055 & Monitor, Physiological \\
\hline $4 \mathrm{~N} / 173$ & 4 North & Drager & MS18597E539D & 5397860563 & Monitor, Physiological \\
\hline $4 N / 174$ & 4 North & Drager & MS18597E539D & 5397815354 & Monitor, Physiological \\
\hline $4 N / 175$ & 4 North & Drager & MS18597E539D & 5397604261 & Monitor, Physiological \\
\hline $4 N / 176$ & 4 Noth & Drager & MS18597E539D & 5397864853 & Monitor, Physiological \\
\hline $4 N / 177$ & 4 North & Drager & MS18597E539D & 5397833655 & Monitor, Physiological \\
\hline $4 N / 222$ & 4 Noth & Nellcor-Mallincrodt & N.65 Oximax & G06834132 & Pulse Oximeter \\
\hline $4 \mathrm{~N} / 223$ & 4 North & Nellcor-Mallincrodt & N-65 Oximax & G06834070 & Pulse Oximeter \\
\hline $4 N / 224$ & 4 North & Nellcor-Mallincroot & N-65 OxImax & G06834135 & Pulse Oxımeter \\
\hline $4 N / 225$ & 4 North & Nellcor-Mallincroot & $\mathrm{N}-65$ OxImax & G06834117 & Pulse Oximeter \\
\hline $4 N / 311$ & 4 North & GE & v100 & SDT08300023 & Monitor, Vital Signs \\
\hline $4 N / 312$ & 4 North & GE & v100 & SDT08300025SP & Monitor, Vital Signs \\
\hline $4 N / 313$ & 4 North & Drager & MS18597 & 53990395555 & Monitor, Physiological \\
\hline $4 N / 314$ & 4 North & Drager & MS18597 & 5398814754 & Monitor, Physiological \\
\hline $4 W / 136$ & 4 West & Nellcor-Maillncrodt & $\mathrm{N}-20$ & 20042682 & Pulse Oximeter \\
\hline $4 W / 149$ & 4 West & Critikon - GE & 8100 & 8100-K9065 & Monitor, Vital Signs \\
\hline $4 W / 150$ & 4 West & Nellcor-Mallincrodt & $\mathrm{N} 200$ & 20784403 & Pulse Oximeter \\
\hline $4 W / 158$ & 4 West & MDI & ESCORT II & 3509 & Monitor, Physiological \\
\hline $4 W / 159$ & 4 West & Nellcor-Mallincrodt & $\mathrm{N}-20$ & 20872610 & Pulse Oximeter \\
\hline $4 W / 161$ & 4 West & Hewlett Packard & $78834 C$ & $2943 G 00696$ & Monitor, Physiological \\
\hline $4 W / 162$ & 4 West & Hewett Packard & $78834 \mathrm{C}$ & $3107 \mathrm{G} 01605$ & Monitor, Physiological \\
\hline $4 W / 163$ & 4 West & Hewlett Packard & $78834 C$ & 3113602699 & Monitor, Physiological \\
\hline $4 W / 164$ & 4 West & Hewlett Packard & $78834 \mathrm{C}$ & $3252 A 00826$ & Monitor, Physiological \\
\hline $4 W / 177$ & 4 West & Critikon - GE & 117222 & $990 \mathrm{HOO} 15410$ & Monitor, Physiological \\
\hline $4 W / 178$ & 4 West & Critikon-GE & 117277 & $4 W / 178$ & Power Supply, Mps \\
\hline
\end{tabular}

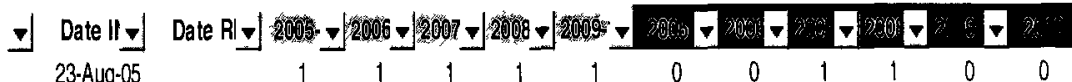

7.Sep-03

$7-\operatorname{Sep}-03$

7-Sep-03

5-Sep-06

30-Nor-06

30-Nov-06

30-Nov-06

30-Nov-06

30-Nov-06

30-Nov-06

23-Jan-07

23-Jan-07

23-Jan-07

23-Jan-07

28-Aug-08

28-Aug-08

6.Jan-09

6-Jan-09

$\begin{array}{llllllllllll}-05 & 1 & 0 & 0 & 0 & 0 & 0 & 0 & 0 & 0 & 0 & 0\end{array}$

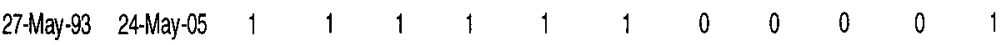

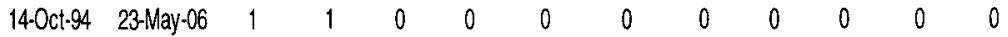

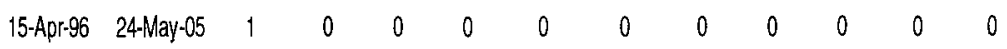

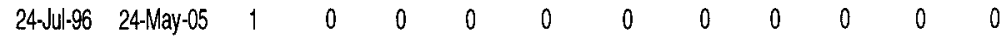

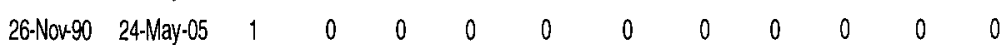

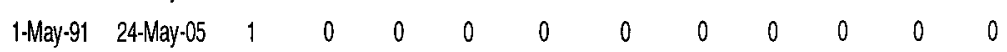

24-Jan-92 24-May-05 $11 \quad 0 \quad 00 \begin{array}{llllllll}0 & 0 & 0 & 0 & 0 & 0 & 0 & 0\end{array}$

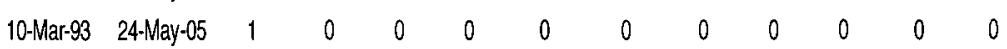

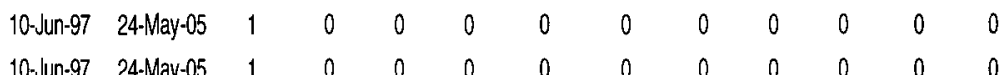




\begin{tabular}{|c|c|c|c|c|c|}
\hline Asset ID & Location & MakelD & ModellD & ISerial Number & Description \\
\hline $4 W / 179$ & 4 West & Critikon - GE & 117322 & $990 \mathrm{H} 0017256$ & Module, ECG/resp/temp \\
\hline $4 W / 180$ & 4 West & Citikon - GE & 117300 & $990 \mathrm{H} 0017692$ & Module, N.I.B.P. \\
\hline $4 W / 181$ & 4 West & Critkon - GE & 117310 & 99040017328 & Module, Saor/pleth \\
\hline $4 W / 182$ & 4 West & Nellcor-Mallincrodt & $\mathrm{N}-20$ & G00838339 & Pulse Oximeter \\
\hline $4 W / 189$ & 4 West & GE & 1000 & $030 \mathrm{MO} 0420003$ & Monitor, Vital Signs \\
\hline $4 W / 190$ & 4 West & GE & 1000 & 030M0700024 & Monitor, Vital Signs \\
\hline $4 W / 195$ & 4 West & GE & 1000 & $030 \mathrm{M} 1980020$ & Montor, Vital Signs \\
\hline $4 W / 196$ & 4 West & GE & 1000 & $030 M 1980016$ & Monitor, Vital Signs \\
\hline 4W/200 & 4 West & Nellcor-Mallincrodt & N-595 & go3850322 & Pulse Oximeter \\
\hline $4 W / 228$ & 4 West & Drager & MS18597E539D & 5397721758 & Monitor, Physiologlcal \\
\hline $4 W / 229$ & 4 West & Drager & MS18597E539D & 7706258 & Monitor, Physiological \\
\hline $4 W / 230$ & 4 West & Drager & MS18597E539D & 97703457 & Monitor, Physiological \\
\hline 4W/231 & 4 West & Drager & MS18597E539D & 997719253 & Monitor, Physiological \\
\hline 4W/232 & 4 West & Drager & MS18597E539D & 5397702565 & Monitor, Physiological \\
\hline $4 W / 233$ & 4 West & Drager & MS18597E539D & 5397703956 & Monitor, Physiological \\
\hline $4 W / 234$ & 4 West & Drager & MS18597E539D & 5397703564 & Monitor, Physiological \\
\hline 4W/235 & 4 West & Drager & MS18597E539D & 5397785056 & Monitor, Physiological \\
\hline $4 W / 236$ & 4 West & Drager & MS18597E539D & 5397725353 & Monitor, Physiological \\
\hline $4 W / 237$ & 4 West & Drager & MS18597E539D & 5397706356 & Monitor, Physiological \\
\hline $4 W / 238$ & 4 West & Drager & MS18597E5390 & 5397702761 & Monitor, Physiological \\
\hline $4 W / 239$ & 4 West & Drager & MS18597E539D & 5397705856 & Monitor, Physiological \\
\hline $4 W / 240$ & 4 West & Drager & MS18597E539D & 5397716599 & Monitor, Physiological \\
\hline $4 W / 241$ & 4 West & Drager & MS18597E539D & 5397703760 & Monitor, Physiological \\
\hline $4 W / 242$ & 4 West & Drager & MS18597E539D & 5397706561 & Monitor, Physiological \\
\hline 4W/298 & 4 West & Nellcor-Mallincrodt & N-65 Oximax & G06834037 & Pulse Oximeter \\
\hline $4 W / 309$ & 4 West & GE & 1000 & $030 \mathrm{M} 2940003$ & Monitor, Physiological \\
\hline $4 W / 313$ & 4 West & Nellicor-Mallincrodt & N-65 Oximax & G08818930 & Pulse Oximeter \\
\hline $4 W / 314$ & 4 West & Nellcor-Mallincrodt & N-65 Oximax & G08818922 & Pulse Oximeter \\
\hline $4 W / 324$ & 4 West & Drager & MS 18597 & 6000927867 & Monitor, Physiological \\
\hline $4 W / 325$ & 4 West & Drager & MS18597 & 6000913579 & Monitor, Physiological \\
\hline
\end{tabular}

\begin{tabular}{|c|c|c|c|c|c|c|c|c|c|c|c|c|}
\hline & & & & & & & & & & & & \\
\hline 10-Jun-97 & 24-May-05 & 1 & 0 & 0 & 0 & 0 & 0 & 0 & 0 & 0 & 0 & 0 \\
\hline 10-Jun-97 & 24-May-05 & 1 & 0 & 0 & 0 & 0 & 0 & 0 & 0 & 0 & 0 & 0 \\
\hline 10-Jun-97 & 24-May-05 & 1 & 0 & 0 & 0 & 0 & 0 & 0 & 0 & 0 & 0 & 0 \\
\hline 18-Dec-00 & 10-Feb-07 & 1 & 1 & 1 & 0 & 0 & 0 & 0 & 0 & 0 & 0 & 0 \\
\hline 4-Feb-03 & & 1 & 1 & 1 & 1 & 1 & 0 & 0 & 0 & 0 & 0 & 0 \\
\hline 4-Feb-03 & & 1 & 1 & 1 & 1 & 1 & 0 & 0 & 0 & 0 & 0 & 0 \\
\hline 4-Feb-03 & & 1 & 1 & 1 & 1 & 1 & 0 & 0 & 0 & 0 & 0 & 0 \\
\hline $4-F e b-03$ & & 1 & 1 & 1 & 1 & 1 & 0 & 0 & 0 & 0 & 0 & 0 \\
\hline 4-Mar-03 & & 1 & 1 & 1 & 1 & 1 & 0 & 0 & 0 & 0 & 0 & 0 \\
\hline 23-Nov-06 & & 0 & 1 & 1 & 1 & 1 & 0 & 0 & 0 & 1 & 0 & 0 \\
\hline 23-Nov06 & & 0 & 1 & 1 & 1 & 1 & 0 & 0 & 0 & 0 & 0 & 0 \\
\hline 23-Nov-06 & & 0 & 1 & 1 & 1 & 1 & 0 & 0 & 0 & 0 & 0 & 0 \\
\hline 23-Nor-06 & & 0 & 1 & 1 & 1 & 1 & 0 & 0 & 0 & 1 & 1 & 0 \\
\hline 23-Nov-06 & & 0 & 1 & 1 & 1 & 1 & 0 & 0 & 0 & 0 & 0 & 0 \\
\hline 23-Nov06 & & 0 & 1 & 1 & 1 & 1 & 0 & 0 & 0 & 1 & 0 & 1 \\
\hline 23-Nor-06 & & 0 & 1 & 1 & 1 & 1 & 0 & 0 & 0 & 0 & 0 & 0 \\
\hline 23-Nor-06 & & 0 & 1 & 1 & 1 & 1 & 0 & 0 & 0 & 0 & 0 & 0 \\
\hline 23-Nov-06 & & 0 & 1 & 1 & 1 & 1 & 0 & 0 & 0 & 0 & 0 & 0 \\
\hline 23-Nov-06 & & 0 & 1 & 1 & 1 & 1 & 0 & 0 & 0 & 0 & 0 & 0 \\
\hline 23-Nov-06 & & 0 & 1 & 1 & 1 & 1 & 0 & 0 & 0 & 0 & 1 & 0 \\
\hline 23-Nov-06 & & 0 & 1 & 1 & 1 & 1 & 0 & 0 & 0 & 0 & 0 & 0 \\
\hline 23-Nov-06 & & 0 & 1 & 1 & 1 & 1 & 0 & 0 & 0 & 0 & 0 & 0 \\
\hline 23-Nov-06 & & 0 & 1 & 1 & 1 & 1 & 0 & 0 & 1 & 0 & 0 & 0 \\
\hline 23-Nov-06 & & 0 & 1 & 1 & 1 & 1 & 0 & 0 & 0 & 0 & 0 & 0 \\
\hline 23-Jan-07 & & 0 & 0 & 0 & 1 & 1 & 0 & 0 & 0 & 0 & 0 & 0 \\
\hline 12-Jan-03 & & 0 & 0 & 0 & 1 & 1 & 0 & 0 & 0 & 0 & 0 & 0 \\
\hline 10-Mar-08 & & 0 & 0 & 1 & 1 & 1 & 0 & 0 & 0 & 0 & 0 & 0 \\
\hline 10-Mar-08 & & 0 & 0 & 1 & 1 & 1 & 0 & 0 & 0 & 0 & 0 & 0 \\
\hline 6-Jan-09 & & 0 & 0 & 0 & 1 & 1 & 0 & 0 & 0 & 0 & 0 & 0 \\
\hline 6-Jan-09 & & 0 & 0 & 0 & 1 & 1 & 0 & 0 & 0 & 0 & 0 & 0 \\
\hline
\end{tabular}




\begin{tabular}{|c|c|c|c|c|c|}
\hline \multicolumn{3}{|c|}{ AssetlD $=$ Location $\nabla$ MakelD } & \multirow{2}{*}{$\nabla$ ModellD } & \multirow{2}{*}{$\underset{20272098}{\text { Serial Number }}$} & \multirow{2}{*}{$\begin{array}{l}\text { Description } \\
\text { Pulse Oximeter }\end{array}$} \\
\hline $5 E / 073$ & 5 East & Nellcor-Mallincrodt & & & \\
\hline 5E/076 & 5 East & Critikon - GE & 8100 & $8100-K 9984$ & Monitor, Vital Signs \\
\hline 5E/085 & 5 East & Critikon-GE & 9300 & $9300-H 1192$ & Monitor, Vital Signs \\
\hline $5 E / 088$ & 5 East & MOI & ESCORT $\|$ & 3508 & Monitor, Physiological \\
\hline $5 E / 095$ & 5 East & $M D$ & ESCORT॥ & 4618 & Monitor, Physiological \\
\hline $5 E / 105$ & 5 East & Nellcor-Mallincrodt & NPB-290 & g00807108 & Pulse Oximeter \\
\hline $5 E / 106$ & 5 East & Nellcor-Mallincrodt & NPB-290 & G00809736 & Pulse Oximeter \\
\hline $5 E / 107$ & 5East & Nellcor-Mallincrodt & NPB-290 & G00817480 & Pulse Oximeter \\
\hline $5 E / 137$ & 5 East & Critikon - GE & PRO 100 & O20MO159050 & Monitor, Vital Signs \\
\hline $5 E / 152$ & 5 East & Drager & MS18597E539D & 5397645849 & Monitor, Physiological \\
\hline $5 E / 153$ & 5 East & Drager & 'MS18597E539D & 5397660957 & Monitor, Physiological \\
\hline $5 E / 154$ & 5 East & Drager & MS18597E539D & 5397866352 & Monitor, Physiological \\
\hline $5 E / 155$ & 5 East & Drager & MS18597E539D & 5397830453 & Monitor, Physiological \\
\hline $5 E / 156$ & 5 East & 'Drager & MS18597E539D & 5397856951 & Monitor, Physiological \\
\hline $5 E / 157$ & 5 East & Drager & MS18597E539D & 5397768850 & Monitor, Physiological \\
\hline $5 E / 158$ & 5 East & Drager & MS18597E539D & 5397845152 & Monitor, Physiological \\
\hline $5 E / 159$ & 5 East & Drager & MS18597E539D & 5397669351 & Monitor, Physiological \\
\hline $5 E / 160$ & 5 East & Drager & MS18597E539D & 5397825450 & Monitor, Physiological \\
\hline $5 E / 161$ & 5 East & Drager & MS18597E539D & 5397648944 & Monitor, Physiological \\
\hline $5 E / 162$ & 5 East & Drager & MS18597E539D & 5397646447 & Monitor, Physiological \\
\hline $5 E / 163$ & 5 East & Drager & MS18597E539D & 5397861063 & Monitor, Physiological \\
\hline $5 E / 164$ & 5 East & Drager & MS18597E539D & 5397646153 & Monitor, Physiological \\
\hline $5 E / 165$ & 5 East & Drager & MS18597E539D & 5397836554 & Monitor, Physiological \\
\hline $5 E / 235$ & 5 East & Nellcor-Mallincrodt & N-65 Oximax & G06834105 & Pulse Oximeter \\
\hline $5 E / 236$ & 5 East & Nellcor-Mallincrodt & N-65 Oximax & G06834021 & Pulse Oximeter \\
\hline $5 \mathrm{E} / 237$ & 5 East & Nellcor-Mallincrodt & $N-65$ Oximax & G06834067 & Pulse Oximeter \\
\hline $5 \mathrm{E} / 255$ & 5 East & Nellcor-Mallincrodt & $\mathrm{N}-65$ Oximax & G08809168 & Pulse Oximeter \\
\hline $5 E / 256$ & 5 East & Nellcor-Mallincrodt & N-65 Oximax & G08809189 & Pulse Oximeter \\
\hline 5E/257 & 5 East & Nellcor-Mallincrodt & N-65 Oximax & G08809198 & Pulse Oximeter \\
\hline $5 E / 258$ & 5 East & Nellcor-Mallincrodt & N-65 Oximax & G08809221 & Pulse Oximeter \\
\hline
\end{tabular}

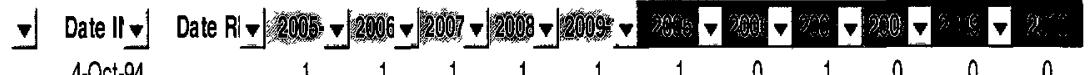

$\begin{array}{cccccccccccc}4-0 \mathrm{ct}-94 & 1 & 1 & 1 & 1 & 1 & 1 & 0 & 1 & 0 & 0 & 0 \\ 6-0 \mathrm{ct}-95 & 1 & 1 & 1 & 1 & 1 & 1 & 1 & 0 & 0 & 0 & 0\end{array}$

$\begin{array}{llllllllllll}\text { 15-Nor-97 } & 1 & 1 & 1 & 1 & 1 & 0 & 1 & 0 & 4 & 2 & 2\end{array}$

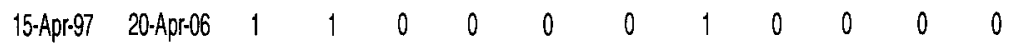

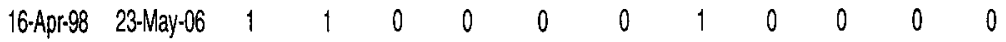

$\begin{array}{llllllllllll}\text { 5-Jan-00 } & 1 & 1 & 1 & 1 & 1 & 0 & 0 & 0 & 0 & 0 & 0\end{array}$

$\begin{array}{llllllllllll}\text { 5-Jan-00 } & 1 & 1 & 1 & 1 & 1 & 1 & 0 & 0 & 0 & 0 & 0\end{array}$

$\begin{array}{llllllllllll}\text { 5-Jan- } 00 & 1 & 1 & 1 & 1 & 1 & 0 & 2 & 0 & 0 & 0 & 0\end{array}$

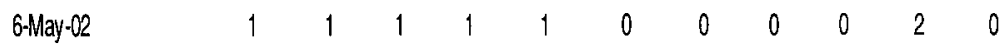

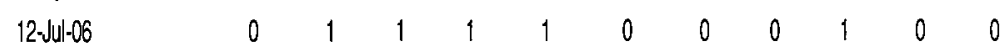

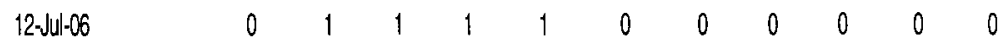

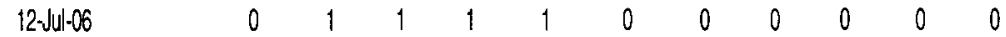

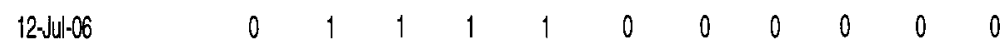

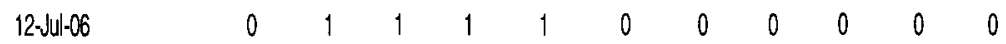

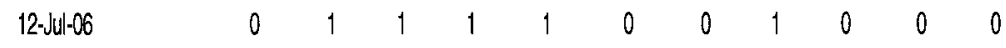

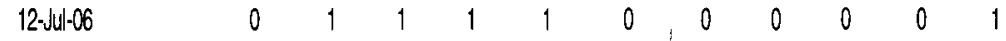

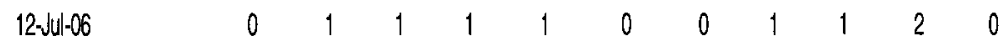

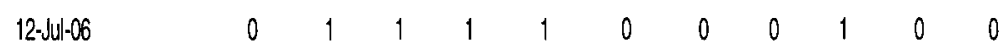

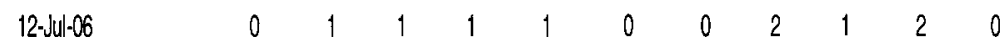

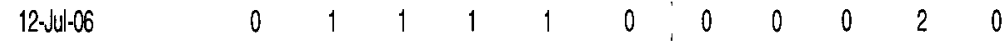

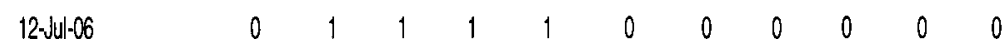

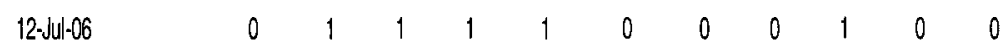

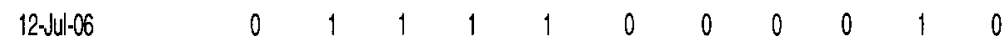

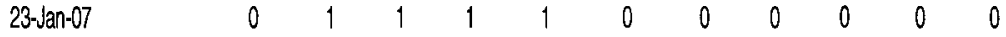

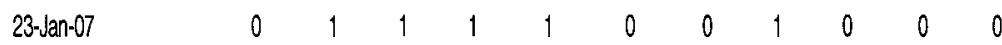

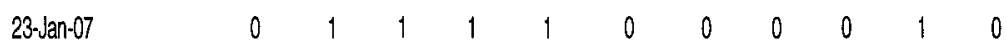

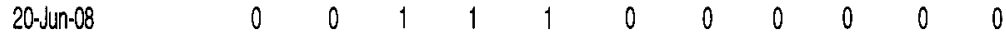

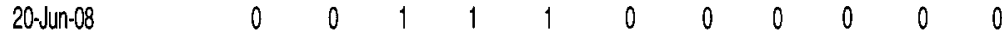

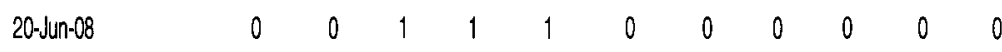

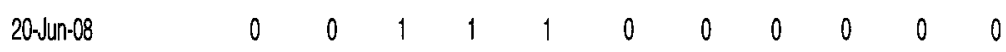




\begin{tabular}{|c|c|c|c|c|c|}
\hline Assetid I & Location $v$ & MakelD & $\checkmark$ ModellD & Serial Number & Description \\
\hline $5 E / 269$ & 5 East & Drager & MS18597 & 5399764057 & Monitor, Physiological \\
\hline $5 E / 270$ & 5 East & Drager & MS18597 & 60001313775 & Monitor, Physiological \\
\hline $5 \mathrm{E} / 271$ & 5 East & Drager & MS18597 & 5399037557 & Monitor, Physiological \\
\hline $5 E / 272$ & 5 East & Drager & MS18597 & 5399001168 & Monitor, Physiological \\
\hline EM/108 & Emergency & Critkon - GE & 8100 & K3295 & Monitor, Vital Signs \\
\hline EM/111 & Emergency & Hewlett Packard & $78834 \mathrm{C}$ & 3204400160 & Monitor, Physiological \\
\hline EM/116 & Emergency & Critikon - GE & 8100 & $8100-k 7537$ & Monitor, Vital Signs \\
\hline EM/117 & Emergency & Critkon - GE & 8100 & $8100-K 7538$ & Monitor, Vital Signs \\
\hline EM/131 & Emergency & Nellcor-Mallincrodt & $\mathrm{N}-20$ & 20086466 & Pulse Oximeter \\
\hline$E M / 132$ & Emergency & Nellcor-Mallincrodt & $N-20$ & 20086465 & Pulse Oximeter \\
\hline$E M / 152$ & Emergency & Nellcor-Mallincroot & $\mathrm{N}-20$ & 20772842 & Pulse Oximeter \\
\hline EM/153 & Emergency & Nellcor-Mallincrodt & $\mathrm{N}-2 \mathrm{O}$ & 20772854 & Pulse Oximeter \\
\hline$E M / 160$ & Emergency & $M D$ & ESCORT $\|$ & 3226 & Monitor, Physiological \\
\hline EM/203 & Emergency & Hewlett Packard & M1094B & 3806187683 & Monitor, Video, Colour \\
\hline EM/204 & Emergency & Hewlett Packard & M1166A & $3826 A 80349$ & Computer Mainframe \\
\hline EM/206 & Emergency & Hewlett Packard & M1020A & $3805 A 97251$ & Module, Sao/pleth \\
\hline EM/207 & Emergency & Hewlett Packard & M1016A & $3805 \mathrm{G} 12156$ & Module, Co2 End Tidal \\
\hline EM/208 & Emergency & Hewlett Packard & M1006B & $3805 G 53268$ & Module, Invasive Pressure \\
\hline EM/212 & Emergency & Hewlett Packard & M1106C & $3504 A 50197$ & Monitor, Keypad \\
\hline EM/213 & Emergency & Hewlett Packard & M1116B & $3809 A 72963$ & Module, Recorder \\
\hline EM/222 & Emergency & Neilcor-Mallincrodt & NPB-290 & G99826039 & Pulse Oximeter \\
\hline$E M / 271$ & Emergency & Hewlett Packard & M1205A & $4006 A 83694$ & Monitor, Physiological \\
\hline$E M / 273$ & Emergency & Hewlett Packard & $\mathrm{M} 1002 \mathrm{~B}$ & DE01765547 & Module, ECG/respiration \\
\hline EM/289 & Emergency & GE & 400 & $030 M 1128038$ & Monitor, Vital Signs \\
\hline EM/292 & Emergency & GE & 400 & 030M3018007 & Monitor, Vital Signs \\
\hline EM/293 & Emergency & GE & 400 & O3OM3018048 & Monitor, Vital Signs \\
\hline EM/295 & Emergency & Nellcor-Mallincrodt & N-595 & G03839501 & Pulse Oximeter \\
\hline EM/296 & Emergency & Nellcor-Mallincrodt & N.595 & G03844804 & Pulse Oximeter \\
\hline EM/297 & Emergency & Nellcor-Mallincrodt & N.595 & G03844593 & Pulse Oximeter \\
\hline EM/349 & Emergency & Nellcor-Mallincrodt & $N-65$ & G06836643 & Pulse Oximeter \\
\hline
\end{tabular}

\begin{tabular}{|c|c|c|c|c|c|c|c|c|c|c|c|c|}
\hline Date $\|$ & D & & & & & 0. & 17 & 0,9 & & & & re \\
\hline 6.Jan-09 & & 0 & 0 & 0 & 1 & 1 & 0 & 0 & 0 & 0 & 0 & 0 \\
\hline 6-Jan-09 & & 0 & 0 & 0 & 1 & 1 & 0 & 0 & 0 & 0 & 0 & 0 \\
\hline 6-Jan-09 & & 0 & 0 & 0 & 1 & 1 & 0 & 0 & 0 & 0 & 0 & 0 \\
\hline 6-Jan-09 & & 0 & 0 & 0 & 1 & 1 & 0 & 0 & 0 & 0 & 0 & 0 \\
\hline $30-0$ ct -92 & & 1 & 1 & 1 & 1 & 1 & 0 & 0 & 1 & 1 & 0 & 0 \\
\hline 16-Mar-93 & 4-Mar-08 & 1 & 1 & 1 & 0 & 0 & 0 & 0 & 0 & 0 & 0 & 0 \\
\hline 18-Jan-94 & & 1 & 1 & 1 & 1 & 1 & 0 & 0 & 0 & 1 & 0 & 1 \\
\hline 18-Jan-94 & & 1 & 1 & 1 & 1 & 1 & 0 & 0 & 2 & 0 & 0 & 0 \\
\hline 8-Mar.96 & & 1 & 1 & 1 & 1 & 1 & 0 & 0 & 0 & 0 & 0 & 0 \\
\hline 24-Mar-96 & & 1 & 1 & 1 & 1 & 1 & 0 & 0 & 0 & 0 & 0 & 0 \\
\hline 30-Mar-98 & & 1 & 1 & 1 & 1 & 1 & 0 & 1 & 0 & 0 & 0 & 0 \\
\hline 30-Mar-98 & & 1 & 0 & 0 & 0 & 0 & 1 & 0 & 0 & 0 & 0 & 0 \\
\hline 2-Jan-97 & $31-M a r-08$ & 1 & 1 & 1 & 0 & 0 & 0 & 0 & 0 & 0 & 0 & 0 \\
\hline 1-Apr.99 & 31-Mar-08 & 1 & 1 & 1 & 0 & 0 & 0 & 0 & 0 & 0 & 0 & 0 \\
\hline 1-Apr-99 & $31 \cdot$ Mar-08 & 1 & 1 & 1 & 0 & 0 & 0 & 0 & 0 & 0 & 0 & 0 \\
\hline 1-Apr-99 & 31-Mar-08 & 1 & 1 & 1 & 0 & 0 & 0 & 0 & 0 & 0 & 0 & 0 \\
\hline 1-Apr-99 & 31 Mar-08 & 1 & 1 & 1 & 0 & 0 & 0 & 0 & 0 & 0 & 0 & 0 \\
\hline 1-Apr-99 & 31-Mar-08 & 1 & 1 & 1 & 0 & 0 & 0 & 0 & 0 & 0 & 0 & 0 \\
\hline 1-Apr-99 & 31-Mar-08 & 1 & 1 & 1 & 0 & 0 & 0 & 0 & 0 & 0 & 0 & 0 \\
\hline 1-Apr-99 & $31-\mathrm{Mar}-08$ & 1 & 1 & 1 & 0 & 0 & 0 & 0 & 0 & 0 & 0 & 0 \\
\hline 1-Apr.99 & 15-Aug-07 & 1 & 1 & 1 & 0 & 0 & 0 & 0 & 0 & 0 & 0 & 0 \\
\hline 15-Feb-01 & $31-M a r-08$ & 1 & 1 & 1 & 0 & 0 & 0 & 0 & 0 & 0 & 0 & 0 \\
\hline 15-Feb-01 & 31-Mar-08 & 1 & 1 & 1 & 0 & 0 & 0 & 0 & 0 & 0 & 0 & 0 \\
\hline 24-Jun-03 & & 1 & 1 & 1 & 1 & 1 & 0 & 0 & 1 & 0 & 0 & 0 \\
\hline 24-Jun-03 & & 1 & 1 & 1 & 1 & 1 & 0 & 0 & 1 & 0 & 0 & 0 \\
\hline 24-Jun-03 & & 1 & 1 & 1 & 1 & 1 & 1 & 1 & 0 & 1 & 1 & 0 \\
\hline 26-Nov-03 & 7-Nov07 & 1 & 1 & 0 & 0 & 0 & 0 & 0 & 0 & 0 & 0 & 0 \\
\hline 26-Nov 03 & 7-Nov-07 & 1 & 1 & 0 & 0 & 0 & 0 & 0 & 0 & 0 & 0 & 0 \\
\hline 26-Nov-03 & 7-Nok07 & 1 & 1 & 0 & 0 & 0 & 0 & 0 & 0 & 0 & 0 & 0 \\
\hline 26-Nov-03 & $7-\mathrm{Nov} 07$ & 1 & 1 & 0 & 0 & 0 & 0 & 0 & 0 & 0 & 0 & 0 \\
\hline
\end{tabular}




\begin{tabular}{|c|c|c|c|c|c|c|c|c|c|c|c|c|c|c|c|c|c|c|}
\hline AssetlD & Location \pm & MakelD & $\nabla$ ModellD & चSerial Number & $\nabla$ Description & Date II & Date Riv: & & & & & & & & & & & 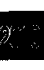 \\
\hline$E M / 350$ & Emergency & Nellcor-Mallincrodt & $N-65$ & G06836674 & Pulse Oximeter & 26-Nov-03 & & 1 & 1 & 1 & 1 & 1 & 0 & 0 & 0 & 0 & 0 & 0 \\
\hline EM/351 & Emergency & Nellcor-Mallincrodt & $N-65$ & G06836629 & Pulse Oximeter & 26-Nov-03 & & 1 & 1 & 1 & 1 & 1 & 0 & 0 & 0 & 0 & 0 & 0 \\
\hline EM/352 & Emergency & Nellcor-Mallincrodt & $N-65$ & G06836640 & Pulse Oximeter & 26-Nov-03 & & 1 & 1 & 1 & 1 & 1 & 0 & 0 & 0 & 0 & 0 & 0 \\
\hline EM/353 & Emergency & Nellcor-Mallincrodt & $N-65$ & G06836638 & Puise Oximeter & $26-\mathrm{Nov}-03$ & & 1 & 1 & 1 & 1 & 1 & 0 & 0 & 0 & 0 & 0 & 0 \\
\hline EM/365 & Emergency & Nellcor-Mallincrodt & $N-600$ & G06835182 & Pulse Oximeter & $26-\mathrm{Nov}-03$ & & 1 & 1 & 1 & 1 & 1 & 0 & 0 & 0 & 0 & 0 & 0 \\
\hline EM/368 & Emergency & Nellcor-Mallincrodt & $N-600$ & G06831535 & Pulse Oximeter & 26-Now-03 & & 1 & 1 & 1 & 1 & 1 & 0 & 0 & 0 & 0 & 0 & 0 \\
\hline EM/373 & Emergency & Nellcor-Mallincrodt & $N-85$ & '97514760 & Monitor, Capnograph/Pulse Oximeter & 27-Nov-08 & & 0 & 0 & 0 & 1 & 1 & 0 & 0 & 0 & 0 & 2 & 0 \\
\hline EM/814 & Emergency & Hewlett Packard & Mtoo8B & DE91106314 & Module, NIBP & 10-Mar-05 & $26 / 02108$ & 1 & 1 & 1 & 1 & 1 & 0 & 0 & 0 & 0 & 0 & 0 \\
\hline EM/816 & Emergency & Hewlett Packard & $\mathrm{Mi116B}$ & $4011 A 00148$ & Module, Recorder & 10-Mar-05 & $26 / 02 / 08$ & 1 & 1 & 1 & 1 & 1 & 0 & 0 & 0 & 0 & 0 & 0 \\
\hline EM/825 & Emergency & Nellcor-Mallincrodt & NPB-40 & G05887064 & Pulse Oximeter & 12-Sep-05 & & 0 & 1 & 1 & 1 & 1 & 0 & 0 & 0 & 0 & 0 & 0 \\
\hline EM/826 & Emergency & Nellcor-Mallincrodt & NPB-40 & G05887063 & Pulse Oximeter & $12-\operatorname{Sep}-05$ & & 0 & 1 & 1 & 1 & 1 & 0 & 0 & 0 & 0 & 0 & 0 \\
\hline EM/832 & Emergency & GE & 1000 & $030 \mathrm{M} 1980018$ & Monitor, Vital Signs & 14-Aug-03 & & 1 & 1 & 1 & 1 & 1 & 0 & 0 & 1 & 0 & 0 & 0 \\
\hline EM/833 & Emergency & Drager & MS18597 & 5399017659 & Monitor, Physiological & 30-Apr-08 & & 0 & 0 & 0 & 1 & 1 & 0 & 0 & 0 & 3 & 0 & 0 \\
\hline EM/837 & Emergency & Drager & MS18597 & 5399009356 & Monitor, Physiological & 30-Mar-08 & & 0 & 0 & 0 & 1 & 1 & 0 & 0 & 0 & 0 & 0 & 0 \\
\hline EM/839 & Emergency & Drager & MS18597 & 5399038057 & Monitor, Physiological & 30-Mar-08 & & 0 & 0 & 0 & 1 & 1 & 0 & 0 & 0 & 0 & 0 & 0 \\
\hline EM/841 & Emergency & Drager & MS 18597 & 5399044451 & Monitor, Physiological & 30-Mar-08 & & 0 & 0 & 0 & 1 & 1 & 0 & 0 & 0 & 1 & 0 & 0 \\
\hline EM/843 & Emergency & Drager & $7862696 \mathrm{E} 559 \mathrm{U}$ & S10727001893 & Module, End-tidal $\mathrm{CO} 2$ pod, microstream & 30-Mar-08 & & 0 & 0 & 0 & 1 & 1 & 0 & 0 & 0 & 0 & 0 & 0 \\
\hline EM/844 & Emergency & Drager & 7862696 E559U & 510727001870 & Module, End-idal $\mathrm{CO}$ pod, microstream & 30-Mar-08 & & 0 & 0 & 0 & 1 & 1 & 0 & 0 & 0 & 0 & 0 & 0 \\
\hline EM/846 & Emergency & Drager & $7862696 \mathrm{E} 559 \mathrm{U}$ & S10723001808 & Module, End-tidal $\mathrm{CO} 2$ pod, microstream & 30-Mar-08 & & 0 & 0 & 0 & 1 & 1 & 0 & 0 & 0 & 0 & 0 & 0 \\
\hline EM/849 & Emergency & Drager & $7862696 \mathrm{E} 559 \mathrm{U}$ & S10723001828 & Module, End-tidal $\mathrm{CO} 2$ pod, microstream & 30-Mar-08 & & 0 & 0 & 0 & 1 & 1 & 0 & 0 & 0 & 0 & 0 & 0 \\
\hline EM/864 & Emergency & Drager & MS18623 & 5750094571 & Monitor, Physiological & 15-Jul-08 & & 0 & 0 & 0 & 0 & 1 & 0 & 0 & 0 & 0 & 0 & 0 \\
\hline EM/865 & Emergency & Drager & $M S 18623$ & 5750094767 & Monitor, Physiological & 15-Jul-08 & & 0 & 0 & 0 & 0 & 1 & 0 & 0 & 0 & 0 & 0 & 0 \\
\hline EM/866 & Emergency & Drager & MS18623 & 5750094669 & Monitor, Physiological & 15-Jul-08 & & 0 & 0 & 0 & 0 & 1 & 0 & 0 & 0 & 0 & 0 & 0 \\
\hline EM/867 & Emergency & Drager & MS18623 & 5750090967 & Monitor, Physiological & 15.Jul-08 & & 0 & 0 & 0 & 0 & 1 & 0 & 0 & 0 & 0 & 0 & 0 \\
\hline EM/868 & Emergency & Drager & MS18623 & 5750091868 & Monitor, Physiological & 15.Jul-08 & & 0 & 0 & 0 & 0 & 1 & 0 & 0 & 0 & 0 & 0 & 0 \\
\hline EM/869 & Emergency & Drager & MS18623 & 5750092965 & Monitor, Physiological & 15-Jull-08 & & 0 & 0 & 0 & 0 & 1 & 0 & 0 & 0 & 0 & 0 & 0 \\
\hline EM/871 & Emergency & $G E$ & v100 & SDT08300026SP & Monitor, Vital Signs & 28-Aug-08 & & 0 & 0 & 0 & 0 & 1 & 0 & 0 & 0 & 0 & 0 & 0 \\
\hline EM/872 & Emergency & GE & $v 100$ & SDT08300030SP & Monitor, Vital Signs & 28-Aug-08 & & 0 & 0 & 0 & 0 & 1 & 0 & 0 & 0 & 0 & 0 & 0 \\
\hline EM/873 & Emergency & GE & v100 & SDT08300032SP & Monitor, Vital Signs & 28-Aug-08 & & 0 & 0 & 0 & 0 & 1 & 0 & 0 & 0 & 0 & 1 & 0 \\
\hline EM/874 & Emergency & GE & v100 & SDT08300015SP & Monitor, Vital Signs & 28-Aug-08 & & 0 & 0 & 0 & 0 & 1 & 0 & 0 & 0 & 0 & 2 & 0 \\
\hline
\end{tabular}




\begin{tabular}{|c|c|c|c|}
\hline AssetlD & Locati & Make|D & $\nabla$ ModellD \\
\hline IC/143 & PICU & Hewlett Packard & $M 1002 \mathrm{~A}$ \\
\hline IC/144 & PICJ & Hewlett Packard & M1006A \\
\hline $1 \mathrm{C} / 148$ & PICU & Hewtett Packard & M1046A \\
\hline IC/149 & $\mathrm{PICU}$ & Hewiett Packard & $M 1002 A$ \\
\hline $\mid C / 150$ & PICU & Hewlett Packard & M1006A \\
\hline $\mid C / 154$ & $\mathrm{PICU}$ & Hewlett Packard & $M \div 046 \mathrm{~A}$ \\
\hline $\mid C / 155$ & PICU & Hewlett Packard & Mi002A \\
\hline IC/157 & PICU & Hewlett Packard & M1006A \\
\hline $\mathrm{IC} / 160$ & PICU & Hewlett Packard & M1046A \\
\hline $\mid C / 161$ & PICU & Hewlett Packard & $M 1002 \mathrm{~A}$ \\
\hline$I_{C} / 162$ & PICU & Hewlett Packard & M1006A \\
\hline $\mathbb{I C} / 166$ & PICU & Hewlett Packard & M1046A \\
\hline $\mid C / 167$ & $\mathrm{PICU}$ & Hewlett Packard & M1002A \\
\hline $\mathrm{IC} / 169$ & PICU & Hewlett Packard & $1006 \mathrm{~A}$ \\
\hline IC/172 & PICU & Hewett Packard & $1046 \mathrm{~A}$ \\
\hline $\mathrm{IC} / 173$ & PICU & Hewlett Packard & M1002A \\
\hline $\mathrm{IC} / 175$ & PICU & Hewlett Packard & M1006A \\
\hline IC/177 & $\mathrm{PICU}$ & Hewett Packard & M1006A \\
\hline $\mathrm{IC} / 778$ & $\mathrm{PICU}$ & Hewlett Packard & M1006A \\
\hline IC/179 & PICU & Hewlett Packard & M1006A \\
\hline IC/180 & $\mathrm{PICU}$ & Hewlett Packard & M1006A \\
\hline IC/181 & $P \mid C U$ & Hewlett Packard & M1006A \\
\hline IC/195 & PICU & Hewlett Packard & M1008A \\
\hline $\mid C / 196$ & $\mathrm{PICU}$ & Hewlett Packard & M1008A \\
\hline IC/204 & $P I C U$ & Hewlett Packard & M1020A \\
\hline $10 / 205$ & PICU & Hewlett Packard & M1020A \\
\hline $10 / 206$ & $\mathrm{PICU}$ & Hewlett Packard & M1020A \\
\hline $10 / 207$ & PICU & Hewlett Packard & M1020A \\
\hline $10 / 208$ & PICU & Hewlett Packard & M1020A \\
\hline $10 / 209$ & $P I C U$ & Hewlett Packard & M1020A \\
\hline
\end{tabular}

\begin{tabular}{|c|c|}
\hline Serial Number & Description \\
\hline $2926 A 02774$ & MODULE,ECG/RESPIRATTON \\
\hline $2922 A 09930$ & MODULE,NVASIVE PRESSURE \\
\hline $2924 A 04478$ & MONTOR,CPU SECTION \\
\hline $2926 A 02768$ & MODULE,ECG/RESPIRATON \\
\hline $2922 A 09937$ & MODULE,NVVASIVE PRESSURE \\
\hline $2924 A 04475$ & MONTOR,CPU SECTION \\
\hline 2926A02772 & MODULE,ECG/RESPIRATION \\
\hline $2922 A 09929$ & MODULE,INVASIVE PRESSURE \\
\hline $2924 A 04479$ & MONITOR,CPU SECTION \\
\hline 2926A02647 & MODULE,ECG/RESPIRATION \\
\hline $2922 A 00003$ & MODULE,INVASIVE PRESSURE \\
\hline 2924404477 & MONTOR,CPU SECTION \\
\hline 2926402648 & MODULE,ECG/RESPIRATON \\
\hline 22922409932 & MODULE,INVASIVE PRESSURE \\
\hline 2924404476 & MONTOR,CPU SECTION \\
\hline 2926402649 & MOOULE,ECG/RESPIRATON \\
\hline 2922409005 & MODULE,INVASIVE PRESSURE \\
\hline $2922 A 00370$ & MODULE,INVASIVE PRESSURE \\
\hline 2922A09938 & MODULE,INVASIVE PRESSURE \\
\hline $2922 A 00002$ & MODULE,INVASIVE PRESSURE \\
\hline 2922409004 & MODULE,INVASIVE PRESSURE \\
\hline 2922400006 & MODULE,INVASIVE PRESSURE \\
\hline $3805 A 70503$ & MODULE,N.IB.P. \\
\hline $3029 A 06783$ & MODULE,N.IB.P. \\
\hline 3039A07667 & MODULE,SAO2/PLETH \\
\hline 3039A07677 & MODULE,SAOZPLETH \\
\hline 303907678 & MODULE,SAOZPLETH \\
\hline 3039A07679 & MODULE,SAOZ/PLETH \\
\hline $3039 A 07683$ & MODULE,SAO2PLETH \\
\hline 3039A07682 & MODULE,SAOZPLETH \\
\hline
\end{tabular}

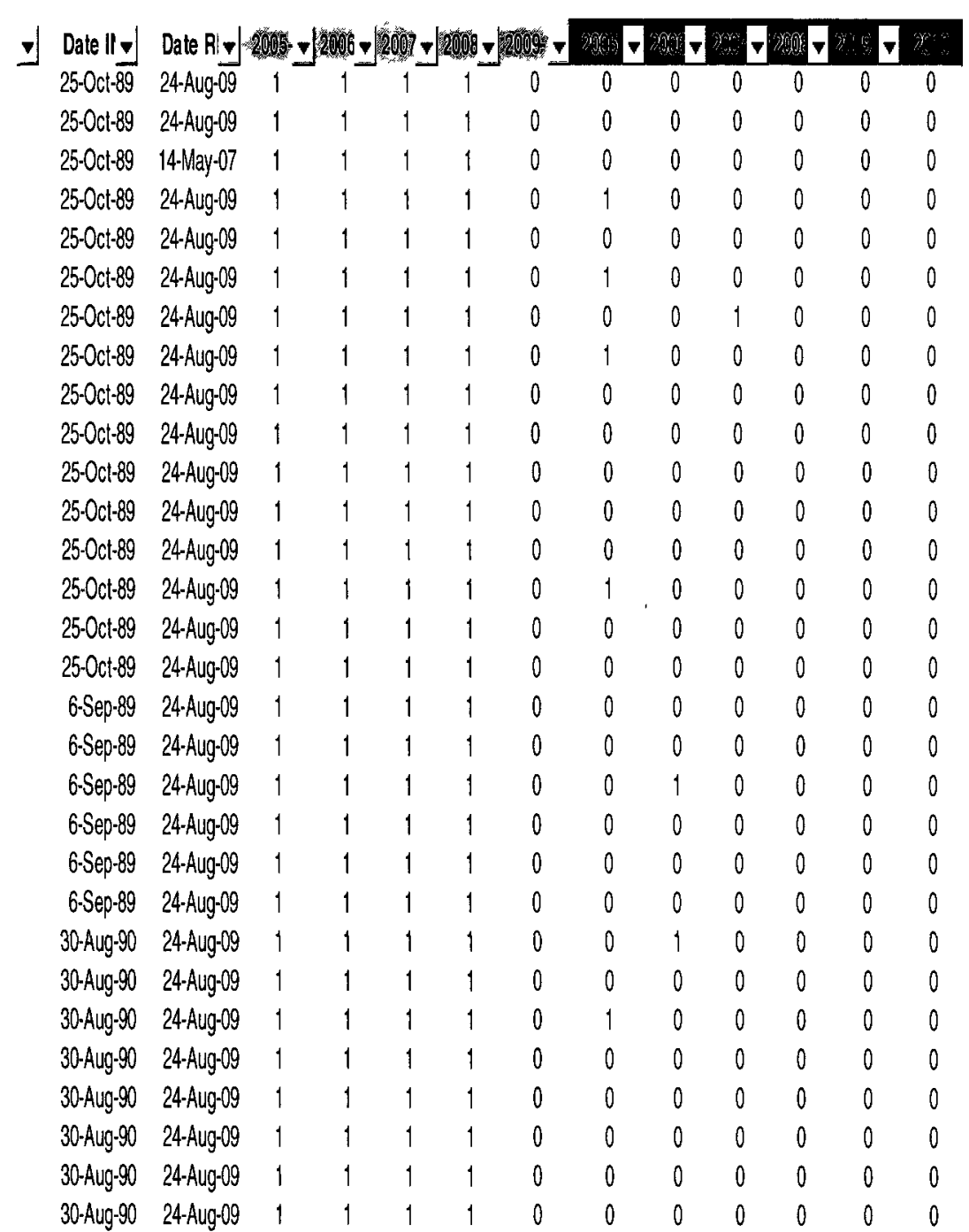




\begin{tabular}{|c|c|c|c|c|c|c|c|c|c|c|c|c|c|c|c|c|c|c|}
\hline AssettD & $\checkmark$ Location & MakelD & V|ModellD & Serial Number & Description & Date IIV] & $e^{\mathrm{h}}$ & & & & & & & & & $86 \mathrm{Y}$ & & \\
\hline EM/875 & Emergency & GE & $\sqrt{100}$ & SDT08300067SP & Monitor, Vita Signs & 28-Aug-08 & & 0 & 0 & 0 & 0 & 1 & 0 & 0 & 0 & 0 & 2 & 0 \\
\hline EM/892 & Emergency & Drager & MS18597 & 5398995549 & Monitor, Physiological & 18-Sep-09 & & 0 & 0 & 0 & 0 & 1 & 0 & 0 & 0 & 0 & 0 & 0 \\
\hline EM/902 & Emergency & Drager & MS 18597 & '5398998644 & Monitor, Physiological & 18-Sep-09 & & 0 & 0 & 0 & 0 & 1 & 0 & 0 & 0 & 0 & 1 & 0 \\
\hline EM/908 & Emergency & Drager & MS18597 & 5399018453 & Monitor, Physiological & 18-Sep-09 & & 0 & 0 & 0 & 0 & 1 & 0 & 0 & 0 & 0 & 0 & 1 \\
\hline EM/gog & Emergency & Drager & MS18597 & 6000919965 & Monitor, Physiological & 18-Sep-09 & & 0 & 0 & 0 & 0 & 1 & 0 & 0 & 0 & 0 & 0 & 0 \\
\hline EM/916 & Emergency & Drager & MS18597 & 6000936964 & Monitor, Physiological & 18-Sep-09 & & 0 & 0 & 0 & 0 & 1 & 0 & 0 & 0 & 0 & 0 & 0 \\
\hline EM/923 & Emergency & Drager & MS18597 & 5398878649 & Monitor, Physiological & 18-Sep-09 & & 0 & 0 & 0 & 0 & 1 & 0 & 0 & 0 & 0 & 0 & 0 \\
\hline EM/926 & Emergency & Drager & MS18597 & '5399958946 & Monitor, Physiological & 18-Sep-09 & & 0 & 0 & 0 & 0 & 1 & 0 & 0 & 0 & 0 & 0 & 0 \\
\hline EM/929 & Emergency & Drager & MS18597 & 5398888647 & Monitor, Physiological & 18-Sep-09 & & 0 & 0 & 0 & 0 & 1 & 0 & 0 & 0 & 0 & 0 & 0 \\
\hline 101025 & PICU & Hewlett Packard & M1012A & 2924400474 & MODULE,CARDIAC OUTPUT & 11-Jan-90 & 24-Aug-09 & 1 & 1 & 1 & 1 & 0 & 0 & 0 & 0 & 0 & 0 & 0 \\
\hline IC/116 & PICU & Hewlett Packard & M1046A & 2924A0472 & MONITOR,CPU SECTION & $25-0 c t-89$ & 24.Aug-09 & 1 & 1 & 1 & 1 & 0 & 0 & 2 & 0 & 0 & 0 & 0 \\
\hline IC/117 & PICU & Hewlett Packard & M1020A & 2922A01923 & MODULE,SAOZPLETH & $25-0 c t-89$ & 24-Aug-09 & 1 & 1 & 1 & 1 & 0 & 1 & 1 & 0 & 0 & 0 & 0 \\
\hline IC/119 & PICU & Hewlett Packard & M1006A & $3731 A 45332$ & MOOULE,NNASIVE PRESSURE & $25-0 c 1-89$ & 24-Aug-09 & 1 & 1 & 1 & 1 & 0 & 0 & 1 & 0 & 0 & 0 & 0 \\
\hline $10 / 120$ & PICU & Hewlett Packard & M1002A & 2926A02770 & MODULE,ECG/RESPIRATION & $25-0 c t-89$ & 24-Aug-09 & 1 & 1 & 1 & 1 & 0 & 0 & 1 & 0 & 0 & 0 & 0 \\
\hline $1 / 123$ & PICU & Hewett Packard & M1002A & 2926A02771 & MODULE,ECG/RESPIRATON & $25-0 \mathrm{ct}-89$ & 24Aug.09 & 1 & 1 & 1 & 1 & 0 & 0 & 0 & 0 & 0 & 0 & 0 \\
\hline $\mid C / 124$ & PICU & Hewlett Packard & M1008A & 3226A07383 & MODULE,N.I.B.P. & 24-vun-93 & 24-Aug-09 & 1 & 1 & 1 & 1 & 0 & 0 & 0 & 3 & 2 & 0 & 0 \\
\hline IC126 & PIOU & Hewlett Packard & M1006A & 2922A09931 & MODULE,INVASIVE PRESSURE & $25-0 \mathrm{ct}-89$ & 24-Aug-09 & 1 & 1 & 1 & 1 & 0 & 0 & 0 & 0 & 0 & 0 & 0 \\
\hline $\mid C / 128$ & PICU & Hewlett Packard & M1046A & 2924A04733 & MONTOR,CPU SECTION & $25-0 c t-89$ & 24-Aug-09 & 1 & 1 & 1 & 1 & 0 & 0 & 0 & 0 & 0 & 0 & 0 \\
\hline $\mid C / 129$ & PICU & Hewlett Packard & M1002A & $2926 A 02776$ & MODULE,ECG/RESPIRATION & $25-0 c t-89$ & 24-Aug-09 & 1 & 1 & 1 & 1 & 0 & 1 & 0 & 0 & 0 & 0 & 0 \\
\hline $\mid \mathrm{C} / 130$ & PICU & Hewlett Packard & M1006A & 2922A09935 & MODULE,INVASIVE PRESSURE & $25-0 \mathrm{ct}-89$ & 24-Aug-09 & 1 & 1 & 1 & 1 & 0 & 0 & 0 & 0 & 0 & 0 & 0 \\
\hline $\mid C / 136$ & PICU & Hewhett Packard & M1046A & 2924404481 & MONITOR,CPU SECTION & $25-0 c t-89$ & 24-Aug-09 & 1 & 1 & 1 & 1 & 0 & 0 & 0 & 0 & 0 & 0 & 0 \\
\hline $\mid C / 137$ & PICU & Hewlett Packard & M1002A & $2926 \mathrm{A02775}$ & MODULE,ECGIRESPIRATON & $25-0 c t-89$ & 24-Aug-09 & 1 & 1 & 1 & 1 & 0 & 0 & 0 & 0 & 0 & 0 & 0 \\
\hline
\end{tabular}




\begin{tabular}{|c|c|c|c|}
\hline AssettD & Loca & MakelD & \\
\hline C/143 & PICU & Hewlett Packard & \\
\hline $1 / 144$ & PICU & Hewlett Packard & \\
\hline 148 & PICU & Hewlett Packard & \\
\hline 149 & PICU & Hewett Packard & \\
\hline 150 & PICU & Hewlett Packard & \\
\hline 154 & PICU & Hewlett Packard & \\
\hline 155 & PICU & Hewlett Packard & \\
\hline$/ 157$ & PICU & Hewlett Packard & \\
\hline 160 & PICU & Hewlett Packard & \\
\hline$y / 161$ & PICU & Hewlett Packard & \\
\hline 1162 & PICU & Hewlett Packard & \\
\hline 166 & PICU & Hewlett Packard & \\
\hline $1 / 167$ & PICU & Hewett Packard & \\
\hline $1 / 69$ & PICU & Hewlett Packard & \\
\hline$y / 172$ & PICU & Hewlett Packard & \\
\hline$: / 173$ & PICU & Hewett Packard & \\
\hline $1 / 175$ & PICU & Hewlett Packard & \\
\hline $1 / 177$ & PICU & Hewlett Packard & \\
\hline$y / 178$ & PICU & Hewlett Packard & \\
\hline$/ / 79$ & PICU & Hewlett Packard & \\
\hline$/ 1 / 180$ & PICU & Hewlett Packard & \\
\hline $1 / 181$ & PICU & Hewlett Packard & \\
\hline$/ 195$ & PICU & Hewlett Packard & \\
\hline$/ 196$ & PICU & Hewlett Packard & \\
\hline $1 / 204$ & PICU & Hewlett Packard & \\
\hline $1 / 205$ & PICU & Hewlett Packard & \\
\hline $1 / 206$ & PICU & Hewett Packard & \\
\hline $1 / 207$ & PICU & Hewlett Packard & \\
\hline $1 / 208$ & PICU & Hewlett Packard & \\
\hline 1209 & PICU & Hewlett Packard & \\
\hline
\end{tabular}

\begin{tabular}{|c|c|}
\hline VSerial Number & Description \\
\hline $2926 A 02774$ & MODULE, ECGIRESPIRATON \\
\hline 2922A09930 & MODULE,NNVASIVE PRESSURE \\
\hline 2924404478 & MONTOR,CPU SECTION \\
\hline 2926A02768 & MODULE,ECG/RESPIRATION \\
\hline 2922A09937 & MODULE,|NVASIVE PRESSURE \\
\hline $2924 A 04475$ & MONTOR,CPU SECTION \\
\hline $2926 A 02772$ & MOOULE,ECGIRESPIRATON \\
\hline 2922A09929 & MODULE,NNVASIVE PRESSURE \\
\hline $2924 A 04479$ & MONTOR,CPU SECTION \\
\hline 2926A02647 & MODULE,ECGIRESPRATION \\
\hline $2922 A 09003$ & MODULE,INVASIVE PRESSURE \\
\hline 2924404477 & MONITOR,CPU SECTON \\
\hline 2926A02648 & MODULE,ECGRESPIRATION \\
\hline 222922A09932 & MOOULE,INVASNE PRESSURE \\
\hline $2924 A 04776$ & MONTOR,CPU SECTION \\
\hline 2926A02649 & MOOULE,ECG/RESPIRATION \\
\hline $2922 A 09005$ & MODULE,NNASNE PRESSURE \\
\hline $2922 A 00370$ & MODULE,NNASNE PRESSURE \\
\hline 2922409938 & MODULE,INVASNE PRESSURE \\
\hline $2922 A 09002$ & MODULE,NNVASVE PRESSURE \\
\hline 2922A09004 & MODULE,NNVASNE PRESSURE \\
\hline 2922A09006 & MODULE,NNVASIVE PRESSURE \\
\hline $3805 A 70503$ & MODULE,N.B.B.P. \\
\hline 3029A06783 & MODULE,N.IB.P. \\
\hline $3039 A 07667$ & MODULE,SAOZ2PLETH \\
\hline 3039A07677 & MODULE,SAO2PLETH \\
\hline 303907678 & MOOULE,SAO2PLETH \\
\hline 3039A07679 & MODULE,SAO2PLETH \\
\hline 3039A07683 & MODULE,SAO2PLETH \\
\hline 3039A07682 & MODULE,SAO2PLETH \\
\hline
\end{tabular}

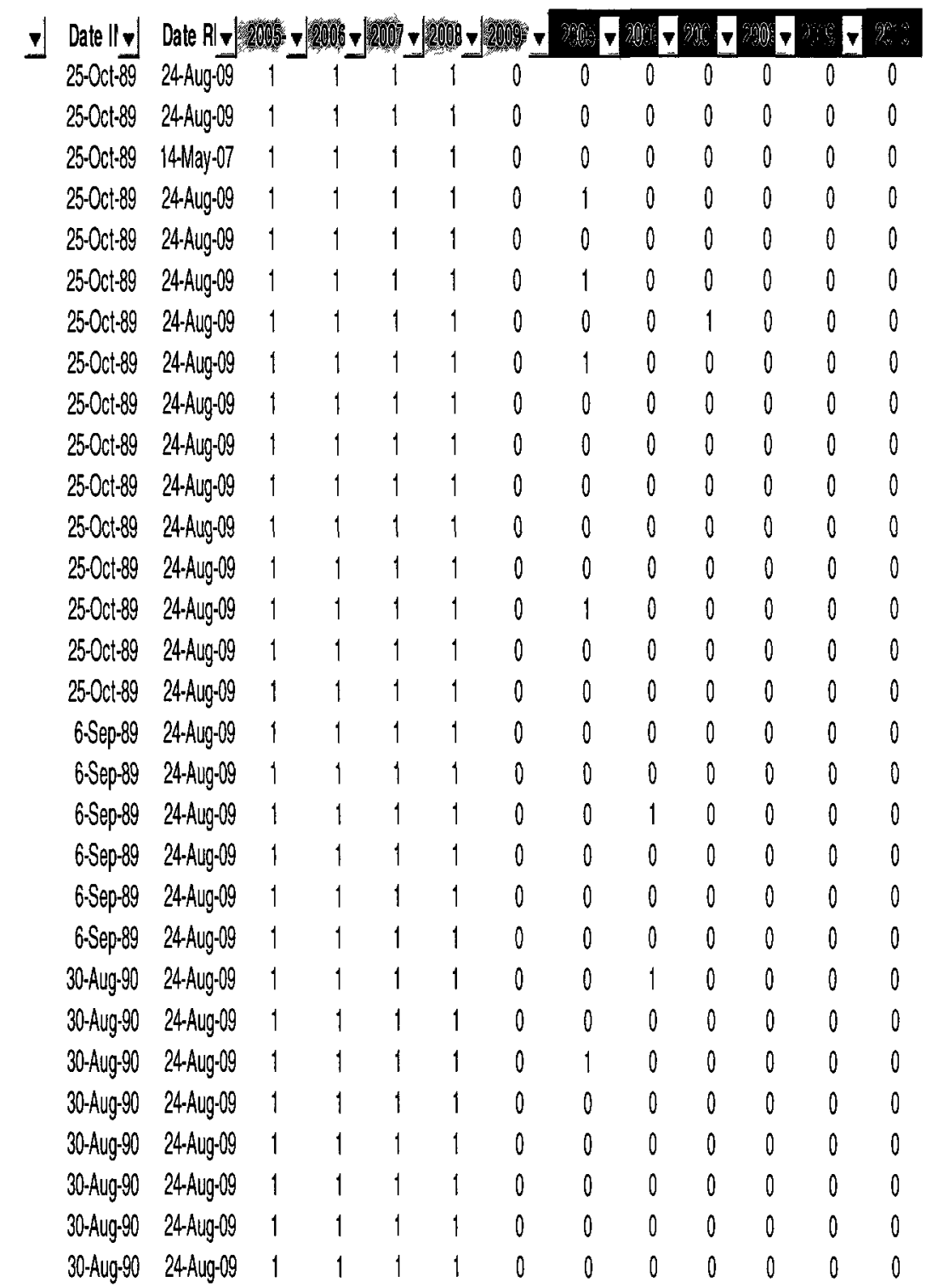




\begin{tabular}{|c|c|c|c|c|c|}
\hline Assetid & Location & MakelD & VodellD & $\nabla$ Serial Number & - Description \\
\hline $1 \mathrm{C} / 233$ & PICU & Hewlett Packard & M1006A & $3126 A 4225$ & MODULE, NVVASNE PRESSURE \\
\hline IC/234 & PICU & Hewlett Packard & M1006A & $3126 \mathrm{A42212}$ & MODULE,INVASIVE PRESSURE \\
\hline $\mid C / 235$ & PICU & Hewlett Packard & M1006A & $3126 \mathrm{~A} 42213$ & MODULE,INVASIVE PRESSURE \\
\hline $1 \mathrm{C} / 236$ & PICU & Hewlett Packard & M1006A & $3126 A 42224$ & MODULE,INVASIVE PRESSURE \\
\hline $\mid C / 237$ & PICU & Hewlett Packard & M1006A & $3126 A 42222$ & MODULE,INVASIVE PRESSURE \\
\hline $1 \mathrm{C} / 238$ & PICU & Hewlett Packard & M1006A & $3126 A 42216$ & MODULE,INVASIVE PRESSURE \\
\hline $1 \mathrm{C} / 239$ & PICU & Hewlett Packard & M1006A & $3126 A 42211$ & MODULE,INVASNE PRESSURE \\
\hline $1 \mathrm{C} / 250$ & PICU & Hewlett Packard & M1008B & $3209 A 01837$ & MODULE,N.I.B.P. \\
\hline $\mid C / 251$ & PICU & Hewlett Packard & M1008B & $3516 A 31016$ & MODULE,N.I.B.P. \\
\hline $\mid \mathrm{C} / 261$ & PICU & Hewlett Packard & M1006A & $3218 A 29259$ & MODULE,INVASIVE PRESSURE \\
\hline $\mid \mathrm{C} / 262$ & PICU & Hewlett Packard & M1006A & $3218 A 47290$ & MODULE,INVASIVE PRESSURE \\
\hline $1 \mathrm{C} / 270$ & $\mathrm{PICU}$ & Hewlett Packard & M1046A & $3110 A 17723$ & MONITOR,CPU SECTION \\
\hline IC/272 & PICU & Hewlett Packard & M1046A & $3130 A 23436$ & MONITOR,CPU SECTION \\
\hline IC/333 & PICU & Hewlett Packard & M1008B & $3413 A 19039$ & MODULE,N.I.B.P. \\
\hline IC/334 & PICU & Hewlett Packard & M1008B & $3523 A 47505$ & MODULE,N.I.B.P. \\
\hline $1 \mathrm{C} / 335$ & PICU & Hewlett Packard & M1008A & $3251 A 06776$ & MODULE,N.I.B.P. \\
\hline $1 \mathrm{C} / 460$ & PICU & Nellcor-Mallincrodt & $N-65$ & G06803389 & Pulse Oximeter \\
\hline IC/475 & PICU & Nellcor-Mallincrodt & N-65 Oximax & G06834097 & Pulse Oximeter \\
\hline IC/476 & PICU & Nellcor-Mallincrodt & $N-600$ & G06831499 & Pulse Oximeter \\
\hline IC/495 & PICU & Nellcor-Mallincrodt & $\mathrm{N} \cdot 2 \mathrm{O}$ & G00853602 & Pulse Oximeter \\
\hline $10 / 768$ & PICU & Drager & MS18596 & 6001025475 & Monitor, Physiological \\
\hline IC/769 & PICU & Drager & MS 18596 & 6001026777 & Monitor, Physiological \\
\hline $10 / 770$ & PICU & Drager & MS18596 & 6001011285 & Monitor, Physiological \\
\hline $\mid \mathrm{I} / 771$ & PICU & Drager & MS18596 & 6000961473 & Monitor, Physiological \\
\hline $1 \mathrm{C} / 772$ & PICU & Drager & MS 18596 & 6000961776 & Monitor, Physiological \\
\hline ICIT73 & PICU & Drager & MS18596 & 6000963872 & Monitor, Physiological \\
\hline $\mathrm{ICI} / 774$ & PICU & Drager & MS18596 & 6001047077 & Monitor, Physiological \\
\hline $1 \mathrm{CI} 775$ & PICU & Drager & MS18596 & 6001025083 & Monitor, Physiological \\
\hline $1 \mathrm{C} / 776$ & PICU & Drager & MS18596 & 6000956773 & Monitor, Physiological \\
\hline $\mathrm{IC} / 77$ & PICU & Drager & MS18596 & 6000959770 & Monitor, Physiological \\
\hline
\end{tabular}

\begin{tabular}{|c|c|c|c|c|c|c|c|c|c|c|c|c|}
\hline $\begin{array}{l}\text { Date } \| \nabla \mid \\
\text { 18-Dec-91 }\end{array}$ & $\begin{array}{l}\text { Uate } \mathrm{R}-\mathrm{\nabla} \\
\text { 24-Aug-09 }\end{array}$ & 1 & 1 & 1 & 1 & 0 & 0 & 0 & 0 & 0 & 0 & 0 \\
\hline 18-Dec-91 & 24-Aug-09 & 1 & 1 & 1 & 1 & 0 & 0 & 0 & 0 & 0 & 0 & 0 \\
\hline 18-Dec-91 & 24-Aug-09 & 1 & 1 & 1 & 1 & 0 & 0 & 0 & 0 & 0 & 0 & 0 \\
\hline 18-Dec-91 & 24-Aug-09 & 1 & 1 & 1 & 1 & 0 & 0 & 0 & 0 & 0 & 0 & 0 \\
\hline 18-Dec-91 & 24-Aug-09 & 1 & 1 & 1 & 1 & 0 & 0 & 0 & 1 & 0 & 0 & 0 \\
\hline 18-Dec-91 & 24-Aug-09 & 1 & 1 & 1 & 1 & 0 & 0 & 0 & 1 & 0 & 0 & 0 \\
\hline 18-Dec-91 & 24-Aug-09 & 1 & 1 & 1 & 1 & 0 & 0 & 0 & 0 & 0 & 0 & 0 \\
\hline 15-Apr-92 & 24-Aug-09 & 1 & 1 & 1 & 1 & 0 & 0 & 0 & 0 & 0 & 0 & 0 \\
\hline 5-Jan-96 & 24-Aug-09 & 1 & 1 & 1 & 1 & 0 & 0 & 1 & 0 & 0 & 0 & 0 \\
\hline $21-$ May-92 & 24-Aug-09 & 1 & 1 & 1 & 1 & 0 & 0 & 1 & 0 & 0 & 0 & 0 \\
\hline 21-May-92 & 24-Aug-09 & 1 & 1 & 1 & 1 & 0 & 0 & 0 & 0 & 0 & 0 & 0 \\
\hline 5-Jun-92 & 24-Aug-09 & 1 & 1 & 1 & 1 & 0 & 0 & 0 & 1 & 0 & 0 & 0 \\
\hline 5-Jun-92 & 24-Aug-09 & 1 & 1 & 1 & 1 & 0 & 0 & 0 & 0 & 0 & 0 & 0 \\
\hline 29-Aug-96 & 24-Aug-09 & 1 & 1 & 1 & 1 & 0 & 1 & 0 & 0 & 0 & 0 & 0 \\
\hline 29-Aug-96 & 24-Aug-09 & 1 & 1 & 1 & 1 & 0 & 0 & 1 & 0 & 0 & 0 & 0 \\
\hline 29-Aug-96 & 24-Aug-09 & 1 & 1 & 1 & 1 & 0 & 0 & 1 & 0 & 0 & 0 & 0 \\
\hline 5-Jan-06 & & 1 & 1 & 1 & 1 & 1 & 1 & 0 & 0 & 0 & 0 & 1 \\
\hline 23-Jan-07 & & 0 & 0 & 1 & 1 & 1 & 0 & 0 & 0 & 0 & 0 & 0 \\
\hline 23.Jan-07 & & 0 & 0 & 1 & 1 & 1 & 0 & 0 & 0 & 0 & 0 & 0 \\
\hline 27-Jan-01 & & 0 & 0 & 1 & 1 & 1 & 0 & 0 & 0 & 1 & 0 & 0 \\
\hline 28-Aug-09 & & 0 & 0 & 0 & 0 & 1 & 0 & 0 & 0 & 0 & 0 & 0 \\
\hline 28-Aug-09 & & 0 & 0 & 0 & 0 & 1 & 0 & 0 & 0 & 0 & 0 & 0 \\
\hline 28-Aug-09 & & 0 & 0 & 0 & 0 & 1 & 0 & 0 & 0 & 0 & 0 & 0 \\
\hline 28-Aug-09 & & 0 & 0 & 0 & 0 & 1 & 0 & 0 & 0 & 0 & 0 & 0 \\
\hline 28-Aug-09 & & 0 & 0 & 0 & 0 & 1 & 0 & 0 & 0 & 0 & 1 & 0 \\
\hline 28-Aug-09 & & 0 & 0 & 0 & 0 & 1 & 0 & 0 & 0 & 0 & 0 & 0 \\
\hline 28-Aug-09 & & 0 & 0 & 0 & 0 & 1 & 0 & 0 & 0 & 0 & 0 & 0 \\
\hline 28-Aug-09 & & 0 & 0 & 0 & 0 & 1 & 0 & 0 & 0 & 0 & 0 & 0 \\
\hline 28-Aug-09 & & 0 & 0 & 0 & 0 & 1 & 0 & 0 & 0 & 0 & 0 & 0 \\
\hline 28-Aug-09 & & 0 & 0 & 0 & 0 & 1 & 0 & 0 & 0 & 0 & 0 & 0 \\
\hline
\end{tabular}




\begin{tabular}{|c|c|c|c|c|c|c|c|c|c|c|c|c|c|c|c|c|c|}
\hline Assetl & Location & MakelD & VIodellD & Serial Number & Description & Date $11 \mathrm{I}$ & Date $R \nabla 200$ & & & & & & & & 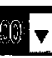 & & $y:$ \\
\hline $10 / 778$ & PICU & Drager & MS18596 & 6001041974 & Monitor, Physiological & 28-Aug-09 & 0 & 0 & 0 & 0 & 1 & 0 & 0 & 0 & 0 & 0 & 0 \\
\hline $10 / 793$ & PICU & Drager & $7862696 E 559 \mathrm{U}$ & S10909002697 & Module, End-tidal $\mathrm{CO} 2$ pod, microstream & 28-Aug-09 & 0 & 0 & 0 & 0 & 1 & 0 & 0 & 0 & 0 & 0 & 0 \\
\hline IC/794 & PICU & Drager & 7862696 E559U & S10909002702 & Module, End-tidal CO2 pod, microstream & 28-Aug-09 & 0 & 0 & 0 & 0 & 1 & 0 & 0 & 0 & 0 & 0 & 0 \\
\hline IC/795 & PICU & Drager & 7862696 E559U & S10909002691 & Module, End.tidal CO2 pod, microstream & 28-Aug-09 & 0 & 0 & 0 & 0 & 1 & 0 & 0 & 0 & 0 & 0 & 0 \\
\hline IC/796 & PICU & Drager & $7862696 \mathrm{E} 559 \mathrm{U}$ & S10909002725 & Module, End-tidal $\mathrm{CO} 2$ pod, microstream & 28-Aug-09 & 0 & 0 & 0 & 0 & 1 & 0 & 0 & 0 & 0 & 0 & 0 \\
\hline IC/797 & PICU & Drager & 7862696 E559U & S10909002701 & Module, End-tidal CO2 pod, microstream & 28-Aug-09 & 0 & 0 & 0 & 0 & 1 & 0 & 0 & 0 & 0 & 0 & 0 \\
\hline IC/798 & PICU & Drager & $7862696 \mathrm{E} 559 \mathrm{U}$ & S10909002689 & Module, End-tidal $\mathrm{CO} 2$ pod, microstream & 28-Aug-09 & 0 & 0 & 0 & 0 & 1 & 0 & 0 & 0 & 0 & 0 & 0 \\
\hline IC/799 & PICU & Drager & 7862696 E559U & S10909002714 & Module, End-tidal CO2 pod, microstream & 28-Aug-09 & 0 & 0 & 0 & 0 & 1 & 0 & 0 & 0 & 0 & 0 & 0 \\
\hline IC/800 & PICU & Drager & 7862696 E559U & S10909002676 & Module, End-tidal CO2 pod, microstream & 28-Aug-09 & 0 & 0 & 0 & 0 & 1 & 0 & 0 & 0 & 0 & 0 & 0 \\
\hline $\mid C / 801$ & PICU & Drager & $7862696 \mathrm{E} 559 \mathrm{U}$ & $\$ 10909002708$ & Module, End-iidal CO2 pod, microstream & 28-Aug-09 & 0 & 0 & 0 & 0 & 1 & 0 & 0 & 0 & 0 & 0 & 0 \\
\hline IC/804 & PICU & Drager & 558822 & 5293818753 & Ininity HemoMed & 28-Aug-09 & 0 & 0 & 0 & 0 & 1 & 0 & 0 & 0 & 0 & 0 & 0 \\
\hline $\mid C / 805$ & $\mathrm{PICU}$ & Drager & 558822 & 5293820064 & Infinity HemoMed & 28-Aug-09 & 0 & 0 & 0 & 0 & 1 & 0 & 0 & 0 & 0 & 0 & 0 \\
\hline $1 \mathrm{C} / 806$ & PICU & Drager & 558822 & 5293818450 & Ininity HemoMed & 28-Aug-09 & 0 & 0 & 0 & 0 & 1 & 0 & 0 & 0 & 0 & 0 & 0 \\
\hline IC/807 & PICU & Drager & 558822 & 5293818949 & Infinity HemoMed & 28-Aug-09 & 0 & 0 & 0 & 0 & 1 & 0 & 0 & 0 & 0 & 0 & 0 \\
\hline $\mid C / 808$ & PICU & Drager & MS17441 & 5700135078 & HemoMed-Picco & 28-Aug.09 & 0 & 0 & 0 & 0 & 1 & 0 & 0 & 0 & 0 & 0 & 0 \\
\hline $\mid C / 853$ & PICU & Drager & $7862696 \mathrm{E} 559 \mathrm{U}$ & Sl0919002999 & Module, End-tidal CO2 pod, microstream & 28-Aug-09 & 0 & 0 & 0 & 0 & 1 & 0 & 0 & 0 & 0 & 0 & 0 \\
\hline IC/854 & $\mathrm{PICU}$ & Drager & $7862696 \mathrm{E} 559 \mathrm{U}$ & S10919003000 & Module, End-tidal CO2 pod, microstream & 28-Aug.09 & 0 & 0 & 0 & 0 & 1 & 0 & 0 & 0 & 0 & 0 & 0 \\
\hline $\mid \mathrm{C} / 860$ & PICU & Drager & $7862696 \mathrm{E} 559 \mathrm{U}$ & S10927003037 & Module, End-tidal CO2 pod, microstream & 28-Aug-09 & 0 & 0 & 0 & 0 & 1 & 0 & 0 & 0 & 0 & 1 & 0 \\
\hline $\mid C / 861$ & $\mathrm{PICU}$ & Drager & $7862696 \mathrm{E} 559 \mathrm{U}$ & S10914002944 & Module, End-tidal CO2 pod, micrositream & 28-Aug-09 & 0 & 0 & 0 & 0 & 1 & 0 & 0 & 0 & 0 & 0 & 0 \\
\hline NN/551 & NICU & Hewlett Packard & M1002A & $3523 A 44901$ & Module, ECG/respiration & $29-A u g-96$ & 1 & 1 & 1 & 1 & 1 & 0 & 0 & 0 & 0 & 0 & 0 \\
\hline NN/552 & $\mathrm{NCU}$ & Hewlett Packard & M1020A & $3616 A 58606$ & Module, Saorspleth & 29-Aug-96 & 1 & 1 & 1 & 1 & 1 & 0 & 0 & 0 & 0 & 0 & 0 \\
\hline$N N / 553$ & $\mathrm{NCU}$ & Hewlett Packard & M1008B & $3523 A 47544$ & Module, N.I.B.P. & 29-Aug-96 & 1 & 1 & 1 & 1 & 1 & 0 & 0 & 0 & 0 & 0 & 0 \\
\hline NN/554 & $\mathrm{NCU}$ & Hewlett Packard & M1204A & $3628 \mathrm{A09901}$ & Monitor, Video, Colour & 29-Aug-96 & 1 & 1 & 1 & 1 & 1 & 0 & 0 & 0 & 0 & 0 & 0 \\
\hline NN/556 & $\mathrm{NICU}$ & Hewlett Packard & M1002A & $3727 a 26120$ & Module, ECG/respiration & 29-Aug.96 & 1 & 1 & 1 & 1 & 1 & 0 & 0 & 0 & 0 & 0 & 0 \\
\hline $\mathrm{NN} / 557$ & NICU & Hewlett Packard & M1020A & 3616458759 & Module, Sao2/pleth & 29-Aug-96 & 1 & 1 & 1 & 1 & 1 & 0 & 0 & 0 & 0 & 0 & 0 \\
\hline NN/558 & $\mathrm{NICU}$ & Hewlett Packard & M1008B & 3523447595 & Module, N.I.B.P. & 29-Aug-96 & 1 & 1 & 1 & 1 & 1 & 0 & 0 & 0 & 0 & 0 & 0 \\
\hline NN/559 & NICU & Hewlett Packard & M1204A & 3628409905 & Monitor, Video, Colour & 29-Aug-96 & 1 & 1 & 1 & 1 & 1 & 0 & 0 & 0 & 0 & 0 & 0 \\
\hline $\mathrm{NN} / 561$ & NICU & Hewlett Packard & M1002A & $3523 A 44961$ & Module, ECG/respiration & 29-Aug-96 & 1 & 1 & 1 & 1 & 1 & 0 & 0 & 0 & 0 & 0 & 0 \\
\hline $\mathrm{NN} / 562$ & $\mathrm{NICU}$ & Hewlett Packard & M1020A & 3616458612 & Module, Sao2pleth & 29-Aug-96 & 1 & 1 & 1 & 1 & 1 & 0 & 0 & 0 & 0 & 0 & 0 \\
\hline NN/563 & $\mathrm{NICU}$ & Hewlett Packard & M1008B & $3523 A 47547$ & Module, N.IB.P. & 29-Aug-96 & 1 & 1 & 1 & 1 & 1 & 0 & 0 & 0 & 0 & 0 & 0 \\
\hline
\end{tabular}




\begin{tabular}{|c|c|c|c|c|c|c|c|c|c|c|c|c|c|c|c|c|c|c|}
\hline AssettD = & Location & MakelD & ModellD & \Serial Number & $\checkmark$ Description & Date $\|$ & Date $\mathrm{R} \mid \mathbf{I}$ & & 0 & 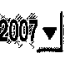 & 然 & 0.t & 20 & 5 & 1 & 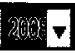 & 5 & wa \\
\hline $\mathrm{NN} / 564$ & $\mathrm{NICU}$ & Hewlett Packard & M1204A & 3628409903 & Monitor, Video, Colour & 29-Aug-96 & & 1 & 1 & 1 & 1 & 1 & 0 & 0 & 0 & 2 & 0 & 0 \\
\hline$N N / 566$ & $\mathrm{NICU}$ & Hewlett Packard & M1002A & $3523 A 44879$ & Module, ECG/respiration & 29-Aug-96 & & 1 & 1 & 1 & 1 & 1 & 0 & 0 & 0 & 0 & 0 & 0 \\
\hline NN/567 & $\mathrm{NICU}$ & Hewlett Packard & M1020A & $3616 A 58608$ & Module, Saozpleth & 29-Aug-96 & & 1 & 1 & 1 & 1 & 1 & 0 & 0 & 0 & 0 & 0 & 0 \\
\hline$N N / 568$ & $\mathrm{NCU}$ & Hewlett Packard & M1008B & $3523 A 47537$ & Module, N.I.B.P. & 29-Aug-96 & & 1 & 1 & 1 & 1 & 1 & 0 & 0 & 0 & 0 & 0 & 0 \\
\hline $\mathrm{NN} / 571$ & $\mathrm{NICU}$ & Hewlett Packard & M1018A & $3604 G 01931$ & Module, 02 / Co2 & 29-Aug-96 & & 1 & 1 & 1 & 1 & 1 & 0 & 0 & 0 & 0 & 0 & 0 \\
\hline NN/572 & INICU & Hewlett Packard & M1018A & $3604 G 01831$ & Module, 02 / $\mathrm{CO}$ & 29-Aug-96 & & 1 & 1 & 1 & 1 & 1 & 0 & 0 & 0 & 0 & 0 & 0 \\
\hline $\mathrm{NN} / 573$ & $\mathrm{NICU}$ & Hewlett Packard & M1018A & $3604 G 01973$ & Module, 02 / Co2 & 29-Aug-96 & & 1 & 1 & 1 & 1 & 1 & 0 & 0 & 0 & 1 & 0 & 0 \\
\hline NN/579 & $\mathrm{NICU}$ & Hewlett Packard & M1008B & $3523 A 48531$ & Module, N.I.B.P. & 29-Aug-96 & & 1 & 1 & 1 & 1 & 1 & 0 & 0 & 0 & 1 & 0 & 0 \\
\hline NN/580 & NICU & Hewlett Packard & $\mathrm{M} 1018 \mathrm{~A}$ & $3604 G 01969$ & Module, 02 / $\mathrm{C} 02$ & 29-Aug-96 & & 1 & 1 & 1 & 1 & 1 & 0 & 0 & 0 & 0 & 0 & 0 \\
\hline NN/581 & $\mathrm{NICU}$ & Hewlett Packard & M1018A & $3604 G 01960$ & Module, 02 / Co2 & 29-Aug-96 & 17-0ct-08 & 1 & 1 & 1 & 1 & 1 & 0 & 0 & 0 & 0 & 0 & 0 \\
\hline $\mathrm{NN} / 593$ & $\mathrm{NICU}$ & Nellcor-Mallincrodt & $N-180$ & 20217603 & Pulse Oximeter & 19.Jan-93 & & 1 & 1 & 1 & 1 & 1 & 0 & 0 & 0 & 0 & 0 & 0 \\
\hline $\mathrm{NN} / 594$ & $\mathrm{NICU}$ & Nellcor-Mallincrodt & $N-180$ & 20217049 & Pulse Oximeter & 19-Jan-93 & & 1 & 1 & 1 & 1 & 1 & 0 & 0 & 0 & 0 & 0 & 0 \\
\hline NN/699 & NICU & Nellicor-Mallincrodt & $\mathrm{N}-20 \mathrm{E}$ & G02800034 & Pulse Oximeter & 28-Feb-02 & & 1 & 1 & 1 & 1 & 1 & 0 & 0 & 1 & 1 & 1 & 0 \\
\hline NN/719 & $\mathrm{NICU}$ & Hewlett Packard & M1002A & $3523 A 44914$ & Module, ECG/respiration & 20-Apr-04 & & 1 & 1 & 1 & 1 & 1 & 1 & 0 & 0 & 0 & 0 & 0 \\
\hline $\mathrm{NN} / 737$ & $\mathrm{NICU}$ & Hewlett Packard & M1008B & 3226404016 & Module, N.I.B.P. & 20-Apr-04 & & 1 & 1 & 1 & 1 & 1 & 0 & 1 & 1 & 0 & 0 & 0 \\
\hline NN/738 & $\mathrm{NICU}$ & Hewlett Packard & M1008B & $3226 A 04015$ & Module, N.I.B.P. & 20-Apr-04 & & 1 & 1 & 1 & 1 & 1 & 0 & 0 & 0 & 0 & 0 & 0 \\
\hline NN/739 & $\mathrm{NICU}$ & Hewlett Packard & M1008B & DE911E1668 & Module, N.I.B.P. & 20-Apr-04 & & 1 & 1 & 1 & 1 & 1 & 0 & 0 & 0 & 0 & 0 & 0 \\
\hline NN/740 & $\mathrm{NICU}$ & Hewlett Packard & M1204A & $3713 A 17826$ & Monitor, Video, Colour, patient & 20-Apr-04 & & 1 & 1 & 1 & 1 & 1 & 0 & 0 & 0 & 0 & 0 & 0 \\
\hline $\mathrm{NN} / 742$ & $\mathrm{NICU}$ & Hewlett Packard & M1002A & $3410 A 30664$ & Module, ECG/respiration & 20-Apr-04 & & 1 & 1 & 1 & 1 & 1 & 0 & 0 & 0 & 0 & 0 & 0 \\
\hline NN/743 & $\mathrm{NICU}$ & Hewlett Packard & M1020A & $2927 A 02895$ & Module, Saor/pleth & 20-Apr-04 & & 1 & 1 & 1 & 1 & 1 & 0 & 1 & 0 & 0 & 0 & 0 \\
\hline NN/744 & $\mathrm{NICU}$ & Hewlett Packard & M1204A & $3713 A 17825$ & Monitor, Video, Colour, patient & 20-Apr-04 & & 1 & 1 & 1 & 1 & 1 & 0 & 0 & 0 & 1 & 0 & 0 \\
\hline NN/746 & $\mathrm{NICU}$ & Hewlett Packard & M1002A & З523A51919 & Module, ECG/resppration & 20-Apr-04 & & 1 & 1 & 1 & 1 & 1 & 0 & 0 & 0 & 0 & 0 & 0 \\
\hline NN/747 & $\mathrm{NICU}$ & Hewlett Packard & M1020A & $2927 A 02896$ & Module, Sao2/pleth & 20-Apr-04 & & 1 & 1 & 1 & 1 & 1 & 0 & 0 & 1 & 0 & 0 & 0 \\
\hline $\mathrm{NN} / 748$ & $\mathrm{NCU}$ & Hewlett Packard & M1008B & $3727 A 38421$ & Module, N.I.B.P. & 20-Apr-04 & & 1 & 1 & 1 & 1 & 1 & 0 & 0 & 0 & 0 & 0 & 0 \\
\hline NN/749 & $\mathrm{NICU}$ & Hewlett Packard & $\mathrm{M} 1008 \mathrm{~B}$ & $372 G 55176$ & Module, N.I.B.P. & 20-Apr-04 & & 1 & 1 & 1 & 1 & 1 & 0 & 0 & 0 & 0 & 0 & 0 \\
\hline NN/750 & $\mathrm{NICU}$ & Hewletl Packard & M1204A & $3642 A 15423$ & Monitor, Video, Colour, patient & 20-Apr-04 & & 1 & 1 & 1 & 1 & 1 & 0 & 0 & 0 & 0 & 0 & 0 \\
\hline NN/752 & INICU & Hewlett Packard & M1002A & $3523 A 51976$ & Module, ECG/respiration & 20-Apr-OA & & 1 & 1 & $:$ & 1 & 1 & 0 & 0 & 1 & 0 & 0 & 0 \\
\hline NN/753 & $\mathrm{NICU}$ & Hewlett Packard & M1020A & $2927 A 02894$ & Module, Sao2/pleth & 20-Apr-04 & & 1 & 1 & 1 & 1 & 1 & 0 & 0 & 1 & 0 & 0 & 0 \\
\hline NN/766 & NICU & Nellcor-Mallincrodt & $N-600$ & G06831482 & Pulse Oximeter & 18.Jan-07 & & 0 & 0 & 1 & 1 & 1 & 0 & 0 & 0 & 0 & 0 & 0 \\
\hline NN/767 & NICU & Nellcor-Mallincrodt & $N-600$ & G06831494 & Pulse Oximeter & 18-Jan-07 & & 0 & 0 & 1 & 1 & 1 & 0 & 0 & 0 & 0 & 0 & 0 \\
\hline
\end{tabular}




\begin{tabular}{|c|c|c|c|c|c|c|c|c|c|c|c|c|c|c|c|c|}
\hline NN/768 & NICU & Nellcor-Mallincrodt & $N-600$ & G06831498 & Pulse Oximeter & 18-Jan-07 & 0 & 0 & 1 & 1 & 1 & 0 & 0 & 0 & 0 & 1 \\
\hline NN/769 & $\mathrm{NICU}$ & Nellcor-Mallincrodt & $\mathrm{N}-600$ & G06831479 & Pulse Oximeter & 18-van-07 & 0 & 0 & 1 & 1 & 1 & 0 & 0 & 0 & 0 & 0 \\
\hline NN/770 & NICU & Nellcor-Mallincrodt & $N-600$ & G06831460 & Pulse Oximeter & 18-Jan-07 & 0 & 0 & 1 & 1 & 1 & 0 & 0 & 0 & 1 & 0 \\
\hline NN/771 & NICU & Nelicor-Mallincrodt & $N-600$ & G06835181 & Pulse Oximeter & 18-Jan-07 & 0 & 0 & 1 & 1 & 1 & 0 & 0 & 0 & 0 & 0 \\
\hline NN/772 & NICU & Nellcor-Mallincrodt & $N-600$ & G06831447 & Pulse Oximeter & $18 \cdot \operatorname{van}-07$ & 0 & 0 & 1 & 1 & 1 & 0 & 0 & 0 & 0 & 0 \\
\hline NN/773 & NICU & Nellcor-Mallincrodt & N.600 & G06831474 & Pulse Oximeter & 18-Jan-.07 & 0 & 0 & 1 & 1 & 1 & 0 & 0 & 0 & 0 & 1 \\
\hline NN/774 & NICU & Nellcor-Mallincrodt & $N-600$ & G06831458 & Pulse Oximeter & 18-van:-07 & 0 & 0 & 1 & 1 & 1 & 0 & 0 & 0 & 0 & 1 \\
\hline NN/775 & $\mathrm{NICU}$ & Nellcor-Mallincrodt & $N-600$ & G06831473 & Pulse Oximeter & 18-Jan-07 & 0 & 0 & 1 & 1 & 1 & 0 & 0 & 0 & 0 & 0 \\
\hline NN/776 & NICU & Nellcor-Mallincrodt & N-65 Oximax & G06834015 & Pulse Oximeter & 18-van-07 & 0 & 0 & 1 & 1 & 1 & 0 & 0 & 0 & 0 & 0 \\
\hline NN/T77 & $\mathrm{NICU}$ & Nellcor-Mallincrodt & $\mathrm{N}-65$ Oximax & G06834044 & Pulse Oximeter & 18-Jan-07 & 0 & 0 & 1 & 1 & 1 & 0 & 0 & 0 & 0 & 0 \\
\hline$N N / 779$ & NCU & Nellcor-Mallincrodt & $\mathrm{N}-600$ & G06834179 & Pulse Oximeter & 18-Jan-07 & 0 & 0 & 1 & 1 & 1 & 0 & 0 & 0 & 0 & 1 \\
\hline NN/780 & $\mathrm{NICU}$ & Nellcor-Mallincrodt & $N-600$ & G06835256 & Pulse Oximeter & 18-Jan-07 & 0 & 0 & 1 & 1 & 1 & 0 & 0 & 1 & 0 & 0 \\
\hline NN/781 & $\mathrm{NICU}$ & Nellcor-Mallincrodt & $N-600$ & G06835259 & Pulse Oximeter & 18-Jan-07 & 0 & 0 & 1 & 1 & 1 & 0 & 0 & 0 & 0 & 0 \\
\hline NN/782 & $\mathrm{NICU}$ & Nellcor-Mallincrodt & $N-600$ & G06831451 & Pulse Oximeter & 18-Jan-07 & 0 & 0 & 1 & 1 & 1 & 0 & 0 & 0 & 0 & 0 \\
\hline NN/783 & NICU & Nellcor-Mallincrodt & $\mathrm{N}-600$ & G06835158 & Pulse Oximeter & 18-Jan- -07 & 0 & 0 & 1 & 1 & 1 & 0 & 0 & 0 & 0 & 0 \\
\hline NN/784 & $\mathrm{NICU}$ & Nellcor-Mallincrodt & $N-600$ & G06831500 & Pulse Oximeter & 18-Jan-07 & 0 & 0 & 1 & 1 & 1 & 0 & 0 & 0 & 1 & 0 \\
\hline NN785 & $\mathrm{NICU}$ & Nellcor-Mallincrodt & $N-600$ & G06831532 & Pulse Oximeter & 18-Jan-07 & 0 & 0 & 1 & 1 & 1 & 0 & 0 & 1 & 0 & 0 \\
\hline NN/786 & $\mathrm{NICU}$ & Nellcor-Mallincrodt & $N-600$ & G06831483 & Pulse Oximeter & 18-Jan-07 & 0 & 0 & 1 & 1 & 1 & 0 & 0 & 0 & 1 & 0 \\
\hline NN/787 & $\mathrm{NICU}$ & Nellcor-Mallincrodt & $N-600$ & G06831478 & Pulse Oximeter & 18-Jan-07 & 0 & 0 & 1 & 1 & 1 & 0 & 0 & 0 & 0 & 0 \\
\hline NN/819 & $\mathrm{NICU}$ & Nellcor-Mallincrodt & $N-600$ & G07812306 & Pulse Oximeter & 18-Jan-07 & 0 & 0 & 1 & 1 & 1 & 0 & 0 & 0 & 0 & 0 \\
\hline NN/820 & $\mathrm{NICU}$ & Nellcor-Mallincrodt & $N-600$ & G0781224 & Pulse Oximeter & 18.Jan-07 & 0 & 0 & 1 & 1 & 1 & 0 & 0 & 0 & 1 & 0 \\
\hline NN/888 & $\mathrm{NICU}$ & Drager & MS18596 & 6000985465 & Monitor, Physiological & 28-Aug-09 & 0 & 0 & 0 & 0 & 1 & 0 & 0 & 0 & 0 & 0 \\
\hline NN/889 & NICU & Drager & MS18596 & 6000961277 & Monitor, Physiological & 28-Aug-09 & 0 & 0 & 0 & 0 & 1 & 0 & 0 & 0 & 0 & 0 \\
\hline NNVB90 & $\mathrm{NICU}$ & Drager & MS18596 & 6000961580 & Monitor, Physiological & 28-Aug-09 & 0 & 0 & 0 & 0 & 1 & 0 & 0 & 0 & 0 & 0 \\
\hline NN/891 & NICU & Drager & MS18596 & 6001038470 & Monitor, Physiological & 28-Aug-09 & 0 & 0 & 0 & 0 & 1 & 0 & 0 & 0 & 0 & 0 \\
\hline NN/892 & NICU & Drager & MS18596 & 6000982967 & Monitor, Physiological & 28-Aug-09 & 0 & 0 & 0 & 0 & 1 & 0 & 0 & 0 & 0 & 0 \\
\hline NN/893 & $\mathrm{NICU}$ & Drager & MS18596 & 6000960875 & Monitor, Physiological & 28-Aug-09 & 0 & 0 & 0 & 0 & 1 & 0 & 0 & 0 & 0 & 0 \\
\hline NN/894 & NICU & Drager & MS18596 & 6001041778 & Monitor, Physiological & 28-Aug-09 & 0 & 0 & 0 & 0 & 1 & 0 & 0 & 0 & 0 & 0 \\
\hline NN/895 & $\mathrm{NICU}$ & Drager & MS18596 & 6000957772 & Monitor, Physiological & 28-Aug-09 & 0 & 0 & 0 & 0 & 1 & 0 & 0 & 0 & 0 & 0 \\
\hline NN/896 & $\mathrm{NICU}$ & Drager & MS18596 & 6000957175 & Monitor, Physiological & 28-Aug-09 & 0 & 0 & 0 & 0 & 1 & 0 & 0 & 0 & 0 & 0 \\
\hline
\end{tabular}




\begin{tabular}{|c|c|c|c|c|c|}
\hline AssettD = & Locatio & MakelD & $\checkmark$ ModellD & Serial Number & Description \\
\hline NN897 & $\mathrm{NCU}$ & Drager & MS18596 & 6000985768 & Monitor, Physiological \\
\hline NN1898 & $\mathrm{NCU}$ & Drager & MS18596 & 6000962472 & Monitor, Physiological \\
\hline NN899 & NCL & Drager & MS18596 & 6001046773 & Moritor, Physiological \\
\hline NN9OO & NICU & Drager & MS18596 & 6001038577 & Monitor, Physiloogical \\
\hline NN901 & NICU & Drager & MS18596 & 6000960973 & Moritor, Physiological \\
\hline NN902 & NCU & Drager & MS18596 & 6000960679 & Moritor, Physiological \\
\hline NN903 & NICU & Drager & MS18596 & '6000963079 & Moritor, Physiological \\
\hline NNGO4 & $\mathrm{NICU}$ & Drager & MS18596 & '6000962971 & Moritor, Physiological \\
\hline NN905 & NICU & Drager & MS18596 & 00095269 & Monitor, Physiological \\
\hline NN906 & $\mathrm{NICU}$ & Drager & MS18596 & '6001048869 & Monitor, Physiological \\
\hline NN907 & NICU & Drager & MS18596 & 6000960376 & Monitor, Physiological \\
\hline & & & & & TOTALS \\
\hline
\end{tabular}

\begin{tabular}{|c|c|c|c|c|c|c|c|c|c|c|c|}
\hline $\begin{array}{l}\text { Date } 11 \text { V } \\
\text { 28-Aug-09 }\end{array}$ & $\begin{array}{r}0 \\
0\end{array}$ & 0 & 0 & 0 & 1 & 0 & 0 & 0 & 0 & 0 & 0 \\
\hline 28-Aug-09 & 0 & 0 & 0 & 0 & 1 & 0 & 0 & 0 & 0 & 0 & 0 \\
\hline 28-Aug-09 & 0 & 0 & 0 & 0 & 1 & 0 & 0 & 0 & 0 & 0 & 0 \\
\hline 28-Aug-09 & 0 & 0 & 0 & 0 & 1 & 0 & 0 & 0 & 0 & 0 & 0 \\
\hline 28-Aug-09 & 0 & 0 & 0 & 0 & 1 & 0 & 0 & 0 & 0 & 0 & 1 \\
\hline 28-Aug-09 & 0 & 0 & 0 & 0 & 1 & 0 & 0 & 0 & 0 & 0 & 0 \\
\hline 28-Aug-09 & 0 & 0 & 0 & 0 & 1 & 0 & 0 & 0 & 0 & 0 & 0 \\
\hline 28-Aug-09 & 0 & 0 & 0 & 0 & 1 & 0 & 0 & 0 & 0 & 0 & 0 \\
\hline 28-Aug-09 & 0 & 0 & 0 & 0 & 1 & 0 & 0 & 0 & 0 & 0 & 0 \\
\hline 28-Aug-09 & 0 & 0 & 0 & 0 & 1 & 0 & 0 & 0 & 0 & 0 & 0 \\
\hline 28-Aug-09 & 0 & 0 & 0 & 0 & 1 & 0 & 0 & 0 & 0 & 0 & 0 \\
\hline & & & & & & 22 & 24 & 40 & 50 & 58 & 15 \\
\hline
\end{tabular}




\section{Appendix 2}

Syringe Pump Data Spreadsheet 


$\begin{array}{lll}\text { AssetID } & \text { SerialNumber } & \text { Description } \\ \text { 4F/057 } & 8002-07934 & \text { Pump, Syringe } \\ \text { 4F/058 } & 8002-05892 & \text { Pump, Syringe } \\ \text { 4F/059 } & 8002-05675 & \text { Pump, Syringe } \\ \text { 4F/060 } & 8002-08011 & \text { Pump, Syringe } \\ \text { 4F/061 } & 8002-08306 & \text { Pump, Syringe } \\ \text { BM/1047 } & \text { M70302 } & \text { Pump, Syringe, Infusion (Medfusion) } \\ \text { IP/088 } & \text { M70036 } & \text { Pump, Syringe, Infusion (Medfusion) } \\ \text { IP/089 } & \text { M70279 } & \text { Pump, Syringe, Infusion (Medfusion) } \\ \text { DS/041 } & 8002-05681 & \text { Pump, Syringe } \\ \text { DS/042 } & 8002-08031 & \text { Pump, Syringe } \\ \text { EM/276 } & 8002-08028 & \text { Pump, Syringe } \\ \text { EM/277 } & 8002-05493 & \text { Pump, Syringe } \\ \text { EM/278 } & 8002-05725 & \text { Pump, Syringe } \\ \text { IP/001 } & \text { M70251 } & \text { Pump, Syringe, Infusion (Medfusion) } \\ \text { IP/002 } & \text { M70322 } & \text { Pump, Syringe, Infusion (Medfusion) } \\ \text { IP/003 } & \text { M70330 } & \text { Pump, Syringe, Infusion (Medfusion) } \\ \text { IP/004 } & \text { M70041 } & \text { Pump, Syringe, Infusion (Medfusion) } \\ \text { IP/005 } & \text { M69994 } & \text { Pump, Syringe, Infusion (Medfusion) } \\ \text { IP/006 } & \text { M70328 } & \text { Pump, Syringe, Infusion (Medfusion) } \\ \text { IP/007 } & \text { M70333 } & \text { Pump, Syringe, Infusion (Medfusion) } \\ \text { IP/008 } & \text { M70350 } & \text { Pump, Syringe, Infusion (Medfusion) } \\ \text { IP/009 } & \text { M70313 } & \text { Pump, Syringe, Infusion (Medfusion) } \\ \text { IP/010 } & \text { M70277 } & \text { Pump, Syringe, Infusion (Medfusion) } \\ \text { IP/011 } & \text { M70011 } & \text { Pump, Syringe, Infusion (Medfusion) } \\ \text { IP/012 } & \text { M70013 } & \text { Pump, Syringe, Infusion (Medfusion) } \\ \text { IP/013 } & \text { M70017 } & \text { Pump, Syringe, Infusion (Medfusion) } \\ \text { IP/014 } & \text { M70329 } & \text { Pump, Syringe, Infusion (Medfusion) } \\ \text { IP/015 } & \text { M70260 } & \text { Pump, Syringe, Infusion (Medfusion) } \\ \text { IP/016 } & \text { M70341 } & \text { Pump, Syringe, Infusion (Medfusion) } \\ & & \end{array}$

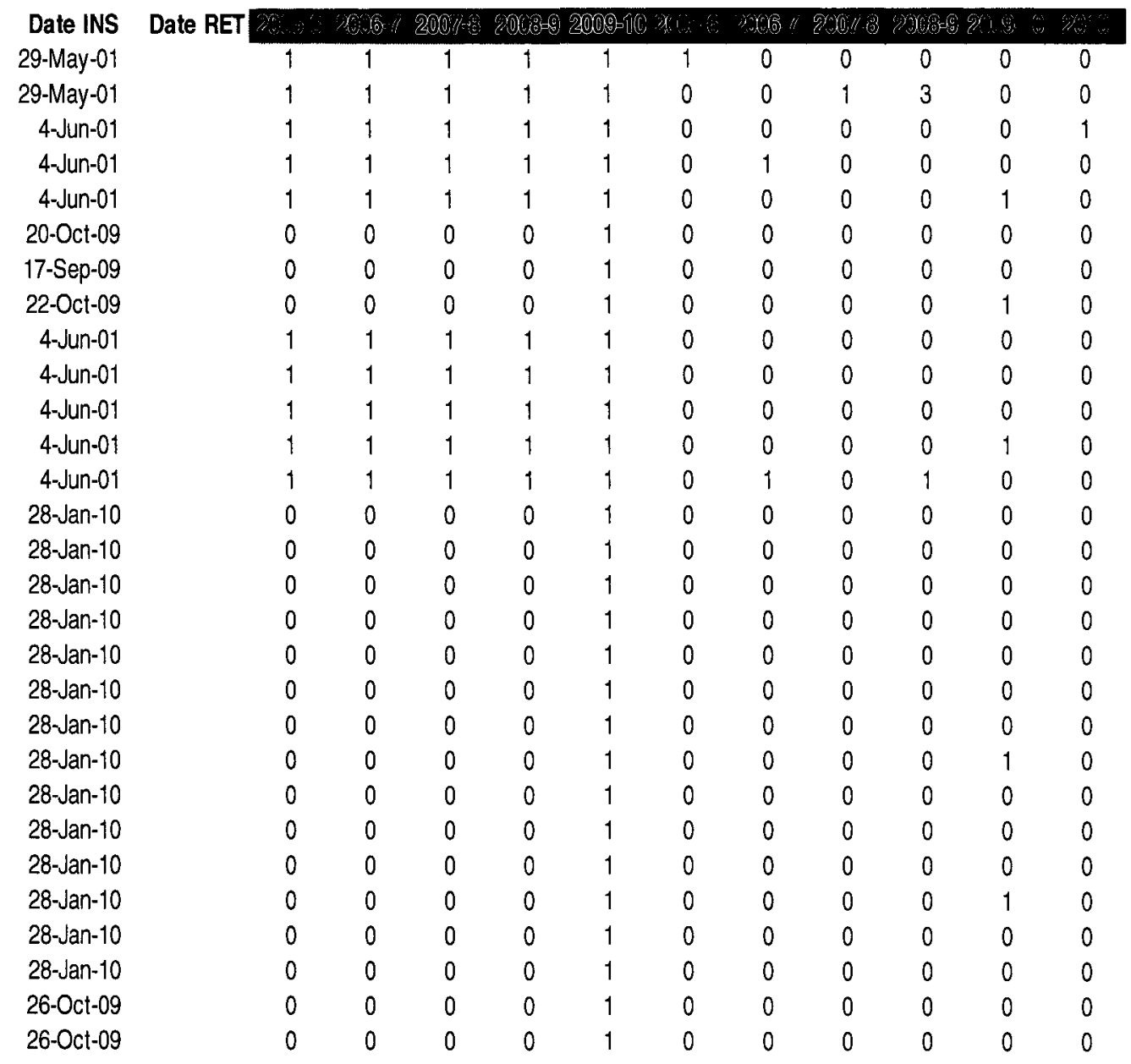




\begin{tabular}{|c|c|c|}
\hline $\operatorname{set} 1 \mathrm{D}$ & SerialNumber & Description \\
\hline $\mathbb{P} / 017$ & M70042 & Pump, Syringe, Infusion (Medfusion) \\
\hline $\mathbb{P} / 018$ & M70284 & Pump, Syringe, Infusion (Medfusion) \\
\hline $\mathbb{P} / 019$ & M70320 & Pump, Syringe, Infusion (Medfusion) \\
\hline $\mathrm{IP} / 020$ & M70342 & Pump, Syringe, Infusion (Medfusion) \\
\hline $\mathbb{P} / 021$ & M70037 & Pump, Syringe, Infusion (Medfusion) \\
\hline $\mathbb{P} / 022$ & M70323 & Pump, Syringe, Infusion (Medfusion) \\
\hline $\mathbb{P} / 023$ & M69999 & Pump, Syringe, Infusion (Medfusion) \\
\hline $\mathrm{IP} / 024$ & M70263 & Pump, Syringe, Infusion (Medfusion) \\
\hline $\mathrm{IP} / 025$ & M69995 & Pump, Syringe, Infusion (Medfusion) \\
\hline $\mathbb{P} / 026$ & M69990 & Pump, Syringe, Infusion (Medfusion) \\
\hline $\mathbb{P} / 027$ & M70355 & Pump, Syringe, Infusion (Medfusion) \\
\hline $\mathbb{P} / 028$ & M70315 & Pump, Syringe, Infusion (Medfusion) \\
\hline $\mathbb{P} / 029$ & M70265 & Pump, Syringe, Infusion (Medfusion) \\
\hline $\mathbb{P} / 030$ & M70314 & Pump, Syringe, Intusion (Medfusion) \\
\hline $\mathbb{P} / 031$ & M70319 & Pump, Syringe, Infusion (Medfusion) \\
\hline $\mathbb{P} / 032$ & M70351 & Pump, Syringe, Infusion (Medfusion) \\
\hline $\mathbb{P} / 033$ & M70291 & Pump, Syringe, Infusion (Medfusion) \\
\hline $\mathbb{P} / 034$ & $M / 70269$ & Pump, Syringe, Infusion (Medfusion) \\
\hline $\mathbb{P} / 035$ & M70282 & Pump, Syringe, Infusion (Medfusion) \\
\hline $\mathbb{P} / 036$ & M70025 & Pump, Syringe, Infusion (Medfusion) \\
\hline $\mathbb{P} / 037$ & M71072 & Pump, Syringe, Infusion (Medfusion) \\
\hline $\mathbb{P} / 038$ & M69937 & Pump, Syringe, Infusion (Medfusion) \\
\hline $\mathbb{P} / 039$ & M70347 & Pump, Syringe, Infusion (Medfusion) \\
\hline $\mathbb{P} / 040$ & M70326 & Pump, Syringe, Infusion (Medfusion) \\
\hline $\mathbb{P} / 041$ & M70276 & Pump, Syringe, Infusion (Medfusion) \\
\hline $\mathbb{P} / 042$ & M70262 & Pump, Syringe, Infusion (Medfusion) \\
\hline IP/043 & M70297 & Pump, Syringe, Infusion (Medfusion) \\
\hline $\mathbb{P} / 044$ & M70348 & Pump, Syringe, Infusion (Medfusion) \\
\hline $\mathbb{P} / 045$ & M70332 & Pump, Syringe, Intusion (Medfusion) \\
\hline IP/046 & M70325 & Pump, Syringe, Infusion (Medfusion) \\
\hline
\end{tabular}

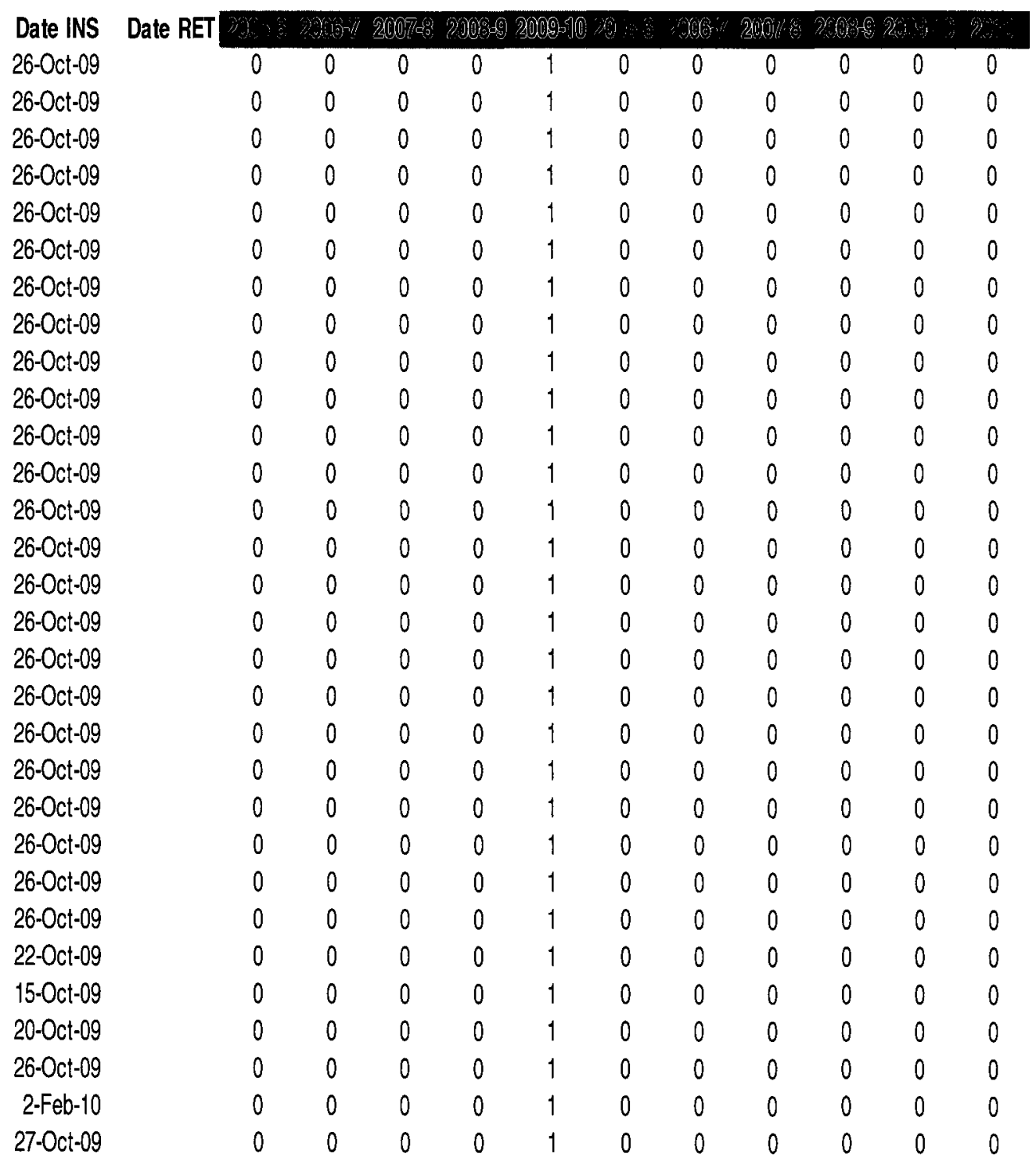




\begin{tabular}{|c|c|}
\hline AssetlD & SerialNumber \\
\hline IP/047 & M70043 \\
\hline IP/048 & M70258 \\
\hline IP/049 & M70275 \\
\hline IP/050 & M70289 \\
\hline IP/051 & M70318 \\
\hline IP/052 & M70022 \\
\hline IP/053 & M70340 \\
\hline IP/054 & M70334 \\
\hline IP/055 & M70317 \\
\hline $\mid \mathrm{P} / 056$ & M70327 \\
\hline$\{P / 057$ & M70278 \\
\hline $\mathrm{IP} / 058$ & M70312 \\
\hline IP/059 & M70274 \\
\hline $\mathbb{I P} / 060$ & 70353 \\
\hline $\mathbb{P} / 061$ & M70000 \\
\hline IP/062 & M70021 \\
\hline $\mathbb{I P} / 063$ & M69988 \\
\hline $\mathbb{I P} / 064$ & M70038 \\
\hline $\mathbb{I P} / 065$ & M70343 \\
\hline $\mathrm{IP} / 066$ & M70299 \\
\hline IP/067 & M70310 \\
\hline $\mathrm{IP} / 068$ & M70030 \\
\hline IP/069 & 70007 \\
\hline $\mathrm{IP} / 070$ & M70337 \\
\hline IP/071 & M70354 \\
\hline IP/072 & M70035 \\
\hline $\mathrm{IP} / 073$ & M69998 \\
\hline IP/074 & M69987 \\
\hline $\mathrm{IP} / 075$ & M70001 \\
\hline $\mathbb{I P} / 076$ & M70280 \\
\hline IP/077 & M70356 \\
\hline
\end{tabular}

Description

Pump, Syrnge, Infusion (Medfusion)

Pump, Syrnge, Infusion (Medfusion)

Pump, Syringe, Infusion (Medfusion)

Pump, Syrnge, Infusion (Medfusion)

Pump, Syringe, Infusion (Medfusion)

Pump, Syringe, Infusion (Medfusion)

Pump, Syringe, Infusion (Medfusion)

Pump, Syringe, Infusion (Medfusion)

Pump, Syringe, Infusion (Medfusion)

Pump, Syrnge, Infusion (Medfusion)

Pump, Syrnge, Infusion (Medfusion)

Pump, Syrnge, Infusion (Medfusion)

Pump, Syringe, Infusion (Medfusion)

Pump, Syringe, Infusion (Medfusion)

Pump, Syringe, Infusion (Medfusion)

Pump, Syringe, Infusion (Medfusion)

Pump, Syrnge, Infusion (Medfusion)

Pump, Syrnge, Infusion (Medfusion)

Pump, Syrnge, Infusion (Medfusion)

Pump, Syrnge, Infusion (Medfusion)

Pump, Syrnge, Infusion (Medfusion)

Pump, Syrnge, Infusion (Mediusion)

Pump, Syrnge, Infusion (Medfusion)

Pump, Syrnge, Infusion (Medfusion)

Pump, Syrnge, Infusion (Medfusion)

Pump, Syringe, Infusion (Medfusion)

Pump, Syringe, Infusion (Medfusion)

Pump, Synnge, Infusion (Medfusion)

Pump, Syringe, Infusion (Medfusion)

Pump, Syrnge, Infusion (Medfusion)

Pump, Syringe, Infusion (Medfusion)

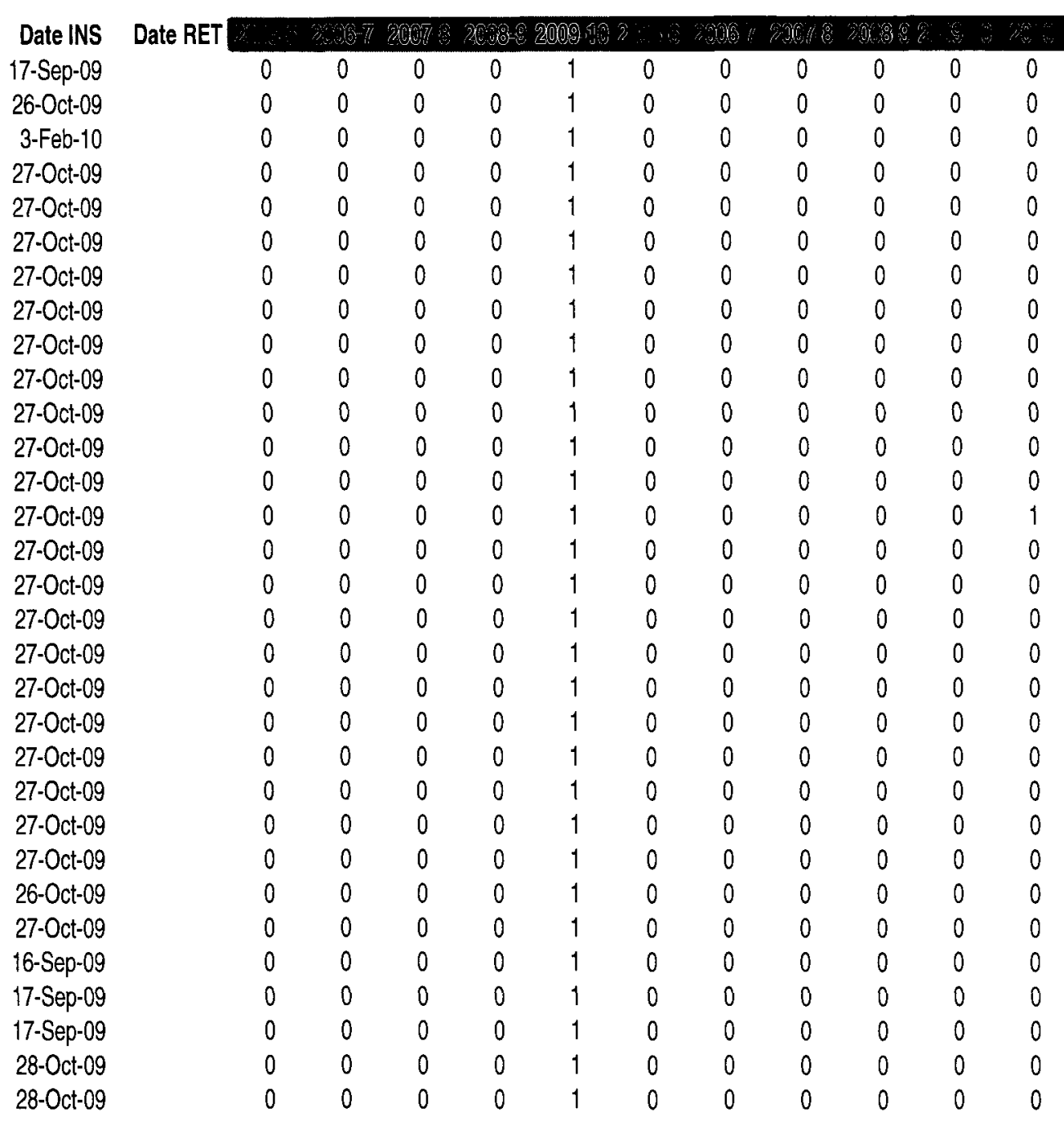




\begin{tabular}{|c|c|c|}
\hline Assetid & SerialNumber & Description \\
\hline $\mathrm{IP} / 078$ & M70307 & Pump, Syringe, Infusion (Medfusion) \\
\hline $\mid P / 079$ & M70039 & Pump, Syringe, Infusion (Medfusion) \\
\hline $\mid \mathrm{P} / 080$ & M70008 & Pump, Syringe, Infusion (Medfusion) \\
\hline $\mid P / 081$ & M70034 & Pump, Syringe, Infusion (Medfusion) \\
\hline IP/082 & M70285 & Pump, Syringe, Infusion (Medfusion) \\
\hline $\mid P / 083$ & M70045 & Pump, Syringe, Infusion (Medfusion) \\
\hline $\mid P / 084$ & M70311 & Pump, Syringe, Infusion (Medfusion) \\
\hline IP/085 & M70270 & Pump, Syringe, Infusion (Medfusion) \\
\hline $\mathrm{IP} / 086$ & M70298 & Pump, Syringe, Infusion (Medfusion) \\
\hline $\mathrm{IP} / 087$ & M70295 & Pump, Syrınge, Infusion (Medfusion) \\
\hline $\mathrm{IP} / 088$ & M70036 & \\
\hline $\mathrm{IP} / 089$ & M70279 & \\
\hline $\mathrm{IP} / 090$ & M70281 & Pump, Syringe, Infusion (Medfusion) \\
\hline IP/091 & M70331 & Pump, Syringe, Infusion (Medfusion) \\
\hline IP/092 & M70256 & Pump, Syringe, Infusion (Medfusion) \\
\hline IP/093 & M70309 & Pump, Syringe, Infusion (Medfusion) \\
\hline IP/094 & M69996 & Pump, Syringe, Infusion (Medfusion) \\
\hline IP/095 & M70012 & Pump, Syringe, Infusion (Medfusion) \\
\hline IP/096 & M70335 & Pump, Syringe, Infusion (Medfusion) \\
\hline IP/097 & M70024 & Pump, Syringe, Infusion (Medfusion) \\
\hline IP/098 & M70002 & Pump, Syringe, Infusion (Medfusion) \\
\hline $\mathrm{IP} / 099$ & M70018 & Pump, Syringe, Infusion (Medfusion) \\
\hline $\mathrm{IP} / 100$ & M71064 & Pump, Syringe, Infusion (Medfusion) \\
\hline $\mid P / 101$ & M70032 & Pump, Syringe, Infusion (Medfusion) \\
\hline $\mathrm{IP} / 102$ & M69991 & Pump, Syringe, Infusion (Medfusion) \\
\hline $\mathbb{P} / 103$ & M70019 & Pump, Syringe, Infusion (Medfusion) \\
\hline $\mathrm{IP} / 104$ & M70261 & Pump, Syringe, Infusion (Medfusion) \\
\hline $\mathrm{IP} / 105$ & M70046 & Pump, Syringe, Infusion (Medfusion) \\
\hline $\mathrm{IP} / 106$ & M70267 & Pump, Syringe, Infusion (Medfusion) \\
\hline $\mathrm{PP} / 107$ & M70292 & Pump, Syringe, Infusion (Medfusion) \\
\hline $\mathrm{P} / 108$ & M70336 & Pump, Syringe, Infusion (Medfusion) \\
\hline $\mid \mathrm{P} / 109$ & M70316 & Pump, Syrınge, Infusion (Medfusion) \\
\hline $\mathrm{P} / 110$ & M70288 & Pump, Syringe, Infusion (Medfusion) \\
\hline $\mid \mathrm{P} / 111$ & M71059 & Pump, Syringe, Infusion (Medfusion) \\
\hline $\mid \mathrm{P} / 112$ & M70028 & Pump, Syringe, Infusion (Medfusion) \\
\hline $\mid \mathrm{P} / 113$ & M71060 & Pump, Syringe, Infusion (Medfusion) \\
\hline $\mid \mathrm{P} / \uparrow 14$ & M71079 & Pump, Syringe, Infusion (Medfusion) \\
\hline $\mid \mathrm{P} / 115$ & M70389 & Pump, Syringe, Infusion (Medfusion) \\
\hline $\mid \mathrm{P} / 116$ & M70708 & Pump, Syringe, Infusion (Medfusion) \\
\hline $\mid \mathrm{P} / 117$ & M71077 & Pump, Syringe, Infusion (Medfusion) \\
\hline $\mathrm{P} / 118$ & M70321 & Pump, Syringe, Infusion (Medfusion) \\
\hline
\end{tabular}

\begin{tabular}{|c|c|c|c|c|c|c|c|c|c|c|c|}
\hline Date INS & Date RET & 桨施 & 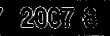 & 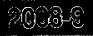 & $2008=16$ & 2 & 20 & 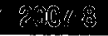 & \% & 8 & 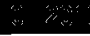 \\
\hline 28-Oct-09 & 0 & 0 & 0 & 0 & 1 & 0 & 0 & 0 & 0 & 0 & 0 \\
\hline $4-F e b-10$ & 0 & 0 & 0 & 0 & 1 & 0 & 0 & 0 & 0 & 0 & 0 \\
\hline 16-Sep-09 & 0 & 0 & 0 & 0 & 1 & 0 & 0 & 0 & 0 & 0 & 0 \\
\hline 27-Oct-09 & 0 & 0 & 0 & 0 & 1 & 0 & 0 & 0 & 0 & 0 & 0 \\
\hline 27-Oct-09 & 0 & 0 & 0 & 0 & 1 & 0 & 0 & 0 & 0 & 0 & 0 \\
\hline 27-Oct-09 & 0 & 0 & 0 & 0 & 1 & 0 & 0 & 0 & 0 & 0 & 0 \\
\hline 27-Oct-09 & 0 & 0 & 0 & 0 & 1 & 0 & 0 & 0 & 0 & 0 & 0 \\
\hline 27-Oct-09 & 0 & 0 & 0 & 0 & 1 & 0 & 0 & 0 & 0 & 0 & 0 \\
\hline 28-Oct-09 & 0 & 0 & 0 & 0 & 1 & 0 & 0 & 0 & 0 & 0 & 0 \\
\hline 28-Oct-09 & 0 & 0 & 0 & 0 & 1 & 0 & 0 & 0 & 0 & 0 & 0 \\
\hline 17-Sep-09 & 0 & 0 & 0 & 0 & 1 & 0 & 0 & 0 & 0 & 0 & 0 \\
\hline 26-Oct-09 & 0 & 0 & 0 & 0 & 1 & 0 & 0 & 0 & 0 & 0 & 0 \\
\hline 20-Oct-09 & 0 & 0 & 0 & 0 & 1 & 0 & 0 & 0 & 0 & 0 & 0 \\
\hline 26-Oct-09 & 0 & 0 & 0 & 0 & 1 & 0 & 0 & 0 & 0 & 0 & 0 \\
\hline 20-Oct-09 & 0 & 0 & 0 & 0 & 1 & 0 & 0 & 0 & 0 & 0 & 0 \\
\hline 26-Oct-09 & 0 & 0 & 0 & 0 & 1 & 0 & 0 & 0 & 0 & 0 & 0 \\
\hline 16-Sep-09 & 0 & 0 & 0 & 0 & 1 & 0 & 0 & 0 & 0 & 0 & 0 \\
\hline $4-F e b-10$ & 0 & 0 & 0 & 0 & 1 & 0 & 0 & 0 & 0 & 0 & 0 \\
\hline $4-F e b-10$ & 0 & 0 & 0 & 0 & 1 & 0 & 0 & 0 & 0 & 0 & 0 \\
\hline 4-Feb-10 & 0 & 0 & 0 & 0 & 1 & 0 & 0 & 0 & 0 & 0 & 0 \\
\hline 4-Feb-10 & 0 & 0 & 0 & 0 & 1 & 0 & 0 & 0 & 0 & 0 & 0 \\
\hline 4-Feb-10 & 0 & 0 & 0 & 0 & 1 & 0 & 0 & 0 & 0 & 0 & 0 \\
\hline 4-Feb-10 & 0 & 0 & 0 & 0 & 1 & 0 & 0 & 0 & 0 & 0 & 0 \\
\hline 4-Feb-10 & 0 & 0 & 0 & 0 & 1 & 0 & 0 & 0 & 0 & 0 & 0 \\
\hline 4-Feb-10 & 0 & 0 & 0 & 0 & 1 & 0 & 0 & 0 & 0 & 0 & 0 \\
\hline 4-Feb-10 & 0 & 0 & 0 & 0 & 1 & 0 & 0 & 0 & 0 & 0 & 0 \\
\hline $15-0 c t-09$ & 0 & 0 & 0 & 0 & 1 & 0 & 0 & 0 & 0 & 0 & 0 \\
\hline $15-$ Oct-09 & 0 & 0 & 0 & 0 & 1 & 0 & 0 & 0 & 0 & 0 & 0 \\
\hline 15-Oct-09 & 0 & 0 & 0 & 0 & 1 & 0 & 0 & 0 & 0 & 0 & 0 \\
\hline 15-Oct-09 & 0 & 0 & 0 & 0 & 1 & 0 & 0 & 0 & 0 & 0 & 0 \\
\hline 4-Feb-10 & 0 & 0 & 0 & 0 & 1 & 0 & 0 & 0 & 0 & 0 & 0 \\
\hline 4-Feb-10 & 0 & 0 & 0 & 0 & 1 & 0 & 0 & 0 & 0 & 0 & 0 \\
\hline 15-Oct-09 & 0 & 0 & 0 & 0 & 1 & 0 & 0 & 0 & 0 & 0 & 0 \\
\hline 4-Feb-10 & 0 & 0 & 0 & 0 & 1 & 0 & 0 & 0 & 0 & 0 & 0 \\
\hline 5-Feb-10 & 0 & 0 & 0 & 0 & 1 & 0 & 0 & 0 & 0 & 0 & 0 \\
\hline $5-F e b-10$ & 0 & 0 & 0 & 0 & 1 & 0 & 0 & 0 & 0 & 0 & 0 \\
\hline 5 -Feb- 10 & 0 & 0 & 0 & 0 & 1 & 0 & 0 & 0 & 0 & 0 & 0 \\
\hline 5-Feb-10 & 0 & 0 & 0 & 0 & 1 & 0 & 0 & 0 & 0 & 0 & 0 \\
\hline $5-F e b-10$ & 0 & 0 & 0 & 0 & 1 & 0 & 0 & 0 & 0 & 0 & 0 \\
\hline 5-Feb-10 & 0 & 0 & 0 & 0 & 1 & 0 & 0 & 0 & 0 & 0 & 0 \\
\hline 5-Feb-10 & 0 & 0 & 0 & 0 & 1 & 0 & 0 & 0 & 0 & 0 & 0 \\
\hline
\end{tabular}




\begin{tabular}{|c|c|c|}
\hline AssetlD & SerialNumber & Description \\
\hline $\mathbb{P} / 119$ & M71063 & Pump, Syrnge, Infusion (Medfusion) \\
\hline IP/120 & M71061 & Pump, Syrnge, Infusion (Medfusion) \\
\hline $\mid \mathrm{P} / 121$ & M71070 & Pump, Syrnge, Infusion (Medfusion) \\
\hline $\mid P / 122$ & M70264 & Pump, Syrnge, Infusion (Medfusion) \\
\hline $\mid P / 123$ & M70705 & Pump, Syringe, Infusion (Medfusion) \\
\hline $\mid \mathrm{P} / 124$ & M70397 & Pump, Syringe, Infusion (Medfusion) \\
\hline $\mathrm{IP} / 125$ & M70706 & Pump, Syrnge, Infusion (Medfusion) \\
\hline $\mathbb{P} / 126$ & M70702 & Pump, Syrnge, Infusion (Medfusion) \\
\hline $\mathbb{P} / 127$ & M71058 & Pump, Syringe, Infusion (Medfusion) \\
\hline $\mathrm{PP} / 128$ & M70014 & Pump, Syringe, Infusion (Medfusion) \\
\hline $\mathbb{P} / 129$ & M70003 & Pump, Syringe, Infusion (Medfusion) \\
\hline $\mathbb{P} / 130$ & M70044 & Pump, Syrnge, Infusion (Medfusion) \\
\hline $\mid \mathrm{P} / 131$ & M71062 & Pump, Syrnge, Infusion (Medfusion) \\
\hline $\mid \mathrm{P} / 132$ & M70400 & Pump, Syrnge, Infusion (Medfusion) \\
\hline IP/133 & M70701 & Pump, Syrnge, Intusion (Mediusion) \\
\hline IP/134 & M70388 & Pump, Syrnge, Infusion (Medfusion) \\
\hline $\mathrm{IP} / 135$ & M70707 & Pump, Syrnge, Infusion (Medfusion) \\
\hline $\mid P / 136$ & M70015 & Pump, Syrnge, Infusion (Medfusion) \\
\hline IP/137 & M69984 & Pump, Syrnge, Infusion (Medfusion) \\
\hline IP/138 & M70399 & Pump, Syringe, Infusion (Medfusion) \\
\hline $\mathbb{P} / 139$ & M70704 & Pump, Syringe, Infusion (Medfusion) \\
\hline IP/140 & M71074 & Pump, Syrnge, Infusion (Medfusion) \\
\hline IP/141 & M70703 & Pump, Syrnge, Infusion (Medfusion) \\
\hline $\mathbb{P} / 142$ & M70710 & Pump, Syrnge, Infusion (Medfusion) \\
\hline $\mid P / 143$ & M71066 & Pump, Syringe, Infusion (Medfusion) \\
\hline $\mathrm{IP} / 144$ & M70398 & Pump, Syringe, Infusion (Medfusion) \\
\hline $\mathbb{I P} / 145$ & M70709 & Pump, Syringe, Infusion (Medfusion) \\
\hline $\mathrm{IP} / 146$ & M71069 & Pump, Syringe, Infusion (Medfusion) \\
\hline $\mid \mathrm{P} / 147$ & M71076 & Pump, Syringe, Infusion (Medfusion) \\
\hline $\mid P / 148$ & M71078 & Pump, Syringe, Infusion (Medfusion) \\
\hline $\mid P / 149$ & M71080 & Pump, Syringe, Infusion (Medfusion) \\
\hline $\mathrm{P} / 150$ & M71075 & Pump, Syringe, Infusion (Medfusion) \\
\hline
\end{tabular}

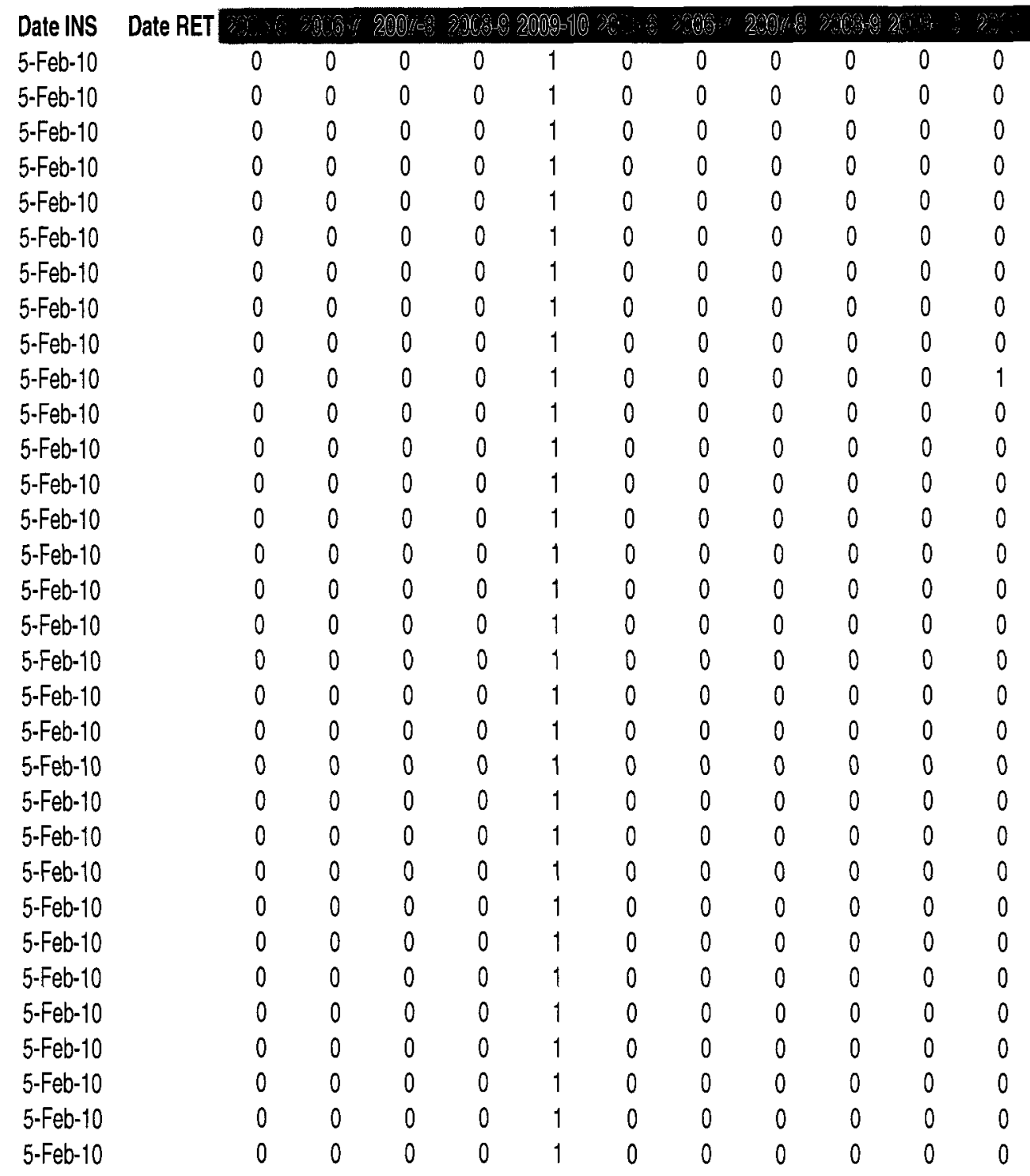




\begin{tabular}{|c|c|c|}
\hline AssetiD & SerialNumber & Description \\
\hline $\mid \mathrm{P} / 151$ & M71042 & Pump, Syringe, Infusion (Medfusion) \\
\hline $\mathbb{P} / 152$ & M70026 & Pump, Syrnge, Infusion (Medfusion) \\
\hline $\mathbb{P} / 153$ & M70006 & Pump, Syrnge, Infusion (Medfusion) \\
\hline $\mathrm{IC} / 409$ & $8002-08336$ & Pump, Syringe \\
\hline $\mathrm{IC} / 410$ & $8002-08305$ & Pump, Syringe \\
\hline $\mathrm{IC} / 411$ & $8002-08323$ & Pump, Syrnge \\
\hline $\mathrm{IC} / 412$ & $8002-08296$ & Pump, Syringe \\
\hline $\mid \mathrm{C} / 413$ & $8002-08304$ & Pump, Syringe \\
\hline $\mathrm{IC} / 414$ & $8002-08324$ & Pump, Syringe \\
\hline IC/415 & $8002-08311$ & Pump, Syringe \\
\hline IC/416 & $8002-08295$ & Pump, Syringe \\
\hline IC/417 & $8002-08313$ & Pump, Syringe \\
\hline $\mathrm{IC} / 418$ & $8002-08330$ & Pump, Syrnge \\
\hline IC/419 & $8002-08328$ & Pump, Syringe \\
\hline $\mathrm{IC} / 420$ & $8002-05741$ & Pump, Syringe \\
\hline IC/421 & $8002-08029$ & Pump, Syringe \\
\hline $\mathrm{IC} / 422$ & $8002-05694$ & Pump, Syringe \\
\hline $\mathrm{IC} / 423$ & $8002-05745$ & Pump, Syringe \\
\hline $\mid C / 424$ & $8002-05682$ & Pump, Syrnge \\
\hline $1 \mathrm{C} / 426$ & $8002-05723$ & Pump, Syringe \\
\hline $\mid \mathrm{C} / 427$ & $8002-05450$ & Pump, Syringe \\
\hline IC/428 & $8002-06018$ & Pump, Syringe \\
\hline $\mathrm{IC} / 429$ & $8002-05679$ & Pump, Syringe \\
\hline $1 \mathrm{C} / 430$ & $8002-08030$ & Pump, Syringe \\
\hline $\mid \mathrm{C} / 431$ & $8002-05684$ & Pump, Syringe \\
\hline IC/432 & $8002-05749$ & Pump, Syrnge \\
\hline $\mathrm{IC} / 433$ & $8002-08025$ & Pump, Syringe \\
\hline $\mathrm{IC} / 434$ & $8002-05771$ & Pump, Syringe \\
\hline IC/435 & $8002-05673$ & Pump, Syringe \\
\hline $\mathrm{IC} / 436$ & $8002-05742$ & Pump, Syringe \\
\hline IC/437 & $8002-05731$ & Pump, Syringe \\
\hline
\end{tabular}

$\begin{array}{rccccccccccc}\text { Date INS } & \text { Date RET } & 0 & 0 & 0 & 1 & 0 & 0 & 0 & 0 & 0 & 0 \\ \text { 5-Feb-10 } & 0 & 0 & 0 & 0 & 1 & 0 & 0 & 0 & 0 & 0 & 0 \\ \text { 5-Feb-10 } & 0 & 0 & 0 & 0 & 1 & 0 & 0 & 0 \\ \text { 5-Feb-10 } & 0 & 0 & 0 & 0 & 1 & 0 & 0 & 0 & 0 & 0 & 0 \\ \text { 5-Apr-01 } & 1 & 1 & 1 & 1 & 1 & 1 & 0 & 0 & 0 & 1 & 0 \\ \text { 5-Apr-01 } & 1 & 1 & 1 & 1 & 1 & 1 & 0 & 0 & 0 & 0 & 0 \\ \text { 5-Apr-01 } & 1 & 1 & 1 & 1 & 1 & 0 & 0 & 0 & 0 & 1 & 0 \\ \text { 5-Apr-01 } & 1 & 1 & 1 & 1 & 1 & 1 & 0 & 0 & 1 & 0 & 0 \\ \text { 5-Apr-01 } & 1 & 1 & 1 & 1 & 1 & 0 & 1 & 0 & 1 & 0 & 0 \\ \text { 5-Apr-01 } & 1 & 1 & 1 & 1 & 1 & 1 & 0 & 0 & 0 & 0 & 0 \\ \text { 5-Apr-01 } & 1 & 1 & 1 & 1 & 1 & 1 & 0 & 2 & 0 & 0 & 0 \\ \text { 15-Jun-01 } & 1 & 1 & 1 & 1 & 1 & 0 & 0 & 1 & 0 & 0 & 0 \\ \text { 5-Apr-01 } & 1 & 1 & 1 & 1 & 1 & 2 & 0 & 1 & 0 & 0 & 1 \\ \text { 15-Jun-01 } & 1 & 1 & 1 & 1 & 1 & 1 & 0 & 1 & 0 & 0 & 0 \\ \text { 5-Apr-01 } & 1 & 1 & 1 & 1 & 1 & 1 & 0 & 0 & 1 & 0 & 0 \\ \text { 6-Apr-01 } & 1 & 1 & 1 & 1 & 1 & 0 & 0 & 1 & 0 & 0 & 0 \\ \text { 6-Apr-01 } & 1 & 1 & 1 & 1 & 1 & 0 & 0 & 0 & 0 & 0 & 0 \\ \text { 6-Apr-01 } & 1 & 1 & 1 & 1 & 1 & 0 & 0 & 0 & 0 & 0 & 0 \\ \text { 6-Apr-01 } & 1 & 1 & 1 & 1 & 1 & 2 & 0 & 0 & 0 & 0 & 0 \\ \text { 6-Apr-01 } & 1 & 1 & 1 & 1 & 1 & 0 & 2 & 1 & 0 & 1 & 0 \\ \text { 6-Apr-01 } & 1 & 1 & 1 & 1 & 1 & 0 & 0 & 0 & 0 & 0 & 0 \\ \text { 6-Apr-01 } & 1 & 1 & 1 & 1 & 1 & 1 & 2 & 0 & 0 & 0 & 0 \\ \text { 6-Apr-01 } & 1 & 1 & 1 & 1 & 1 & 1 & 0 & 0 & 1 & 0 & 0 \\ \text { 6-Apr-01 } & 1 & 1 & 1 & 1 & 1 & 1 & 2 & 0 & 0 & 0 & 0 \\ \text { 6-Apr-01 } & 1 & 1 & 1 & 1 & 1 & 0 & 0 & 0 & 2 & 0 & 0 \\ \text { 6-Apr-01 } & 1 & 1 & 1 & 1 & 1 & 0 & 0 & 0 & 0 & 0 & 0 \\ \text { 6-Apr-01 } & 1 & 1 & 1 & 1 & 1 & 1 & 0 & 0 & 0 & 0 & 0 \\ \text { 6-Apr-01 } & 1 & 1 & 1 & 1 & 1 & 1 & 0 & 0 & 0 & 1 & 0 \\ \text { 6-Apr-01 } & 1 & 1 & 1 & 1 & 1 & 1 & 0 & 0 & 0 & 0 & 0 \\ \text { 6-Apr-01 } & 1 & 1 & 1 & 1 & 1 & 0 & 0 & 0 & 0 & 0 & 0 \\ \text { 6-Apr-01 } & 1 & 1 & 1 & 1 & 1 & 0 & 0 & 1 & 1 & 0 & 0 \\ \text { 6-Apr-01 } & 1 & 1 & 1 & 1 & 1 & 1 & 0 & 0 & 0 & 0 & 0\end{array}$




$\begin{array}{lll}\text { AssetlD } & \text { SerialNumber } & \text { Description } \\ \text { IC/438 } & 8002-08024 & \text { Pump, Syrnge } \\ \text { IC/439 } & 8002-08021 & \text { Pump, Syrnge } \\ \text { IC/440 } & 8002-05685 & \text { Pump, Syrnge } \\ \text { IC/456 } & 800235203 & \text { Pump, Syrnge } \\ \text { IC/457 } & 800235195 & \text { Pump, Syrnge } \\ \text { IC/425 } & 8002-05773 & \text { Pump, Syrnge } \\ \text { NN/667 } & 8002-08376 & \text { Pump, Syrnge } \\ \text { NN/676 } & 8002-08329 & \text { Pump, Syrnge } \\ \text { NN/678 } & 8002-08326 & \text { Pump, Syrnge } \\ \text { NN/797 } & 800329475 & \text { Pump,Syrnge } \\ \text { NN/807 } & 800329473 & \text { Pump,Syrnge } \\ \text { OR/0619 } & 030049 & \text { Pump, Infusion, Syrnge } \\ \text { NN/663 } & 8002-07941 & \text { Pump, Syrnge } \\ \text { NN/664 } & 8002-07936 & \text { Pump, Syrnge } \\ \text { NN/665 } & 8002-07940 & \text { Pump, Syrnge } \\ \text { NN/666 } & 8002-08010 & \text { Pump, Syrnge } \\ \text { NN/667 } & 8002-08010 & \text { Pump, Syrnge } \\ \text { NN/668 } & 8002-08546 & \text { Pump, Syrnge } \\ \text { NN/669 } & 8002-08317 & \text { Pump, Syrnge } \\ \text { NN/670 } & 8002-08300 & \text { Pump, Syrnge } \\ \text { NN/671 } & 8002-08310 & \text { Pump, Syrnge } \\ \text { NN/672 } & 8002-08299 & \text { Pump, Syrnge } \\ \text { NN/673 } & 8002-08314 & \text { Pump, Syrnge } \\ \text { NN/674 } & 8002-08547 & \text { Pump, Syrnge } \\ \text { NN/675 } & 8002-08298 & \text { Pump, Syrnge } \\ \text { NN/677 } & 8002-08303 & \text { Pump, Syrnge } \\ \text { NN/679 } & 8002-08327 & \text { Pump, Syrnge } \\ \text { NN/680 } & 8002-08309 & \text { Pump, Syrnge } \\ \text { NN/681 } & 8002-08318 & \text { Pump, Syrnge } \\ \text { NN/682 } & 8002-08325 & \text { Pump, Synnge } \\ \text { NN/683 } & 8002-08307 & \text { PuMP,SYRINGE } \\ & & \end{array}$

\begin{tabular}{|c|c|c|c|c|c|c|c|c|c|c|c|c|}
\hline INS & & & & Hethe & & & & & d & & & 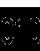 \\
\hline 6-Apr-01 & & 1 & 1 & 1 & 1 & 1 & 1 & 1 & 0 & 0 & 0 & 0 \\
\hline 6-Apr-01 & & 1 & 1 & 1 & 1 & 1 & 2 & 1 & 0 & 0 & 0 & 0 \\
\hline 6-Apr-01 & & 1 & 1 & 1 & 1 & 1 & 0 & 0 & 0 & 0 & 0 & 0 \\
\hline 15-Mar-05 & & 1 & 1 & 1 & 1 & 1 & 1 & 1 & 0 & 0 & 0 & 1 \\
\hline 15-Mar-05 & & 1 & 1 & 1 & 1 & 1 & 2 & 1 & 0 & 1 & 0 & 0 \\
\hline 6-Apr-01 & & 1 & 1 & 1 & 1 & 1 & 0 & 0 & 0 & 0 & 0 & 0 \\
\hline 31-Mar-01 & & 1 & 1 & 1 & 1 & 1 & 0 & 1 & 1 & 0 & 1 & 0 \\
\hline 31-Mar-01 & & 1 & 1 & 1 & 1 & 1 & 0 & 1 & 0 & 0 & 0 & 0 \\
\hline 31-Mar-01 & & 1 & 1 & 1 & 1 & 1 & 0 & 1 & 1 & 0 & 0 & 0 \\
\hline 4-Jun-07 & 30-May-08 & 0 & 0 & 0 & 1 & 0 & 0 & 0 & 0 & 0 & 0 & 0 \\
\hline 4-Jun-07 & 30-May-08 & 0 & 0 & 0 & 1 & 0 & 0 & 0 & 0 & 0 & 0 & 0 \\
\hline $8 / 16 / 1996$ & 16-Dec-09 & 1 & 1 & 1 & 1 & 0 & 1 & 0 & 0 & 1 & 0 & 0 \\
\hline 22-Mar-01 & & 1 & 1 & 1 & 1 & 1 & 1 & 0 & 0 & 0 & 0 & 0 \\
\hline 22-Mar-01 & & 1 & 1 & 1 & 1 & 1 & 0 & 1 & 0 & 0 & 0 & 0 \\
\hline 22-Mar-01 & & 1 & 1 & 1 & 1 & 1 & 0 & 0 & 0 & 1 & 0 & 0 \\
\hline 22-Mar-01 & 27-May-09 & 1 & 1 & 1 & 1 & 0 & 0 & 0 & 0 & 0 & 0 & 0 \\
\hline 22-Mar-01 & 27-May-09 & 1 & 1 & 1 & 1 & 0 & 0 & 2 & 1 & 1 & 0 & 0 \\
\hline 31-Mar-01 & & 1 & 1 & 1 & 1 & 1 & 0 & 1 & 2 & 0 & 0 & 0 \\
\hline 31-Mar-01 & & 1 & 1 & 1 & 1 & 1 & 0 & 0 & 1 & 0 & 1 & 0 \\
\hline 31-Mar-01 & & 1 & 1 & 1 & 1 & 1 & 2 & 0 & 2 & 0 & 0 & 0 \\
\hline 31-Mar-01 & & 1 & 1 & 1 & 1 & 1 & 0 & 0 & 0 & 0 & 0 & 0 \\
\hline 31-Mar-01 & & 1 & 1 & 1 & 1 & 1 & 1 & 0 & 0 & 0 & 0 & 0 \\
\hline 31-Mar-01 & & 1 & 1 & 1 & 1 & 1 & 0 & 0 & 0 & 0 & 0 & 0 \\
\hline 31-Mar-01 & & 1 & 1 & 1 & 1 & 1 & 0 & 0 & 1 & 0 & 0 & 0 \\
\hline 31-Mar-01 & & 1 & 1 & 1 & 1 & 1 & 0 & 0 & 1 & 0 & 0 & 0 \\
\hline 31-Mar-01 & & 1 & 1 & 1 & 1 & 1 & 0 & 0 & 1 & 0 & 0 & 0 \\
\hline $31-$ Mar-01 & & 1 & 1 & 1 & 1 & 1 & 0 & 0 & 0 & 1 & 0 & 0 \\
\hline 31-Mar-01 & & 1 & 1 & 1 & 1 & 1 & 1 & 0 & 0 & 1 & 0 & 0 \\
\hline $31-$ Mar-01 & 16-Jan-10 & 1 & 1 & 1 & 1 & 0 & 0 & 0 & 1 & 0 & 0 & 0 \\
\hline 31-Mar-01 & & 1 & 1 & 1 & 1 & 1 & 0 & 1 & 0 & 1 & 0 & 0 \\
\hline 31-Mar-01 & & 1 & 1 & 1 & 1 & 1 & 0 & 0 & 0 & 0 & 0 & 0 \\
\hline
\end{tabular}




\begin{tabular}{|c|c|c|}
\hline AssetlD & SerialNumber & Description \\
\hline NN/684 & $8002-08384$ & Pump, Syrnge \\
\hline NN/685 & $8002-08383$ & Pump, Syrnge \\
\hline NN/686 & $8002-08373$ & Pump, Syringe \\
\hline NN/687 & $8002-08492$ & Pump, Syrnge \\
\hline NN/688 & $8002-08386$ & Pump, Syringe \\
\hline NN/689 & $8002-08301$ & Pump, Syringe \\
\hline NN/690 & $8002-08368$ & Pump, Syringe \\
\hline NN/691 & $8002-08380$ & Pump, Syringe \\
\hline NN/796 & 800329486 & Pump,Syringe \\
\hline NN/798 & 800329482 & Pump,Syringe \\
\hline NN/799 & 800329423 & Pump,Syringe \\
\hline NN/800 & 800329452 & Pump,Syringe \\
\hline NN/801 & 800329465 & Pump,Syrnge \\
\hline NN/802 & 800329476 & Pump,Syringe \\
\hline NN/803 & 800329470 & Pump,Syringe \\
\hline NN/804 & 800329471 & Pump,Syringe \\
\hline NN/805 & 800329477 & Pump,Syringe \\
\hline NN/806 & 800329487 & Pump,Syringe \\
\hline NN/696 & 80855 & Pump,Syringe \\
\hline NN/697 & 80888 & Pump,Syringe \\
\hline NN/698 & 79207 & Pump,Syringe \\
\hline OR/0544 & 005918 & Pump, Infusion, Syringe \\
\hline OR/0545 & 012452 & Pump, Infusion, Syringe \\
\hline OR/0567 & 015206 & Pump, Infusion, Syringe, anaesthesia \\
\hline OR/0568 & 015143 & Pump, Infusion, Syringe \\
\hline OR/0618 & 030048 & Pump, Infusion, Syringe \\
\hline OR/0676 & 487061998 & Pump, Infusion, Syringe \\
\hline OR/0818 & $8002-08502$ & Pump, Syringe \\
\hline OR/0819 & $8002-08371$ & Pump, Syrnge \\
\hline OR/0820 & $8002-08370$ & Pump, Syringe \\
\hline OR/0821 & $8002-08302$ & Pump, Syringe \\
\hline
\end{tabular}

\begin{tabular}{|c|c|c|c|c|c|c|c|c|c|c|c|c|}
\hline Date INS & Date RET & 3) & 6. & Uith & & yyer & & & $\alpha \theta$ & 8 & & 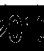 \\
\hline 31-Mar-01 & & 1 & 1 & 1 & 1 & 1 & 0 & 0 & 0 & 0 & 0 & 0 \\
\hline 31-Mar-01 & & 1 & 1 & 1 & 1 & 1 & 0 & 0 & 0 & 0 & 1 & 0 \\
\hline 31-Mar-01 & & 1 & 1 & 1 & 1 & 1 & 1 & 1 & 0 & 0 & 1 & 0 \\
\hline 31-Mar-01 & & 1 & 1 & 1 & 1 & 1 & 1 & 0 & 0 & 0 & 0 & 0 \\
\hline 31-Mar-01 & 21-Jan-10 & 1 & 1 & 1 & 1 & 0 & 0 & 1 & 0 & 0 & 1 & 0 \\
\hline 31-Mar-01 & 19-Feb-10 & 1 & 1 & 1 & 1 & 0 & 0 & 0 & 0 & 0 & 0 & 0 \\
\hline 31-Mar-01 & 18-Jan-10 & 1 & 1 & 1 & 1 & 0 & 0 & 0 & 0 & 0 & 0 & 0 \\
\hline 31-Mar-01 & 15-Jan-09 & 1 & 1 & 1 & 1 & 0 & 0 & 0 & 0 & 1 & 0 & 0 \\
\hline 4-Jun-07 & & 0 & 0 & 0 & 1 & 1 & 0 & 0 & 0 & 0 & 0 & 0 \\
\hline 4-Jun-07 & & 0 & 0 & 0 & 1 & 1 & 0 & 0 & 0 & 0 & 0 & 0 \\
\hline 4-Jun-07 & & 0 & 0 & 0 & 1 & 1 & 0 & 0 & 0 & 0 & 0 & 0 \\
\hline 4-Jun-07 & & 0 & 0 & 0 & 1 & 1 & 0 & 0 & 0 & 0 & 0 & 0 \\
\hline 4-Jun-07 & & 0 & 0 & 0 & 1 & 1 & 0 & 0 & 0 & 0 & 0 & 0 \\
\hline 4-Jun-07 & & 0 & 0 & 0 & 1 & 1 & 0 & 0 & 0 & 0 & 0 & 1 \\
\hline 4-Jun-07 & & 0 & 0 & 0 & 1 & 1 & 0 & 0 & 0 & 0 & 0 & 0 \\
\hline 4-Jun-07 & & 0 & 0 & 0 & 1 & 1 & 0 & 0 & 0 & 0 & 0 & 0 \\
\hline 4-Jun-07 & & 0 & 0 & 0 & 1 & 1 & 0 & 0 & 0 & 0 & 0 & 0 \\
\hline 4-Jun-07 & & 0 & 0 & 0 & 1 & 1 & 0 & 0 & 0 & 0 & 0 & 0 \\
\hline 24-Jan-02 & 1-Jan-10 & 1 & 1 & 1 & 1 & 1 & 0 & 0 & 0 & 0 & 0 & 0 \\
\hline 24-Jan-02 & 1-Jan-10 & 1 & 1 & 1 & 1 & 1 & 0 & 0 & 0 & 0 & 0 & 0 \\
\hline 24-Jan-02 & 1-Jan-10 & 1 & 1 & 1 & 1 & 1 & 0 & 0 & 0 & 0 & 0 & 0 \\
\hline 1-Nov-94 & & 1 & 1 & 1 & 1 & 1 & 0 & 0 & 0 & 0 & 0 & 0 \\
\hline 1-Nov-94 & & 1 & 1 & 1 & 1 & 1 & 0 & 0 & 0 & 0 & 0 & 0 \\
\hline 1-Apr-96 & & 1 & 1 & 1 & 1 & 1 & 0 & 0 & 0 & 0 & 2 & 0 \\
\hline 1-Apr-96 & & 1 & 1 & 1 & 1 & 1 & 0 & 0 & 0 & 0 & 1 & 0 \\
\hline 2-Jun-97 & & 1 & 1 & 1 & 1 & 1 & 1 & 0 & 0 & 0 & 1 & 0 \\
\hline 2-Jun-97 & & 1 & 1 & 1 & 1 & 1 & 0 & 0 & 0 & 0 & 0 & 0 \\
\hline 9-Feb-01 & & 1 & 1 & 1 & 1 & 1 & 0 & 0 & 0 & 0 & 0 & 0 \\
\hline 9-Feb-01 & & 1 & 1 & 1 & 1 & 1 & 0 & 0 & 0 & 0 & 0 & 0 \\
\hline 9-Feb-01 & & 1 & 1 & 1 & 1 & 1 & 0 & 0 & 0 & 0 & 0 & 0 \\
\hline 9-Feb-01 & & 1 & 1 & 1 & 1 & 1 & 0 & 0 & 0 & 0 & 0 & 0 \\
\hline
\end{tabular}




\begin{tabular}{|c|c|}
\hline AssetID SerialNumber & Description \\
\hline OR/0822 8002-08312 & Pump, Syringe \\
\hline OR/0823 $8002-08297$ & Pump, Syringe \\
\hline OR/0824 8002-08548 & Pump, Syringe \\
\hline OR/0825 8002-08504 & Pump, Syrnge \\
\hline OR/0871 6002-17641 & Pump, syringe, dose rate \\
\hline OR/0872 6002-17647 & Pump, syringe, dose rate \\
\hline OR/0873 6002-17559 & Pump, syringe, dose rate \\
\hline OR/0874 6002-17644 & Pump, syringe, dose rate \\
\hline OR/0875 6002-17566 & Pump, syringe, dose rate \\
\hline OR/0876 $6002-17553$ & Pump, syringe, dose rate \\
\hline OR/4445 M70273 & Pump, Syrnge, Infusion (Medfusion) \\
\hline OR/1446 M70294 & Pump, Syrnge, Infusion (Mediusion) \\
\hline OR/1447 M70346 & Pump, Syrnge, Infusion (Medfusion) \\
\hline OR/1448 M70308 & Pump, Syrnge, Infusion (Medfusion) \\
\hline OR/1449 M70290 & Pump, Syrnge, Infusion (Mediusion) \\
\hline OR/1450 M70283 & Pump, Syringe, Infusion (Mediusion) \\
\hline OR/1451 M70272 & Pump, Syrnge, Infusion (Medfusion) \\
\hline $\mathrm{OR} / 1452 \mathrm{M} 70266$ & Pump, Syrnge, Infusion (Mediusion) \\
\hline $\mathrm{OR} / 1453 \mathrm{M} 70005$ & Pump, Syrnge, Infusion (Medfusion) \\
\hline OR/1454 M70031 & Pump, Syrnge, Infusion (Medfusion) \\
\hline OR/1455 M70029 & Pump, Syrnge, Infusion (Medfusion) \\
\hline OR/1456 M70300 & Pump, Syringe, Infusion (Medfusion) \\
\hline OR/1457 M69993 & Pump, Syrnge, Infusion (Medfusion) \\
\hline $\mathrm{OR} / 1458 \mathrm{M} 70286$ & Pump, Syrnge, Infusion (Medfusion) \\
\hline OR/1459 M70301 & Pump, Syringe, Infusion (Medfusion) \\
\hline $\mathrm{OR} / 1460 \mathrm{M} 69989$ & Pump, Syrnge, Infusion (Medfusion) \\
\hline OR/1461 M70338 & Pump, Syringe, Infusion (Medfusion) \\
\hline OR/1462 M70020 & Pump, Syringe, Infusion (Medfusion) \\
\hline OR/1463 M70009 & Pump, Syringe, Infusion (Medfusion) \\
\hline OR/1464 M70004 & Pump, Syringe, Infusion (Medfusion) \\
\hline
\end{tabular}

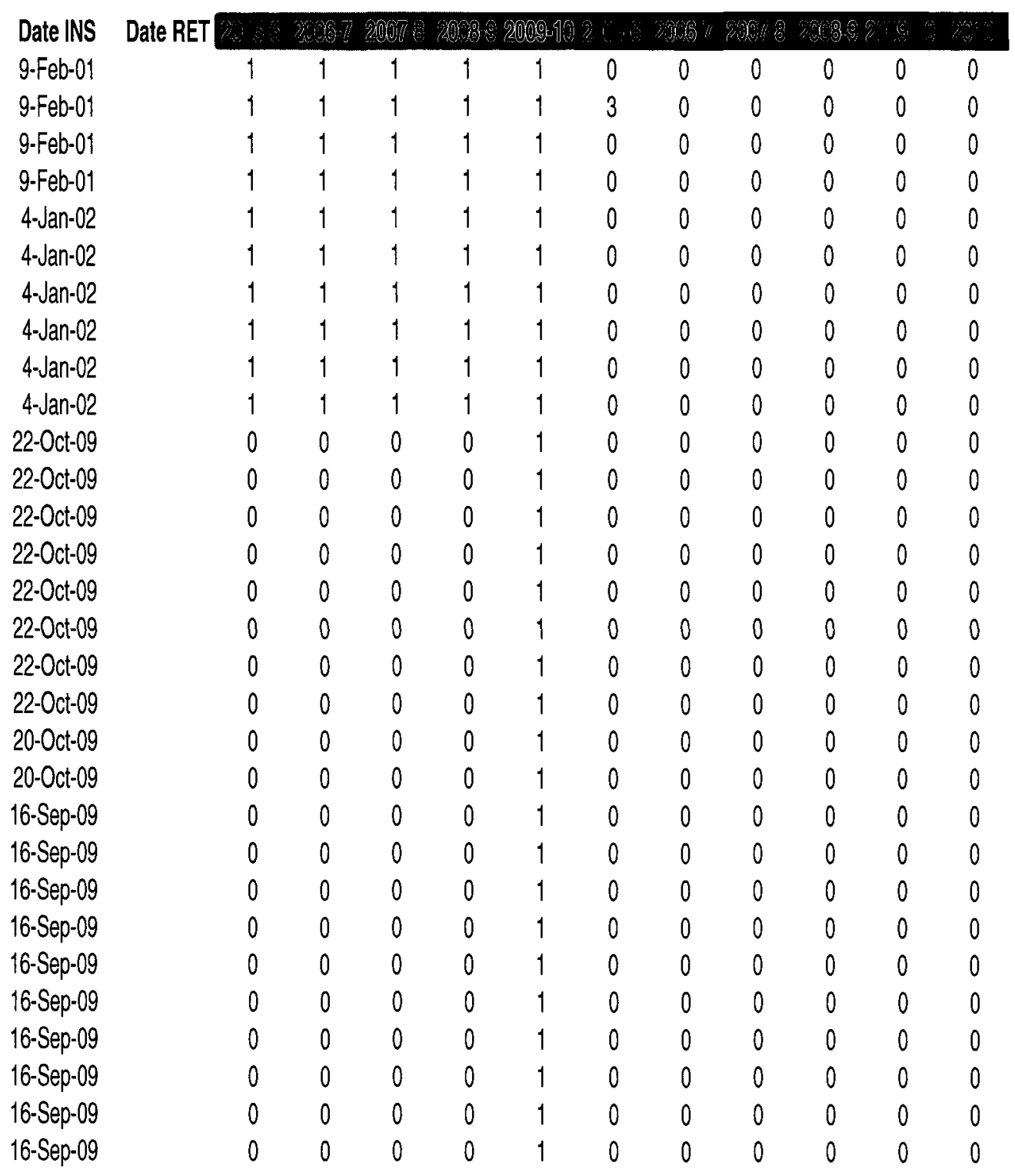




$\begin{array}{ll}\text { AssetlD SerialNumber } & \text { Description } \\ \text { OR/1465 M70010 } & \text { Pump, Syringe, Infusion (Medfusion) } \\ \text { OR/1466 M69997 } & \text { Pump, Syringe, Infusion (Medfusion) } \\ \text { OR/1467 M70027 } & \text { Pump, Syringe, Infusion (Medfusion) } \\ \text { OR/1468 M70287 } & \text { Pump, Syringe, Infusion (Medfusion) } \\ \text { OR/1469 M70040 } & \text { Pump, Syringe, Infusion (Medfusion) } \\ \text { OR/1470 M70344 } & \text { Pump, Syringe, Infusion (Medfusion) } \\ \text { OR/1471 M70339 } & \text { Pump, Syringe, Infusion (Medfusion) } \\ \text { OR/1472 M70345 } & \text { Pump, Syringe, Infusion (Medfusion) } \\ \text { OR/1473 M70293 } & \text { Pump, Syringe, Infusion (Medfusion) } \\ \text { OR/1474 M70296 } & \text { Pump, Syringe, Infusion (Medfusion) } \\ \text { OR/1475 M70306 } & \text { Pump, Syringe, Infusion (Medfusion) } \\ \text { UY/026 } 8002-07932 & \text { Pump, Syringe } \\ \text { UY/027 } 8002-08337 & \text { Pump, Syringe } \\ & \text { TOTALS }\end{array}$

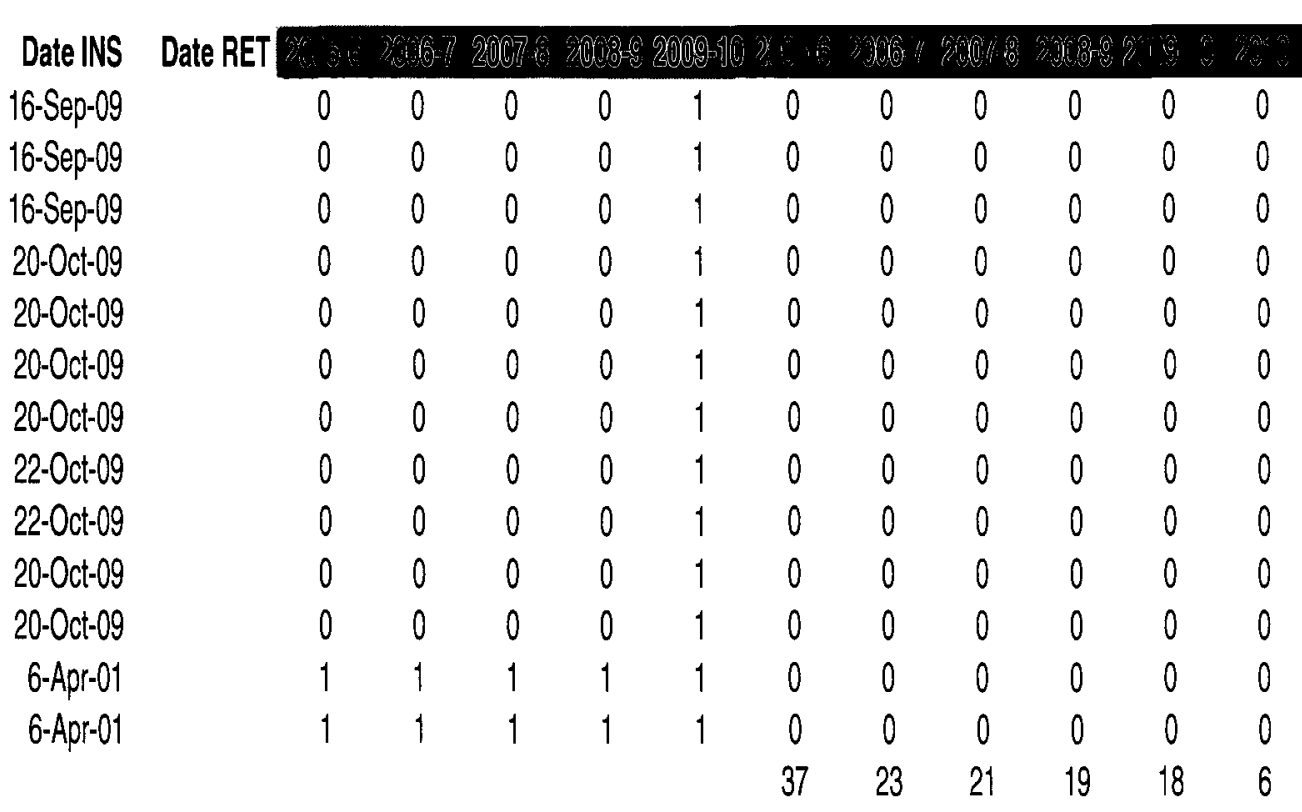




\section{Appendix 3}

\section{Detailed Summary Tables for the Monitor and Infusion Pump}

Data 


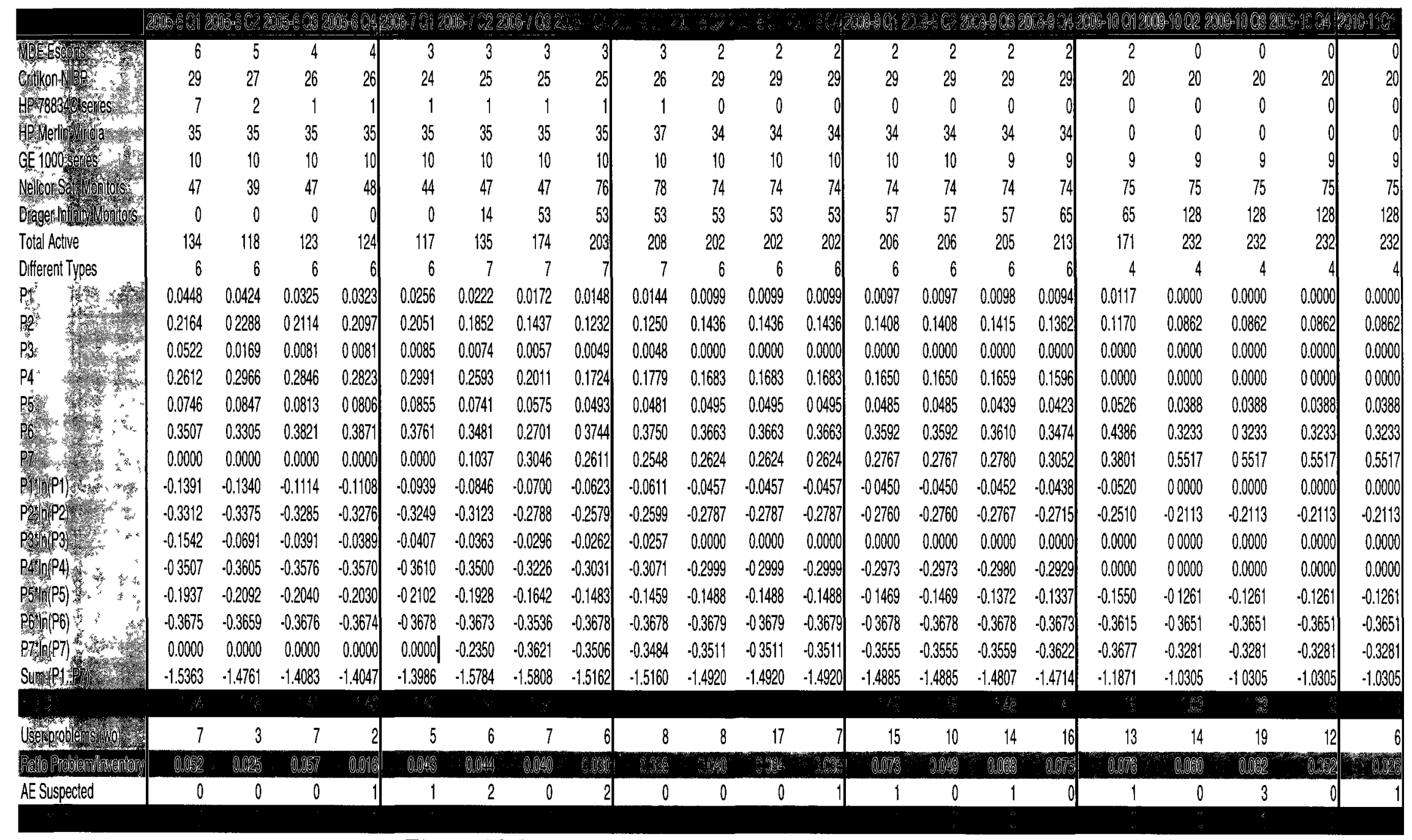

Figure A3.1 - Expanded Physiological Monitor Data Table 


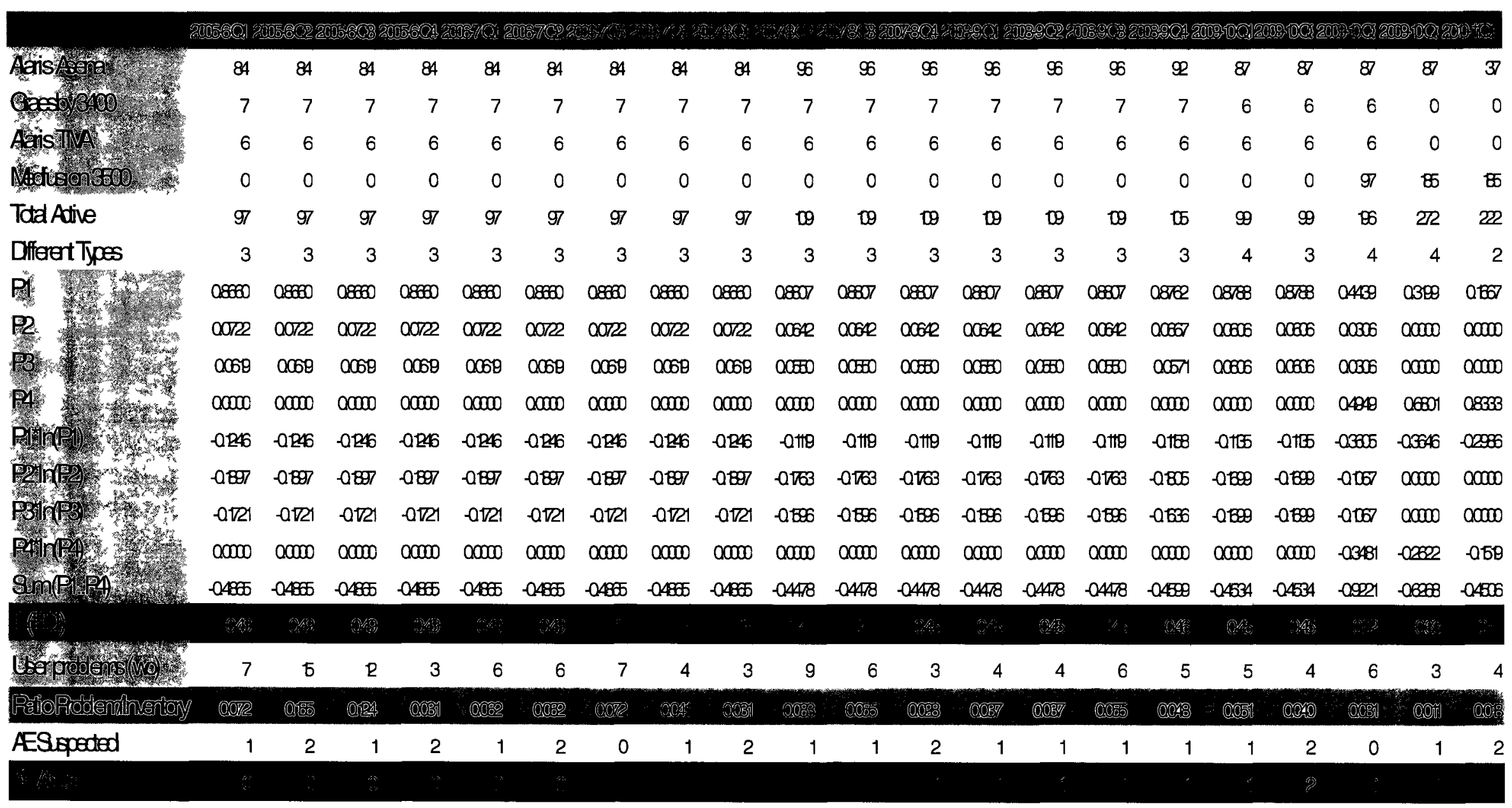

Table A3.2 - Summary of Inventory, EDI Calculations, User problems and Adverse Event Data for the Syringe Pumps 


\section{Appendix 4}

\section{Research Ethics and Corporate Approval Documentation}


Children's Hospial of Eastem Oncarto

Quluber 1, 2010

Kin Granutud

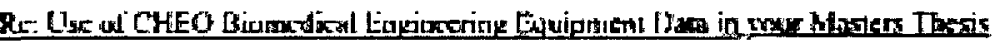

\section{Desr Kin:}

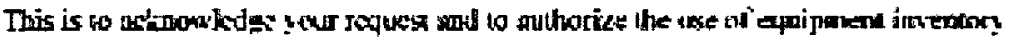

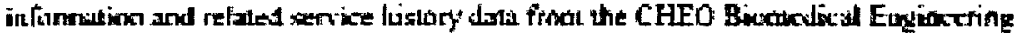

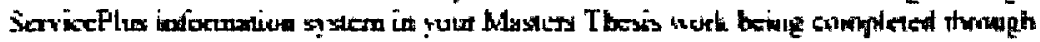

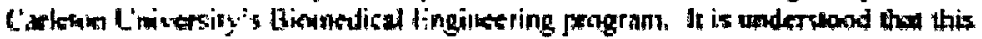

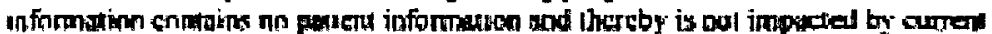

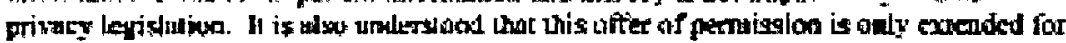
exte in this specific project and calnot be uad for obter purposes withou permixgiun.

Yours inify

$\sim$ re J 


\section{กบ次}

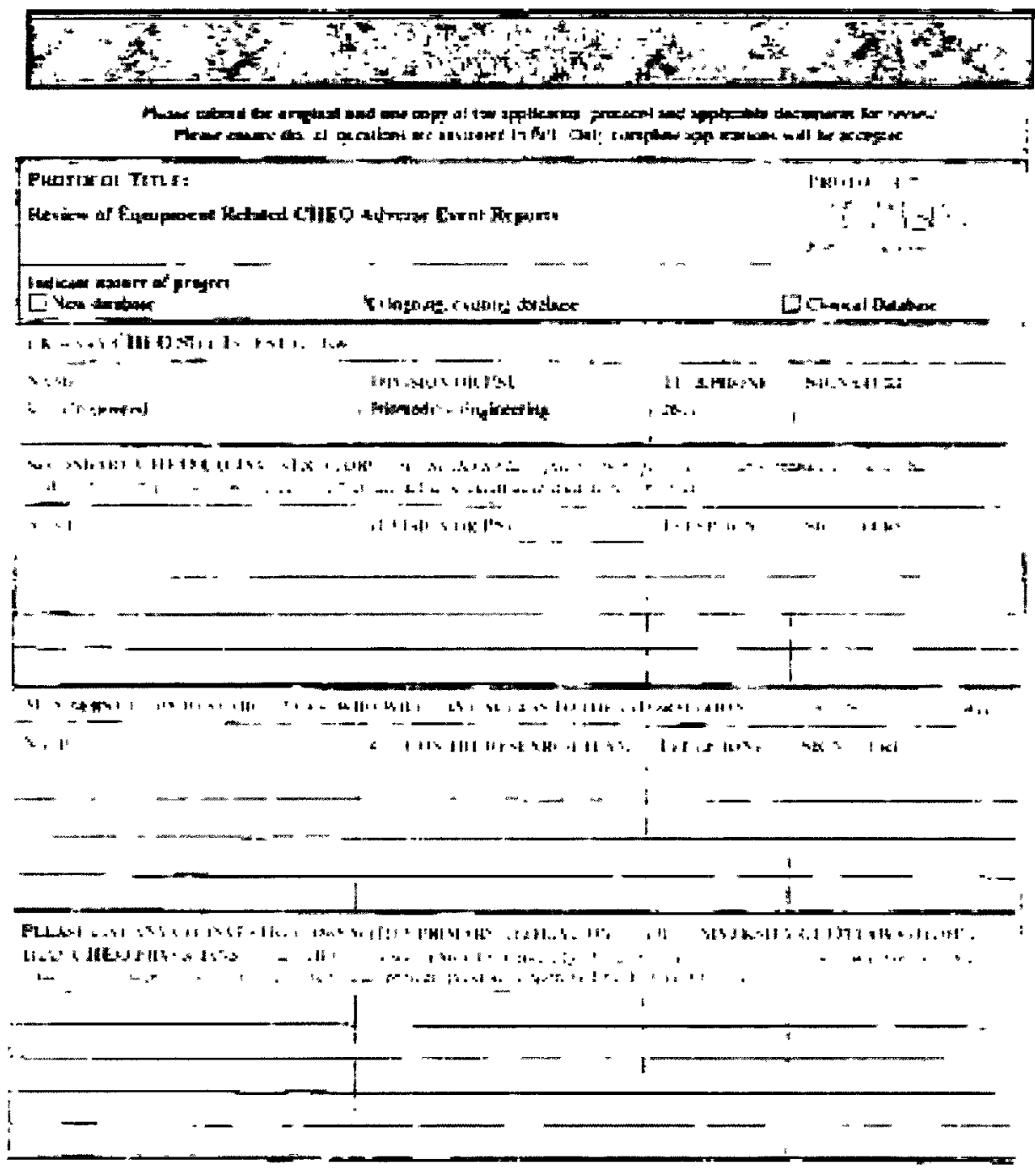

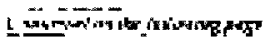

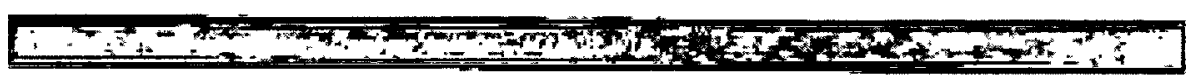




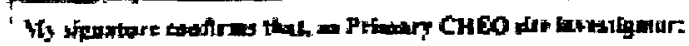

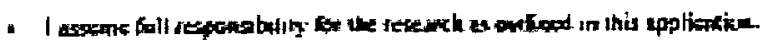

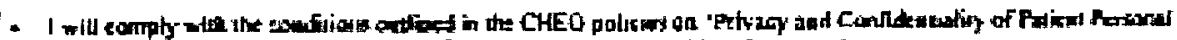

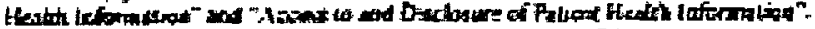

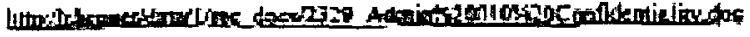

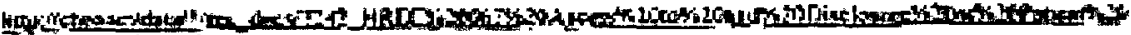

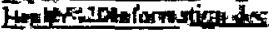

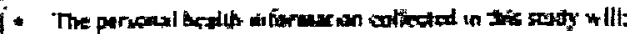

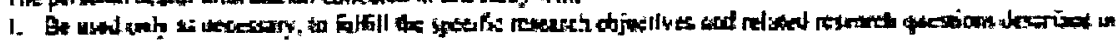

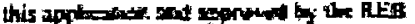

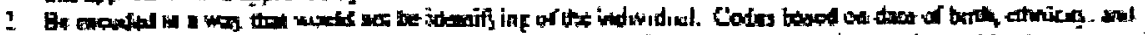

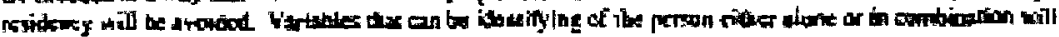

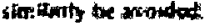

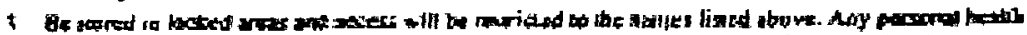

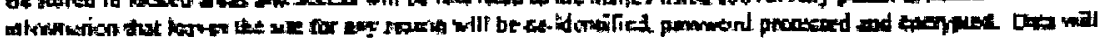

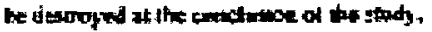

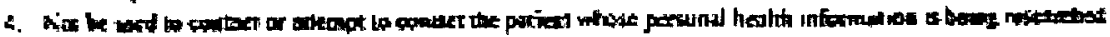

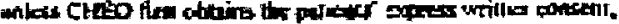

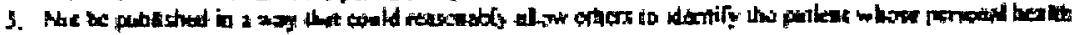

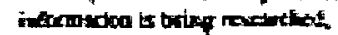

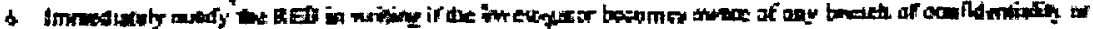

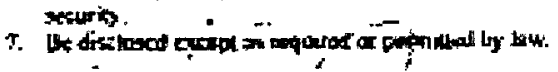

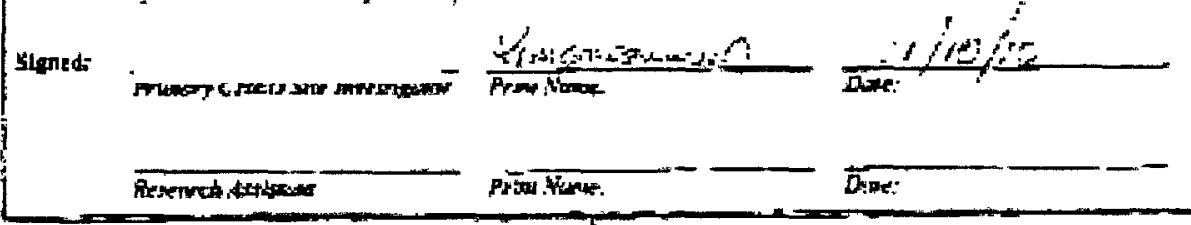

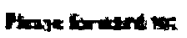

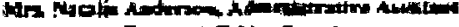

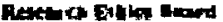

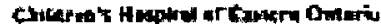

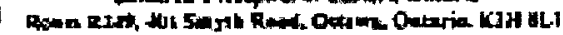

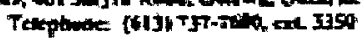

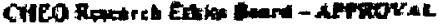

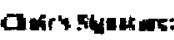

Dues $\rightarrow$

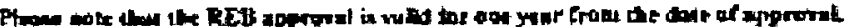

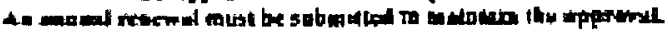

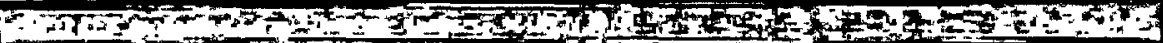




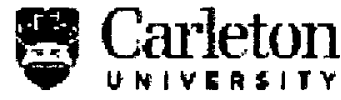

Canado's captat Unbrarsily
Cortagen Uamaraty fromorth Offex

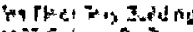

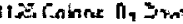

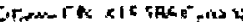

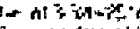

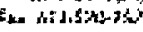

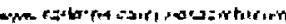

\section{Ethics Clearance form}

This is to certify that the Corteton Uniwsraty Researeh Ethics Bosord has axomined the application for athical ciazrance. The Res tound the research profect to meet appropriate ethical standards as

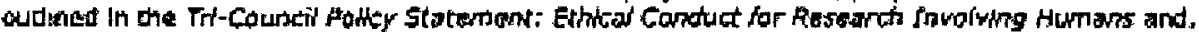

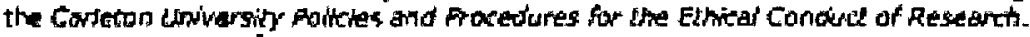

\section{$X$ Now clearance}

I Rentewal of original clearance Orlginal data of clearances

Date of dedance 12 November 2010

Student Researcier Kim Granwwaod

Staicus

Faculty supervisor Profeasar Monique Frize, syobume and Computar Englnạrting

Departmor:

Funding status

Tote of project Blomedtcol Enalneering

Not funded

Clinical equipment etandardlathan and its Impact on pationt Eatety

\section{Cloarance expura: $\quad 31$ Mter 2011}

\section{All regearchere are ooverned by the following conditionst}

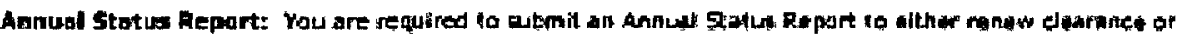
dosa th file Fulure to subenit the Anrual Status Report will result in the immediate suspondon of the prof os.

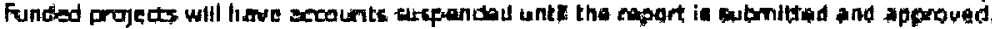

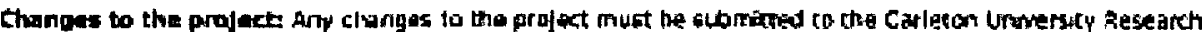

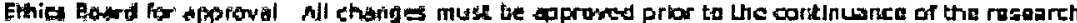

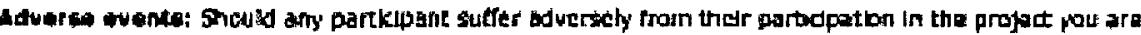

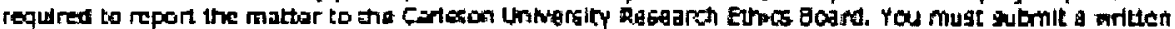

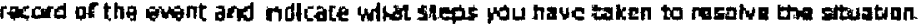

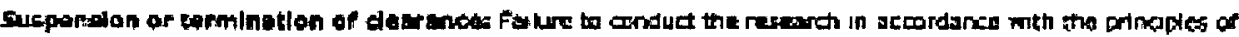

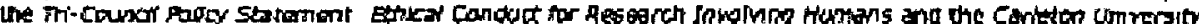

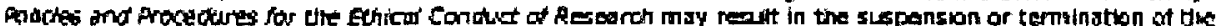
retreh praject.

Letie J. Mattoonand-Hicks -

Rosalch Ethis5 Board Coordinator

For the Chatr of the Cortiton Unversity Reserrch Ethics Bosed

Arof. Antoniso Glastueri 